ANA CAROLINA ESMERALDO APOLINÁRIO

\title{
AVALIAÇÃO DA QUALIDADE ÓSSEA MANDIBULAR EM CRIANÇAS COM OSTEOGÊNESE IMPERFEITA EM USO DE PAMIDRONATO
}

BRASÍLIA

2015 


\section{AVALIAÇÃO DA QUALIDADE ÓSSEA MANDIBULAR EM CRIANÇAS COM OSTEOGÊNESE IMPERFEITA EM USO DE PAMIDRONATO}

Tese apresentada ao programa de Pós-graduação em Ciências da Saúde da Universidade de Brasília, como pré-requisito para obtenção do título de Doutor em Ciências da Saúde.

Orientadora: Profa. Dra. Lílian Marly de Paula Co-orientador: Prof. Dr. André Ferreira Leite

BRASÍLIA

2015 


\section{DEDICATÓRIA}

Dedico este trabalho a meus filhos, Lucas, Ana Gabriela e Arthur, motivo maior da minha vida! Por quem sempre vale a pena continuar e investir. Com alegria e muito amor realizo meu trabalho-missão de vida, contribuindo para que vocês encontrem um mundo melhor, mais justo e feliz.

A meus pais, a quem reverencio e agradeço a chance de aprender a respeito da vida. Exemplos de força e superação. 


\section{AGRADECIMENTOS}

Agradeço aos vários mestres que cruzaram minha vida nessa caminhada.

Em primeiro lugar, a minha mãe, que representa toda uma dinastia de mulheres fortes que nasceram na nossa família. Nesse berço, aprendi que é possível ser delicada por fora e uma rocha, invencível, por dentro!

Agradeço imensamente a honra de ter tido o Prof. André Ferreira Leite como meu orientador nesse trabalho, pessoa que me mostra todos os dias que, além de amigo e salvador da pátria, é um grande mestre na área acadêmica e na Vida. Obrigada por todas as palavras de incentivo, correção de textos e ideias, e pela PACIÊNCIA, que vindo dele, só pode ser escrita em caixa alta!

À maravilhosa equipe do HUB, da qual muito me orgulho de fazer parte, especialmente a Nilce Melo, Paulo Tadeu Figueiredo e Lilian Marly de Paula que contribuíram com seus ensinamentos, observações e análise criteriosa do meu trabalho. É estimulante trabalhar ao lado de pessoas que praticam a ciência com tanta seriedade e paixão ao mesmo tempo!

À queridíssima Ana Teresa Guimarães, que transformou dias e dias de intermináveis cálculos em momentos de muita diversão! Você faz a estatística parecer um passeio de domingo! Obrigada por todo o conhecimento e horas dispensados a mim, sempre com bom humor e espírito investigativo!

Ao amigo, ouvido de plantão, solucionador de todos os problemas de informática e mestre em ImageJ, Rafael Sindeaux. Obrigada pela amizade, carinho, e presença inspiradora. Hoje, mais um brinde com vinho tinto é levantado. Cheers!!!

Ao Dr. Luiz Cláudio Castro, com quem tenho aprendido muito. Sempre! E posso dizer, felizmente, que já temos uma grande estrada percorrida com as crianças da Ostogênese. Mas, sobretudo, é emocionante acompanhar sua trajetória de vida, e perceber como é possível manter a serenidade e a alegria no dia a dia, com seus altos e baixos. Obrigada por compartilhar tantos conhecimentos e sorrisos! 
Aos amigos da Clínica de Anomalias do Desenvolvimento Dentário, pessoas muito especiais, que se dedicam a cuidar de uma população muitas vezes excluída e extremamente carente. É um prazer trabalhar ao seu lado, compartilhando ciência, cuidados e amor!

Aos funcionários do HUB, especialmente Alessandro, Daniel, Adriana e Teresa, técnicos da Radiologia, que receberam a mim e às crianças, semanalmente, com carinho e atenção para a realização das radiografias.

Às minhas queridas companheiras e amigas maravilhosas, Thaís Bastos Turatti, Marily Silva e Andrea Amorim, pelo companheirismo, incentivo, compreensão e administração da Alcance Odontologia \& Terapias Integradas.

Aos amigos, família escolhida, que estão aí pra o que der e vier! Obrigada por acreditarem no meu trabalho e trazerem sempre tanta alegria à minha vida!

Aos meus clientes, pela compreensão e paciência com tantas ausências.

À minha querida secretária para todos os assuntos, Gicélia Magalhães. Obrigada por cuidar tão bem de mim e das crianças! Presença fundamental para que eu possa trilhar meu caminho profissional com tranquilidade.

A todas as crianças que participaram dessa pesquisa e a seus pais, que depositaram confiança no meu trabalho.

A Deus, cuja Presença posso sentir em cada passo e a cada encontro. Peço Sua bênção para seguir em frente, trabalhando para um mundo melhor e mais feliz. 
“Dentro de cada um de nós jaz o mundo inteiro, e para aquele que consegue olhar e aprender, a porta está à sua frente e a chave em sua mão. Ninguém sobre a face da Terra é capaz de lhe dar a chave ou a porta, a não ser você mesmo."

(J. Krishnamurti) 


\section{RESUMO}

Esse trabalho surgiu da hipótese de que crianças com osteogênese imperfeita (OI) teriam suas corticais mandibulares mais finas e porosas, e que seu padrão ósseo trabecular apresentaria uma microarquitetura alterada devido a sua extrema fragilidade óssea. Além disso, ao longo de seu tratamento, com pamidronato intravenoso, essas características relacionadas à baixa massa óssea melhorariam. Para isso foram avaliadas 206 radiografias panorâmicas da face de 67 crianças com OI tipos I, III e IV, entre 3 e 19 anos, que estavam em tratamento com pamidronato cíclico intravenoso, em diferentes etapas do tratamento. Foram testados três índices radiomorfométricos - mentual, mandibular cortical e visual - e dimensões fractais de três diferentes sítios, um em osso cortical e dois em osso trabecular ângulo e ramo mandibulares. Foi verificada a associação entre os índices qualitativos e as medidas da espessura da cortical e de dimensão fractal. Também foram analisadas as correlações entre a espessura da cortical mandibular e as medidas de dimensão fractal. As diferenças nos valores de espessura da cortical e de dimensão fractal em relação às faixas etárias, início do tratamento, número de ciclos de pamidronato e tipos de OI foram comparadas por meio de teste ANOVA. Para todos os testes estatísticos foi considerado um nível de significância de 95\%. Esse estudo mostrou que crianças com OI, de todos os tipos, apresentam corticais mais finas e porosas ao início de seu tratamento e que ao longo dos ciclos de pamidronato essa estrutura fica mais espessa. A dimensão fractal da cortical aumenta com o tempo de tratamento. Não foram encontradas diferenças estatisticamente significativas nas análises das dimensões fractais de osso trabecular ( $>>0,05)$. Foi verificada ainda a associação entre densidade mineral óssea e a espessura da cortical inferior da mandíbula em um grupo de 92 crianças saudáveis. Após essa etapa, foi construído um modelo de regressão logística linear que relacionava a espessura da cortical com os ciclos de pamidronato. Os resultados do trabalho demonstraram que a análise da cortical inferior da mandíbula pode auxiliar na avaliação da baixa densidade mineral óssea em pacientes com OI, bem como na evolução do tratamento com pamidronato. 


\begin{abstract}
We hypothesized that mandibular cortical is smaller and more porous in OI than in healthy children, and that their trabecular microarchitecture is altered due to their extreme bone fragility. Also, we suppose that the treatment with pamidronate can improve these low bone mass characteristics. So, 206 dental panoramic radiographs (DPRs) from 67 OI children types I, III and IV, from 3 to 19 years old, in treatment with PAM, were evaluated. We analyzed three radiomorphometric indices - mandibular cortical width (MCW), mandibular cortical index (MCI) and the visual estimation of the cortical width (SVE) - and fractal dimension (FD) of three ROIs, one in cortical bone and two in trabecular bone - mandibular angle and ramus. There was an association between the qualitative indices and the measures of cortical width and fractal dimension. The correlations between MCW and FD were also analyzed. Differences in MCW and FD regarding age groups, age at the beginning of treatment, number of PAM cycles and OI types were compared by ANOVA test. For all statistic tests it was considered 95\% of significance level. It was found that OI children, of all types, have thinner and more porous mandibular cortices at the beginning of treatment, and that through PAM cycles, the cortical becomes thicker. Cortical FD increases with treatment. It was not found statistical differences at trabecular bone FD analyses ( $>>0.05)$. It was verified the relation between bone mineral density (BMD) and MCW in a group of 92 healthy children. After this, it was constructed a linear logistic regression model to relate MCW and the number of pamidronate cycles. Our results show that mandibular inferior cortex analysis may provide a way to evaluate low BMD and identify cyclic PAM treatment outcomes in OI patients.
\end{abstract}




\section{LISTA DE FIGURAS}

Figura 1 - Mudanças histológicas durante o tratamento com o pamidronato $\quad 24$

Figura 2 - Modelo de como o tratamento com o pamidronato aumenta a espessura da cortical de pacientes acometidos por OI em crescimento

Figura 3 - Modelo de como o pamidronato afeta o número do trabeculado

Figura 4 - I Índice Mandibular Cortical (adaptado de Klemetti, 1994)

Figura 5 - $\quad$ Índice Visual (Lee et al, 2005)

Figura 6 - I Índice Mentual - IM (adaptado de Delvin e Horner, 2002).

Figura 7 - Passos para o cálculo da dimensão fractal do ROIcortical

Figura 8 - Cálculo da dimensão fractal do ROI selecionado

Figura 9 - Frequência relativa percentual de categorias do índice visual em função do tipo de OI e frequência de ciclos de pamidronato. OI = osteogênese imperfeita, $\mathrm{NF}=$ cortical classificada como não fina, $\mathrm{F}=$ cortical classificada como fina.

Figura 10 - Frequência relativa percentual de categorias do índice mandibular cortical em função do tipo de OI e frequência de ciclos de pamidronato. Classificações C1, C2 e C3, OI = osteogênese imperfeita.

Figura 11 - Frequência relativa percentual de categorias do índice visual (NF - não fina e $\mathrm{F}$ - fina) em relação às categorias do índice mandibular cortical (C1, C2 e C3)

Figura 12 - Médias e intervalos de confiança do Índice Mentual em função das classes do índice mandibular cortical

Figura 13 - Médias e intervalos de confiança das dimensões fractais ROICortical (A) e Índice Mentual (B) em função dos tipos de OI e quantidade de ciclos de pamidronato.

Figura 14 - Diagrama de dispersão do modelo de regressão linear de ROiCortical e Índice Mentual.

Figura 15 - Médias e intervalos de confiança de índice mentual ao longo de classes etárias de crianças sadias e com diferentes tipos de osteogênese imperfeita (OI)

Figura 16 - Médias e intervalos de confiança de índice mentual das classes de ciclos de pamidronato em crianças osteogênese imperfeita que iniciaram o tratamento em idade precoce ( 0 a 5 anos) e tardia ( $>5$ anos)

Figura 17 - Médias e intervalos de confiança de índice mentual das classes de ciclos de pamidronato em crianças com diferentes tipos de osteogênese imperfeita que tiveram diagnóstico precoce ( 0 a 5 anos) e diagnóstico tardio ( $>5$ anos)

Figura 18 - Médias e intervalos de confiança de índice mentual das classes de ciclos de pamidronato em crianças sadias e com diferentes tipos de osteogênese 
imperfeita

Figura 19 Diagrama de dispersão e modelo de regressão linear entre índice mentual 70 (X) e densidade mineral óssea da coluna lombar (BMDLombar) (Y)

Figura 20 Diagrama de dispersão e modelo de regressão linear entre índice mentual 71 (X) e densidade mineral óssea do corpo total (BMDTotal) (Y)

Figura 21 Diagrama de dispersão e modelo de regressão linear entre índice mentual 72 (Y) e idade de crianças com padrão normal de densidade óssea (X) 


\section{LISTA DE TABELAS}

Tabela 1 - Número de radiografias panorâmicas dos pacientes com OI, com relação aos diferentes grupos de idade e número de ciclos de PAM

Tabela 2 - Relação entre as medidas de índice visual e medidas quantitativas (espessura da cortical mandibular e medidas de dimensão fractal nas regiões de interesse selecionadas)

Tabela 3 - Critérios numéricos de classificação para o índice qualitativo visual.

Tabela 4 - Estatísticas descritivas dos dados de Índice Mentual, ROI Ang, ROI Ramo e ROICortical em função das classes do índice mandibular cortical (C1, C2, C3)

Tabela 5 - Matriz de Coeficientes de correlação de Pearson entre dimensões fractais e índice mentual.

Tabela 6 - Estatísticas descritivas dos dados de ROI Ang e ROI Ramo em função dos tipos de osteogênese imperfeita e quantidade de ciclos de pamidronato.

Tabela 7 - vúmero de radiografias panorâmicas dos pacientes com OI, com 'elação às diferentes faixas etárias, número de ciclos de PAM e idade ao nício do tratamento.

Tabela 8 - Estatísticas descritivas e significâncias de índice mentual entre as classes etárias de crianças sadias e com osteogênese imperfeita (OI)

Tabela 9 - Estatísticas descritivas de índice mentual entre as classes etárias de crianças dos gêneros masculino e feminino, sadias e com osteogênese imperfeita (OI)

Tabela 10 - Estatísticas da bondade de ajuste do modelo de regressão linear

Tabela 11 - Parâmetros do modelo de regressão linear

Tabela 12 - Estatísticas da bondade de ajuste do modelo de regressão linear múltipla

Tabela 13 Análise da variância do ajuste do modelo de regressão linear múltipla 


\section{LISTA DE ABREVIATURAS E SIGLAS}

\begin{tabular}{|c|c|c|}
\hline AIC & & Critério de Akaike \\
\hline BMDLombar & & Densidade mineral óssea da coluna lombar \\
\hline BMDTotal & & Densidade mineral óssea do corpo total \\
\hline BMO & & Baixa massa óssea \\
\hline $\mathrm{CPf}$ & & Ciclo de pamidronato final \\
\hline $\mathrm{CPi}$ & & Ciclo de pamidronato inicial \\
\hline DF & & Dimensão fractal \\
\hline DMO & - & Densidade Mineral Óssea \\
\hline $\mathrm{DP}$ & - & Desvio-padrão \\
\hline dpi & & Dots per inch $=$ pontos por polegada \\
\hline DPR & & Dental panoramic radiograph \\
\hline DXA & - & Densitometria óssea por dupla emissão de fótons de raios $\mathrm{X}$ \\
\hline $\mathrm{F}$ & & Cortical classificada como fina \\
\hline FD & & Fractal dimension \\
\hline HUB & & Hospital Universitário de Brasília \\
\hline IC & - & Intervalo de confiança \\
\hline If & & Idade final (última radiografia) \\
\hline $\mathrm{Ii}$ & & Idade inicial (primeira radiografia) \\
\hline IM & - & Índice mentual \\
\hline IMCo & - & Índice mandibular cortical \\
\hline IMf & & Índice mentual final \\
\hline IMi & & Índice mentual inicial \\
\hline ISCD & - & International Society of Clinical Densitometry \\
\hline IV & - & Índice visual \\
\hline $\mathrm{kVp}$ & - & Pico de quilovoltagem \\
\hline M & & Megabyte \\
\hline $\mathrm{mA}$ & - & Miliamperagem \\
\hline MCI & & Mandibular cortical index \\
\hline MCW & & Mandibular cortical width \\
\hline
\end{tabular}




$\begin{array}{lll}\text { mm } & - & \text { Milímetro } \\ \text { NF } & \text { Cortical classificada como não fina } \\ \text { NIH } & - & \text { National Institute of Health } \\ \text { OI } & - & \text { Osteogênese Imperfeita } \\ \text { PAM } & \text { Pamidronato cíclico intravenoso } \\ \text { ROI } & \text { Region of Interest = região de interesse } \\ \text { ROIAng } & \begin{array}{l}\text { Região de interesse para o cálculo da dimensão fractal na região do } \\ \text { ângulo da mandíbula } \\ \text { ROICortical }\end{array} & \begin{array}{l}\text { região de interesse para cálculo da dimensão fractal na cortical } \\ \text { inferior da mandíbula }\end{array} \\ \text { ROIRamo } & \begin{array}{l}\text { Região de interesse para cálculo da dimensão fractal no ramo } \\ \text { mandibular }\end{array} \\ \text { s } & \text { segundos } \\ \text { SVE } & \text { Simple visual estimation } \\ \text { TCLE } & \text { Termo de consentimento livre e esclarecido } \\ \alpha & \text { Alfa }\end{array}$




\section{SUMÁRIO}

1. INTRODUÇÃO 16

2. REVISÃO DA LITERATURA 20

2.1. OSTEOGÊNESE IMPERFEITA

2.2. DENSITOMETRIAS DE CRIANÇAS COM DiAgNÓSTICO DE OSTEOGÊNESE IMPERFEITA 29

2.3. RADIOGRAFIAS PANORÂMICAS DA FACE E DENSIDADE MINERAL ÓSSEA 31

3. OBJETIVOS 35

3.1. OBJETIVOS ESPECÍ́FICOS - ARTIGO 1

3.2. OBJETIVOS ESPECÍFICOS - ARTIGO 2

4. PACIENTES E MÉTODOS 38

4.1. AMOSTRA 39

4.1.1. CRITÉRIOS DE INCLUSÃO 40

4.1.2. CRITÉRIOS DE EXCLUSÃO 40

4.2. PROCEDIMENTOS PARA COLETA E ANÁLISE DOS DADOS 41

4.3. ANÁLISE ESTATÍSTICA 48

4.3.1. ANÁLISE ESTATÍSTICA DO ARTIGO 1

4.3.2.ANÁLISE ESTATÍSTICA DO ARTIGO 2

5. RESULTADOS

5.1. RESULTADOS DO ARTIGO 1

RELAÇÃO ENTRE ÍNDICES RADIOMORFOMÉTRICOS E DIMENSÃO FRACTAL

DE MANDÍBULA EM CRIANÇAS COM OI EM TRATAMENTO COM PAMIDRONATO 53

5.1.1. AVALIAÇÃO DOS ÍNDICES RADIOMORFOMÉTRICOS QUALITATIVOS DE MANDÍBULA EM CRIANÇAS COM OI 54

5.1.2. AVALIAÇÃO DO ÍNDICE MENTUAL E DAS DIMENSÕES FRACTAIS MANDIBULARES DAS CRIANÇAS, EM FUNÇÃO DO TIPO DE OI E DA FREQUÊNCIA DE CICLOS DE PAMIDRONATO

5.2. RESULTADOS DO ARTIGO 2

EFEITO DO PAMIDRONATO NA CORTICAL MANDIBULAR DE PACIENTES

COM OSTEOGÊNESE IMPERFEITA

65

5.2.1. ASSOCIAÇÃO ENTRE ÍNDICE MENTUAL E DENSIDADE MINERAL ÓSSEA EM CRIANÇAS SAUDÁVEIS COM DIAGNÓSTICO DENSITOMÉTRICO NORMAL 73

5.2.2. MODELO DE VARIAÇÃO DO ÍNDICE MENTUAL PARA CRIANÇAS SAUDÁVEIS COM DIAGNÓSTICO DENSITOMÉTRICO NORMAL 
5.2.3. MODELO PREDITIVO DA QUANTIDADE NECESSÁRIA DE CICLOS DE PAMIDRONATO E VARIÁVEIS RELATIVAS AO TRATAMENTO DA OSTEOGÊNESE IMPERFEITA

6. DISCUSSÃO

6.1. LIMITAÇÕES DO ESTUDO

90

6.2. CONSIDERAÇÕES FINAIS

7. CONCLUSÕES

REFERÊNCIAS

96

ANEXO

APÊNDICES 
1. INTRODUÇÃO 


\section{INTRODUÇÃO}

A osteogênese imperfeita (OI) é um distúrbio hereditário do tecido conjuntivo, transmitido por herança genética autossômica dominante ou recessiva, caracterizado por ossos frágeis e fraturas recorrentes que podem levar a deformidades esqueléticas ou até mesmo à morte, nos casos mais graves. É heterogênea em termos de herança e fenótipo e parece não haver predileção por etnia ou gênero. Foi originalmente classificada em quatro tipos, baseados em características clínicas, radiológicas e genéticas, sendo que a gravidade da desordem, considerando a fragilidade óssea, aumenta na seguinte ordem: tipo I < tipo IV < tipo III < tipo II (Sillence et al, 1979). Mais recentemente, houve a identificação de diferentes mutações e aspectos histológicos, adicionando outros tipos à classificação original, mas ainda não utilizados com frequência na prática clínica (Cheung e Glorieux, 2008; Byers e Pyott, 2012).

O tratamento da OI visa aumentar a mobilidade, diminuir a fragilidade óssea e permitir maior qualidade de vida ao paciente. Para isso, o tratamento envolve uma abordagem multidisciplinar, que inclui a terapia medicamentosa, geralmente com bisfosfonatos intravenosos, como o pamidronato (PAM). A administração cíclica do pamidronato intravenoso inibe a função dos osteoclastos, reduzindo, assim, a reabsorção e aumentando a densidade mineral óssea, com isso, diminui a incidência de fraturas (Zeitlin et al, 2003). Estudos com amostras de osso da crista ilíaca demonstraram que essa terapia medicamentosa aumenta a espessura da cortical e do trabeculado, assim como amplia o número de trabéculas, alterando possivelmente a microarquitetura óssea (Rauch et al, 2006). 
O exame padrão-ouro para avaliação da densidade mineral óssea (DMO) em crianças é a densitometria óssea da coluna lombar e corpo total (ISCD, 2013). No entanto, a baixa disponibilidade desse exame na rede pública de saúde, assim como a dificuldade em realizá-lo nos pacientes com OI tornam limitadas as evidências densitométricas nos estudos. Esses pacientes apresentam ossos pequenos, deformidades, compressão das vértebras por fratura, escoliose e história de imobilização prolongada, o que traz muitas particularidades na interpretação dos resultados densitométricos. Ainda assim, há evidências de baixa DMO nos pacientes com OI, assim como de um aumento dessa densidade após o tratamento com pamidronato (Alvarez et al, 2003; Dwan et al, 2014).

Diversos estudos têm utilizado a radiografia panorâmica da face como ferramenta auxiliar para predizer o diagnóstico densitométrico de baixa DMO em adultos (Drozdzowska et al, 2002; Taguchi et al, 2004 e 2006; White et al, 2005; Alonso et al, 2011). Grande parte dos estudos utiliza índices radiomorfométricos para avaliar a cortical óssea inferior da mandíbula. Nos pacientes com osteoporose, a cortical óssea aparece mais fina e com maior grau de erosão, quando comparado a pacientes com DMO normal. O índice mais utilizado nos estudos é o índice quantitativo mentual, que avalia a espessura da cortical mandibular abaixo do forame mentual (Alonso et al, 2011; Taguchi et al, 2011). No entanto, outros autores demonstraram que índices qualitativos, como o índice mandibular cortical e o índice visual podem também predizer o diagnóstico de osteoporose (Lee et al, 2005; Yassar e Akgünlü, 2006). Outros estudos também avaliaram a microarquitetura óssea por meio da dimensão fractal, um método matemático que analisa a complexidade estrutural do trabeculado ósseo. Na maioria dos estudos, a dimensão fractal do trabeculado ósseo está alterada nos pacientes com osteoporose (Alman et al, 2011; Oliveira et al, 2012). 
Apesar dos resultados dos estudos supracitados, que relacionaram radiografias panorâmicas da face, amplamente utilizadas na rotina clínica, com DMO, somente foi encontrado um estudo recente que avaliou o índice mentual em crianças (PaulssonBjörnsson et al, 2015). No entanto, a relação entre os índices radiomorfométricos e métodos que analisam o trabeculado ósseo com a DMO precisa ser melhor investigada na população pediátrica.

Assim, o objetivo desse trabalho foi verificar, em radiografias panorâmicas da face, as alterações no trabeculado e na cortical do osso mandibular ocorridas, ao longo do tempo e dos ciclos de administração de pamidronato intravenoso, em pacientes com diferentes tipos de OI. A principal hipótese do estudo foi que a imagem radiográfica da cortical e do trabeculado ósseo da mandíbula seria modificada à medida que a densidade mineral óssea dessas crianças fosse sendo aumentada pelo tratamento farmacológico.

O trabalho foi dividido em dois artigos principais. O primeiro, em fase final de envio para publicação, teve como objetivo verificar a relação entre alguns índices de radiografias panorâmicas da face e o cálculo da dimensão fractal no trabeculado e cortical ósseos da mandíbula em crianças com diferentes tipos de OI. Também foi analisado o efeito da terapia com pamidronato nessas medidas radiográficas. Os resultados preliminares desse primeiro estudo apontaram melhores resultados para o índice mentual, que analisa a espessura da cortical mandibular. Com isso, foi realizada uma análise aprofundada do efeito do pamidronato na espessura da cortical mandibular, que está apresentada no artigo 2, já aceito para publicação. 
2. REVISÃO DA LITERATURA 


\section{REVISÃO DA LITERATURA}

\subsection{Osteogênese Imperfeita}

A osteogênese imperfeita (OI) é uma desordem genética do tecido conjuntivo que afeta a formação do colágeno, quantitativa ou qualitativamente, caracterizada por vários graus de baixa massa óssea e aumento da susceptibilidade a fraturas. A maioria dos casos são formas autossômico-dominantes com mutações nos genes COL1A1 ou COL1A2, que provocam alterações na síntese da cadeia $\alpha$ (alfa) do colágeno tipo I, representante de mais de $90 \%$ do colágeno tecidual total. O restante dos casos apresenta mutações recessivas nos genes que codificam uma proteína associada à cartilagem e outra à 3-prolyl-hidroxilase, dois componentes fundamentais no processo de formação do colágeno tipo I (Santilli et al, 2005; Van Dijk e Sillence, 2014). Essas mutações podem causar a redução da síntese e da secreção do colágeno tipo I, além disso, há o aumento da taxa de remodelação óssea devido à atividade reparadora para substituição do tecido ósseo enfraquecido (Glorieux, 2007). A produção diminuída do colágeno tipo I com estrutura molecular normal geralmente leva à osteogênese imperfeita tipo I, mais branda e com ausência de grandes deformidades. Já a formação de colágeno com estrutura molecular alterada leva às formas mais graves da doença, até mesmo letal (OI tipo II, devido à falência respiratória decorrente de múltiplas fraturas nas costelas), dependendo da natureza da mutação, de seu efeito em nível molecular, da estabilidade e da capacidade de alterar a fibrinogênese. Em ambas as situações, o tecido osteóide formado é incapaz de manter a mineralização normal, tornando os ossos desses indivíduos frágeis e deformados (Miller e Hangarter, 1999). 
Foi estimada uma prevalência em torno de 1:15.000 nascimentos/ano (Osteogenesis Imperfecta Foundation, 2013), porém é possível que este dado esteja subestimado, visto que formas leves da doença não são evidentes ao nascimento e podem não ser detectadas na primeira infância. O diagnóstico é geralmente clínico, outras investigações como radiografias, biópsia da crista ilíaca e análises genéticas podem ajudar a fechar o diagnóstico. Há uma grande heterogeneidade entre os pacientes com OI, sendo esses classificados por tipos, conforme com suas características. De acordo com a classificação original (Sillence, 1979), a OI tipo I corresponde à forma mais branda; tipo II, letal ao nascimento; tipo III é a forma mais grave com deformações ósseas progressivas; e a tipo IV corresponde aos fenótipos intermediários entre I e III. Outros tipos de OI foram sendo incorporados a essa classificação, com base em achados histológicos e genéticos além dos clínicos; até os dias atuais, 9 tipos da doença já foram descritos (Arundel e Bishop, 2009; Byers e Pyott, 2012 Maines et al, 2012). Indivíduos com graus mais graves da doença possuem maior fragilidade óssea e, consequentemente, maior número de fraturas.

Além da grande suscetibilidade a fraturas, geralmente os indivíduos apresentam outros problemas, como articulações frouxas, perda precoce de audição, problemas respiratórios e contusões (Osteogenesis Imperfecta Foundation, 2013). Ainda, é comum apresentarem características bucais importantes, como dentinogênese imperfeita. A primeira dentição é geralmente mais afetada, podendo ter uma coloração cinza, marrom ou amarelada. Radiograficamente, a dentinogênese imperfeita apresenta-se com constrição cervical nos dentes, coroas bulbosas, raízes curtas, e câmaras e canais pulpares obliterados com o tempo. Estudos mostram que alguns traços faciais são comuns em adultos, como fáscies triangular, testa larga e más oclusões de classe III (Kindelan, 2003). 
Diante do quadro de saúde apresentado pelo paciente, o tratamento da osteogênese imperfeita é multidisciplinar, envolvendo várias áreas da medicina, fisioterapia, psicologia e odontologia. O objetivo é reduzir o número de fraturas, prevenir deformidades de ossos longos e escoliose, e obter a maior mobilidade e capacidades funcionais possíveis. Programas de atividade física são encorajados, quando possível, para prevenção de contraturas e perdas ósseas induzidas pela imobilidade. Órteses são utilizadas para proteger as pernas durante as fases precoces de mobilização. Em alguns casos a marcha só pode ser conseguida após o fêmur e a tíbia terem sido retificados com hastes metálicas (Rauch e Glorieux, 2004; Glorieux, 2007).

Ainda que traga inúmeros benefícios para a qualidade de vida do paciente com osteogênese imperfeita, a abordagem não farmacológica muitas vezes é insuficiente para diminuir a fragilidade óssea extrema dos pacientes, assim, torna-se necessária a administração de medicações que aumentam a força dos ossos. Por muitos anos, diferentes tratamentos, como hormônios (calcitonina, cortisona, estrogênio, androgênio e tiroxina), vitaminas (A, C e D), minerais (alumínio, cálcio, flúor, magnésio, fosfato e estrôncio) e outros não se mostraram efetivos. Esse quadro começou a alterar-se em 1987, após a publicação, por Devogelaer et al, do caso de um paciente de 12 anos acometido por osteogênese imperfeita, que apresentou uma pronunciada melhora clínica e radiológica após um ano de tratamento com pamidronato oral (Glorieux, 2001).

As observações pioneiras de Devogelaer e de outros estudos pilotos subsequentes levaram ao tratamento de grandes grupos de pacientes portadores de OI com os bisfosfonatos. A evidência disponível dessa abordagem de tratamento em crianças originase de estudos observacionais em pacientes afetados de forma moderada a avançada. Nenhum desses estudos teve grupo controle placebo, mas alguns incluíram controles 
históricos do tipo antes-depois, sendo que a maioria dos pacientes nesses estudos foi tratada com pamidronato cíclico intravenoso (Glorieux, 2001).

O Pamidronato (PAM) é uma droga da família dos bisfosfonatos, potentes agentes anti-reabsortivos, que interfere na biossíntese do colesterol nos osteoclastos inibindo sua função, mas não levando à apoptose. A hipótese que justifica o uso dessas drogas é que a diminuição na atividade de reabsorção óssea poderia compensar a deficiência das células formadoras de osso. O aumento da remodelação óssea, estabelecido por estudos histológicos, subsidia o uso racional dos bisfosfonatos em pacientes com OI (Glorieux, 2001 e 2007). Pelos aparentes benefícios apresentados, até mesmo em crianças com menos de 24 meses (Kusumi et al, 2014), muitos autores procuraram estudar os efeitos sistêmicos dos bisfosfonatos, bem como o efeito local no tecido ósseo (Glorieux, 2008; Drake, 2008; Bishop, 2010; Bocanegra-Pèrez et al, 2012).

Um rápido aumento de peso tem sido notado em muitas crianças durante o tratamento com o pamidronato (Zeitlin et al, 2003). Pronunciado declínio na dor óssea crônica pode ser observado após poucas semanas do início do tratamento, somado a um aumento da sensação de bem-estar e da força muscular. Tem sido reportado rápido aumento da massa óssea vertebral atribuído ao aumento da densidade mineral óssea, do tamanho vertebral e da espessura da cortical metacarpal, diminuição do número de fraturas e melhora da mobilidade. Alguns autores reportaram a impressão de que corpos vertebrais deformados adquirem morfologia mais semelhante ao normal durante o tratamento com pamidronato. Também tem sido notado um aumento na espessura da cortical, no número de trabéculas e na massa óssea das diáfises de ossos longos. Não têm sido observados efeitos negativos no crescimento nem em reparação de fraturas (Rauch e Glorieux, 2004; Rauch et al, 2006; Vallo et al, 2006; Glorieux, 2007 e 2008). 
Achados em estudos histomorfométricos de amostras de osso da crista ilíaca mostraram que o maior efeito do tratamento com o pamidronato foi um aumento da espessura cortical de até $88 \%$ (figuras 1 e 2). A quantidade de osso trabecular também aumenta, devido a um maior número de trabéculas, apesar de não mostrar nenhum efeito detectável na espessura do trabeculado (figura 3). Essa droga diminui a remodelação óssea por alterar o mecanismo de homeostase e inibir os osteoclastos, podendo interferir na forma do osso (Rauch e Glorieux, 2004; Rauch et al, 2006; Drake, 2008; Glorieux, 2008).
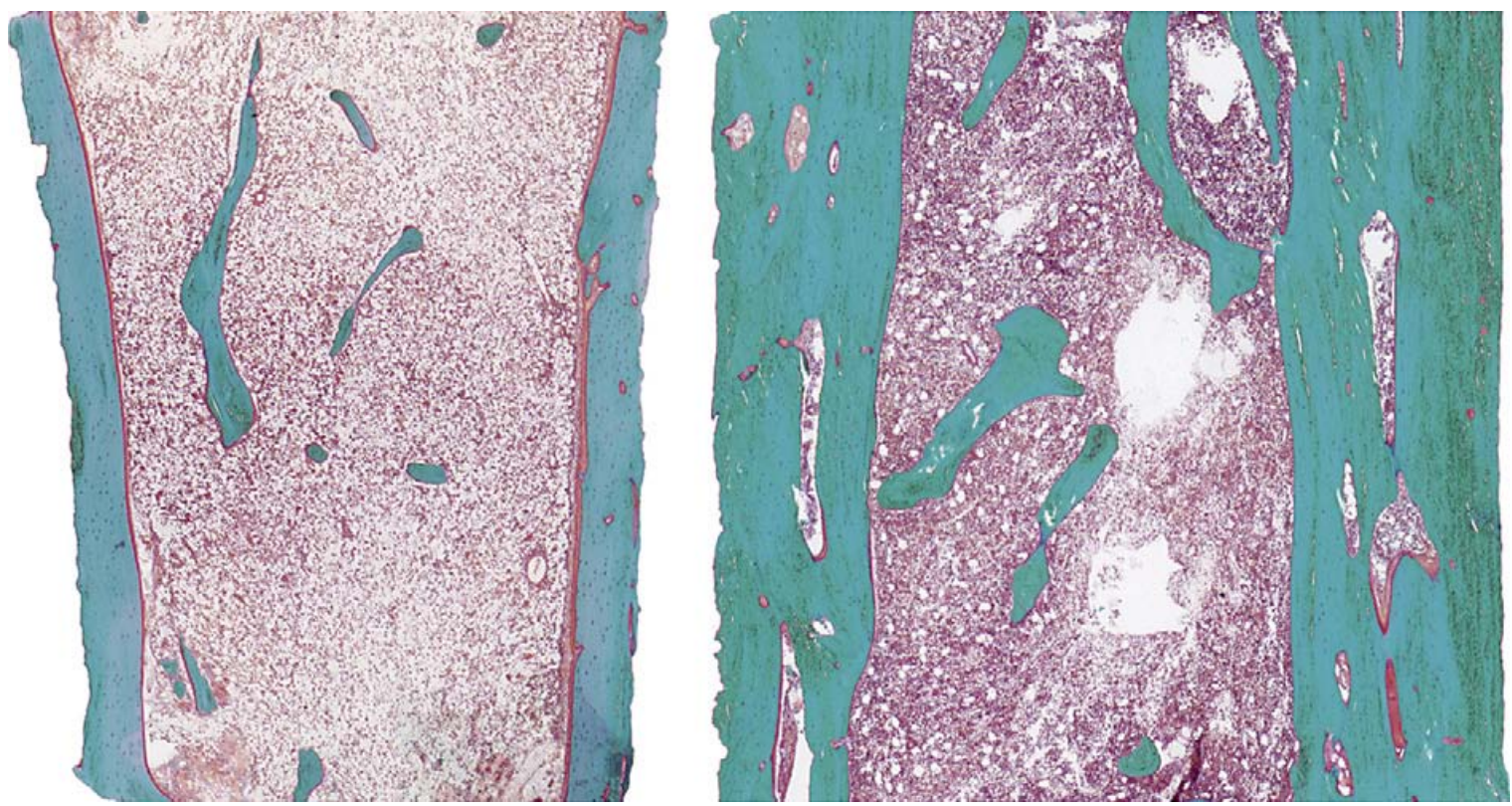

Figura 1 - Mudanças histológicas durante o tratamento com pamidronato.

Biópsia de osso da crista ilíaca de um menino portador de OI tipo I. Do lado esquerdo, amostra obtida aos 2 anos, época da sua primeira infusão com o pamidronato; do lado direito, biópsia após 3 anos de tratamento. A espessura do córtex ósseo mais que triplicou neste intervalo de tratamento.

Fonte: Glorieux, 2008 


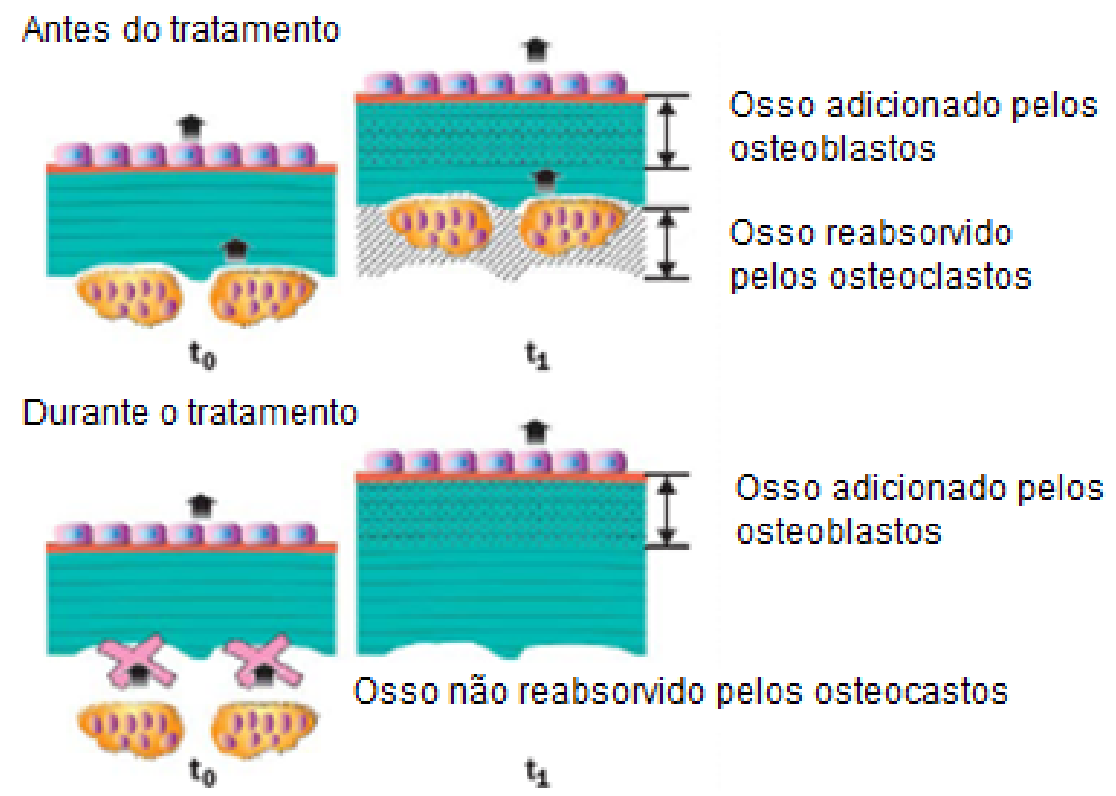

Figura 2 - Modelo de como o tratamento com pamidronato aumenta a espessura da cortical de pacientes acometidos por $\mathrm{OI}$ em crescimento.

Durante o período de crescimento a espessura da cortical é determinada pelo remodelamento ósseo. Nesse mecanismo, osteoblastos e osteoclastos estão ativos em lados opostos do córtex e não são diretamente emparelhados. Os osteoclastos são atingidos pelo pamidronato e a contínua formação óssea pode aumentar a espessura da cortical.

Fonte: Rauch e Glorieux, 2004

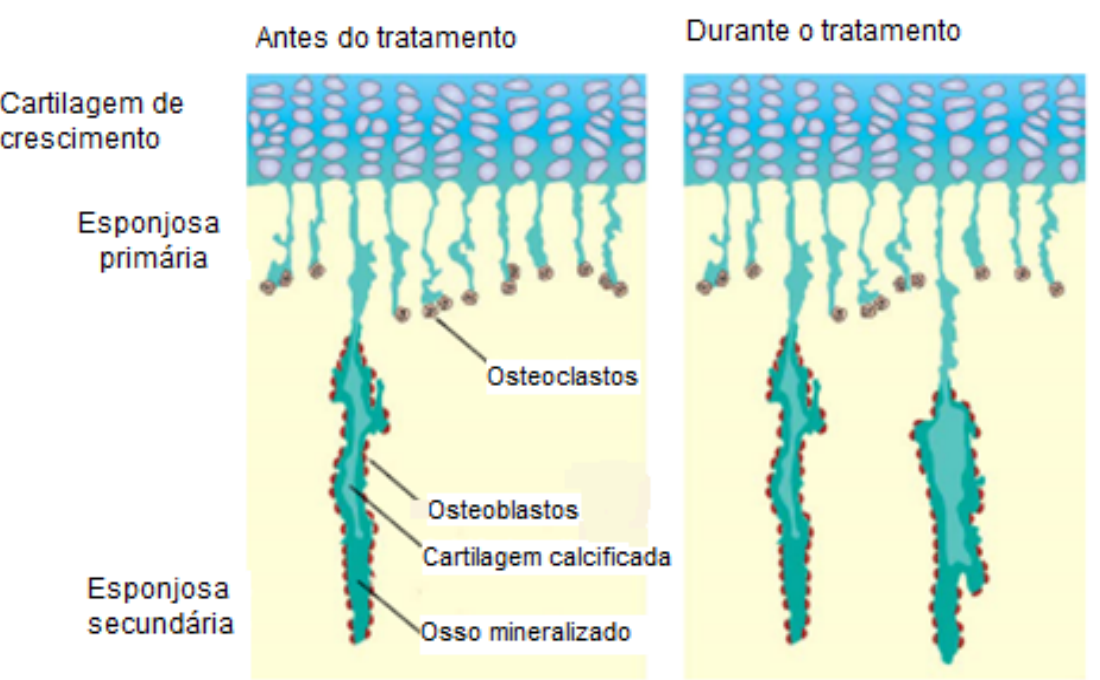

Figura 3 - Modelo de como o pamidronato afeta o número de trabéculas.

Durante o processo de crescimento endocondral, a maioria do trabeculado primário é perdida durante a conversão de esponjosa primária para secundária. O pamidronato aumenta o número de trabéculas secundárias, provavelmente porque mais trabéculas primárias sobrevivam para tornarem-se secundárias.

Fonte: Rauch e Glorieux, 2004 
Mesmo com resultados tão encorajadores, alguns efeitos adversos são preocupantes quando bisfosfonatos são administrados em crianças e adolescentes. O efeito imediato da infusão de pamidronato é uma queda na concentração de cálcio sérico (Rauch et al, 2003b). Muitas crianças apresentam, após sua primeira infusão, uma reação semelhante a uma gripe, que pode ser acompanhada de febre, exantemas e vômitos. Esses sintomas normalmente começam 12-36 horas após o início da infusão e são geralmente controlados com antipiréticos de uso comum e não necessitam de outros tratamentos, porém trazem preocupações para crianças que têm condição sistêmica comprometida ou dificuldades respiratórias (Rauch e Glorieux, 2004).

Além disso, as consequências em longo prazo desse medicamento ainda são desconhecidas. Após um longo período de tratamento, os bisfosfonatos diminuem a taxa de remodelação óssea a níveis menores que a de crianças saudáveis, o que pode retardar os reparos de microlesões e de fraturas no tecido ósseo (Rauch et al, 2003a; Melo e Obeid, 2005).

Segundo Glorieux, 2008, os efeitos dos bisfosfonatos no esqueleto são dependentes do crescimento, assim, adolescentes após a puberdade e adultos não têm tantos benefícios com o tratamento em comparação a pacientes mais jovens. Além disso, seus efeitos parecem tornar-se menos evidentes com o aumento da duração do tratamento. Por exemplo, o z-score específico para cada idade na densitometria da coluna lombar aumenta, em média, 2,0 desvios-padrão durante o primeiro ano de tratamento, mas apenas 0,6 entre o segundo e o quarto anos. Estudos histomorfométricos têm mostrado que a espessura da cortical do osso ilíaco quase dobra nos primeiros dois a três anos, mas muda pouco quando a terapia continua por mais de três anos (Mariani, 2003; Rauch et al, 2006). Estudos longitudinais prévios sugerem que a terapia com pamidronato intravenoso, nas doses 
atuais, não tem efeito negativo no crescimento nem na função renal de pacientes com forma de moderada a severa de osteogênese imperfeita (Zeitlin et al, 2003). Há relatos de que o tratamento prolongado com os bisfosfonatos pode resultar em achados característicos da osteopetrose, como densidade óssea aumentada e remodelação defeituosa, as quais persistem por mais de 18 meses após a interrupção do tratamento (Mariani, 2003). Outro efeito adverso relatado na literatura é a osteonecrose de maxila e mandíbula associada ao uso dos bisfosfonatos (Hoff et al, 2008; Bocanegra-Pérez et al, 2012).

A osteonecrose mandibular é um fator de grande preocupação associado com a administração de bisfosfonatos, principalmente em pacientes com câncer. A real incidência dessa complicação permanece desconhecida, mas estudos prévios têm mostrado uma relação direta com a duração do tratamento e a dose administrada, além de saúde bucal comprometida e extrações dentárias (Hoff et al, 2008; Bocanegra-Pérez et al, 2012). Até os dias atuais, não foram reportados casos de osteonecrose em mandíbulas de crianças portadoras de OI tratadas com bisfosfonatos, mesmo após 10 anos de tratamento (Malmgren et al, 2008; Schwarz et al, 2008; Maines et al, 2012).

Apesar do uso contínuo de bisfosfonatos intravenosos ser associado à osteonecrose dos maxilares, parece que o esqueleto apendicular não é afetado. O estudo de Stefanik et al, 2008, com cultura de células de mandíbula e crista ilíaca, mostrou que as células mandibulares são mais susceptíveis ao pamidronato que as da crista ilíaca, baseado na diminuição da sobrevida celular, menor produção de fosfatase alcalina e regeneração óssea estruturalmente menos organizada, favorecendo a desregulação da homeostase do osso mandibular.

A terapia com os bisfosfonatos não constitui a cura da osteogênese imperfeita, mas auxilia enormemente o tratamento, pois traz evidente melhora na qualidade de vida dos 
pacientes com forma moderada a severa da doença. Porém, esses resultados não podem ser extrapolados para as formas leves, com duas ou poucas fraturas por ano, ausência de fraturas por compressão vertebral e de deformidades ósseas. Essas crianças têm menos a ganhar porque seu status funcional é melhor mesmo sem tratamento, assim, até o momento é recomendado que elas não sejam tratadas com fármacos. Cirurgias ortopédicas, programas de fisioterapia e reabilitação são partes integrais do protocolo de tratamento, e essa abordagem deve prevalecer até que as terapias genéticas tornem-se clinicamente aplicáveis (Glorieux, 2007).

\subsection{Densitometrias de crianças com diagnóstico de OI}

Atualmente, o exame de referência para avaliação da densidade mineral óssea expressa em gramas de mineral por área ou volume e determinada por pico de massa óssea e quantidade de perda óssea (NIH - Consensus Statement, 2000) - é a densitometria por dupla emissão de raios X (DXA). Estudos com DXA são unânimes em afirmar que a maioria das crianças e adolescentes com Osteogênese Imperfeita apresenta baixa densidade mineral óssea (Alvarez et al, 2003; Rauch et al, 2005 e Gatti et al, 2003). No exame, são avaliados principalmente quadril, coluna lombar e corpo total, ainda que as fraturas em ossos longos sejam uma importante característica dessa desordem. Mesmo sendo o exame de eleição para a avaliação da densidade mineral óssea, os resultados da densitometria são de difícil interpretação nesses pacientes devido ao tamanho pequeno e à deformidade dos ossos, fraturas vertebrais, escoliose e histórico de imobilização prolongada (Rauch et al, 2005). 
Ainda que haja uma dificuldade em analisar dados densitométricos de crianças com OI, estudos como o de Rauch et al (2003a) demonstraram que, ao longo dos ciclos de pamidronato, o conteúdo mineral ósseo, o tamanho e a densidade mineral volumétrica aumentam consideravelmente em comparação com indivíduos não tratados, pareados por idade e tipo de osteogênese imperfeita. Além disso, nesse mesmo estudo pôde-se observar que os pacientes com maiores déficits na massa óssea antes do tratamento foram os que tiveram maiores ganhos com a terapia.

Em estudo realizado por Miller e Hangartner (1999), 14 indivíduos portadores de OI tipo I, com idades entre 8 meses a 45 anos, tiveram suas densidades minerais ósseas, cortical e trabecular avaliadas por meio de tomografia computadorizada e comparadas a 1000 indivíduos com densidades minerais ósseas normais. Como resultados, concluíram que crianças com OI tipo I tinham baixa DMO cortical e trabecular quando comparadas ao grupo controle, enquanto que os adultos com OI tiveram baixa DMO trabecular e alta densidade cortical quando comparados com os controles, o que talvez explique a diminuição da frequência de fraturas na idade adulta.

No intuito de entender melhor as anormalidades esqueléticas que caracterizam a osteogênese imperfeita, sem a interferência de fenômenos secundários, Rauch et al, em 2005, estudaram, por meio de DXA, tomografia computadorizada quantitativa periférica e radiogrametria, 42 indivíduos, de 6 a 19 anos, com OI tipo I leve, que não apresentavam deformidades em ossos longos ou fraturas vertebrais por compressão. O conteúdo mineral ósseo na coluna lombar, metáfise e diáfise do rádio encontrado foi entre 25 e 31\% mais baixo que o esperado para indivíduos saudáveis pareados por idade e gênero. O tamanho dos ossos encontrava-se normal ou pouco abaixo dos resultados esperados para crianças saudáveis na coluna lombar e metáfise do rádio, porém, bastante diminuído nas diáfises do 
rádio e segundo metacarpo. Essas diferenças de tamanho levaram a resultados muito discrepantes para a DMO total: mais baixas na coluna lombar (-23\%) e metáfise do rádio (-15\%), e mais alta na diáfise do rádio (+25\%). Os resultados deste estudo demonstraram que a DMO volumétrica pode ser anormalmente alta e baixa em um mesmo osso, concluindo que a densitometria volumétrica nos sítios de diáfises pode não prover uma boa estimativa para a resistência óssea quando o tamanho dos ossos é anormal.

Mesmo existindo tantos problemas na interpretação em crianças com OI, a DMO parece ser um indicador da severidade da doença, já que existe uma relação entre esta e os resultados de função física, número de fraturas e quantidade de cirurgias nesses pacientes. Assim, o tratamento da OI tem sido direcionado à melhora da DMO (Huang et al, 2006).

\subsection{Radiografias panorâmicas da face e densidade mineral óssea}

Vários estudos compararam e analisaram resultados obtidos de densitometrias da coluna lombar e quadril e radiografias panorâmicas da face. Esses estudos sugeriram que alterações na cortical e no trabeculado ósseos podem predizer uma baixa densidade mineral óssea (Taguchi et al, 2004, 2006). A mandíbula possui uma série de marcas anatômicas que podem servir como indicadores radiográficos para a avaliação de mudanças quantitativas e qualitativas no tecido ósseo (Arkadani e Niafar, 2004). Grande número de índices mandibulares baseados em radiografias panorâmicas e técnicas de processamento e análises de imagens foram desenvolvidos para permitir a quantificação da massa óssea mandibular e da microarquitetura do trabeculado ósseo, na tentativa de prever um diagnóstico densitométrico de baixa massa óssea em idosos. Embora alguns estudos afirmem que os índices radiomorfométricos usados nas radiografias panorâmicas 
promovem um suporte limitado para este fim (Devlin e Horner, 2002), vários outros tiveram sucesso em mostrar forte correlação entre esses índices, em especial o índice mentual (IM), e a DMO (Drozdzowska et al, 2002; Taguchi et al, 2004 e 2006; White et al, 2005; Leite et al 2010; Alonso et al, 2011).

O índice mentual (IM) corresponde à medida da espessura da cortical inferior da mandíbula na região do forame mentoniano. Muitos estudos demonstraram que pacientes com osteoporose apresentavam o córtex mandibular inferior mais fino em poroso. Alguns autores verificaram erosões na cortical mandibular de pacientes com baixa massa óssea utilizando índices qualitativos e visuais, como o índice cortical mandibular (IMCo) e o índice visual (IV) (Lee et al, 2005; Yassar e Akgünlü, 2006; Leite et al, 2010). O índice mentual também tem sido usado em pacientes pediátricos (Paulsson-Björnsson et al, 2014), no entanto, até onde sabemos, dados a respeito da relação entre a espessura da cortical mandibular abaixo do forame mentual e baixa DMO em crianças ainda não estão disponíveis.

Em estudo prévio, comparando densitometrias ósseas e índices radiomorfométricos de mandíbula de crianças saudáveis e crianças com OI, foi observado que crianças com OI tiveram uma tendência a apresentar corticais mais porosas, IMCo como C3; e espessuras da cortical, em média, mais baixas que crianças saudáveis (Apolinário, 2009).

A microarquitetura óssea é deteriorada em pacientes com osteoporose, a espessura e o número de trabéculas são diminuídos, e as trabéculas são mais separadas. Assim, isso altera a imagem do padrão ósseo na radiografia, alterando sua densidade e textura (Eckstein et al, 2007). Outra técnica que tem se mostrado um forte indicador de mudanças no tecido ósseo - tanto no padrão do osso alveolar, pela da malha trabecular, como do osso 
cortical mandibular - é a análise da dimensão fractal (Alman et al, 2011; Yasar e Akgunlu, 2008). Trata-se de uma descrição matemática que auxilia na quantificação de formas complexas, que não podem ser analisadas pela geometria euclidiana. Atualmente, encontram-se estudos com esta técnica em diversas áreas do conhecimento odontológico, como para avaliação de alterações periodontais (Bosshardt et al, 2008), implantes (Traini et al, 2010), movimentações ortodônticas (Rothe et al, 2006), cirurgias ortognáticas (Heo et al, 2002), lesões periapicais (Chen et al, 2005; Yu et al, 2009) e doenças sistêmicas, principalmente as relacionadas às estruturas ósseas (Law et al, 1996; Tosoni et al, 2006).

A maioria das pesquisas que abordou a análise da dimensão fractal (DF) do osso mandibular verificou que esse método foi eficaz na diferenciação entre ossos osteoporóticos e normais, ainda que não haja um padrão para a essa mensuração, podendo ser encontradas várias formas de se calcular a dimensão fractal. Mesmo não havendo um consenso a respeito da melhor técnica a ser utilizada, é muito comum encontrar-se o método “box counting” (Dermibas et al, 2008; Ergün et al, 2009; Pothuaud et al; 1998; Oliveira et al, 2012).

Embora as radiografias panorâmicas sejam importantes exames de rotina na clínica odontológica pediátrica, os índices radiomorfométricos e análise da DF ainda precisam ser estudados nessa população. A infância e a adolescência são períodos de extrema importância para o crescimento esquelético, quando mais de $90 \%$ da massa óssea adulta é adquirida. A otimização da aquisição do pico de massa óssea e força em idade precoce tem se mostrado um fator de grande importância na prevenção de fraturas por osteoporose em adultos (Leonard e Zemel, 2004; Borges e Brandão, 2006; Bachrach, 2007). Muitos fatores podem levar à baixa massa óssea em crianças, como mobilidade reduzida, taxa de crescimento diminuída, nutrição inadequada, uso de anticonvulsivantes, baixas taxas de 
vitamina D, irregularidades na puberdade e maturação esquelética e desordens genéticas que afetam a aquisição e o remodelamento ósseo (Hough, 2010). Indivíduos com osteogênese imperfeita apresentam baixa massa óssea (Alvarez et al, 2003; Gatti et al, 2003) e, ao longo do tratamento com o PAM, o tamanho e massa ósseas aumentam substancialmente quando comparados a indivíduos não tratados (Rauch et al, 2003a). Mesmo sendo limitadas, as evidências densitométricas disponíveis para pacientes com OI são um indicador da severidade da doença. Vários estudos mostram que a DMO aumenta ao longo do tratamento com o PAM (Rauch et al, 2003a, 2003b, 2005).

No que diz respeito ao acompanhamento odontológico de indivíduos com OI, há, até os dias atuais, uma dificuldade em estabelecer parâmetros para o estudo da morfologia craniofacial e densidade óssea mandibular nesses pacientes. Sendo as radiografias panorâmicas exames relativamente acessíveis e de baixo custo, seria muito útil verificar se alterações radiográficas na mandíbula podem ser um indicador da evolução do tratamento com pamidronato, tendo assim um importante papel no acompanhamento dos pacientes acometidos pela OI.

Assim, esse trabalho se propôs a verificar, em radiografias panorâmicas da face, as alterações no trabeculado e na cortical ósseos da mandíbula ocorridas em pacientes com diferentes tipos de OI, ao longo do tempo e dos ciclos de administração de pamidronato intravenoso. A principal hipótese do estudo foi que a cortical e o trabeculado ósseo da mandíbula apareceriam alterados à medida que a densidade mineral óssea dessas crianças fosse sendo aumentada pelo tratamento farmacológico. 
3. OBJETIVOS 


\section{OBJETIVOS}

O objetivo da pesquisa foi verificar as alterações na cortical e no trabeculado mandibular ocorridas ao longo do tempo e dos ciclos de administração do pamidronato intravenoso, em crianças com diferentes tipos de OI, por meio da avaliação de índices radiomorfométricos e análise da dimensão fractal em radiografias panorâmicas.

\subsection{Objetivos específicos do artigo 1}

- Avaliar se havia diferença na espessura e no grau de erosão da cortical óssea inferior da mandíbula e na medida de dimensão fractal no osso mandibular em radiografias panorâmicas de pacientes com diferentes tipos de OI.

- Avaliar se havia diferença na espessura e no grau de erosão da cortical óssea inferior da mandíbula e na medida de dimensão fractal no osso mandibular em radiografias panorâmicas de pacientes com diferentes tipos de OI, ao longo do tratamento com o pamidronato.

\subsection{Objetivos Específicos do artigo 2}

- Verificar se há diferença na espessura da cortical mandibular nos diferentes tipos de OI, nas diferentes faixas etárias e idades de início do tratamento, ao longo dos ciclos de PAM.

- Comparar a espessura da cortical do osso mandibular de pacientes com OI e crianças saudáveis. 
- Verificar se é possível, por meio do IM, estimar a quantidade de ciclos de PAM que crianças com OI devem tomar para atingir espessura cortical compatível com crianças saudáveis. 
- 


\section{PACIENTES E MÉTODOS}

Esse foi um estudo longitudinal retrospectivo, por meio da avaliação de radiografias panorâmicas já realizadas e arquivadas nos prontuários dos pacientes com OI que estiveram em tratamento no Hospital Universitário de Brasília nos anos entre 2007 e 2013.

Esta pesquisa foi autorizada pelo CEP da Faculdade de Ciências da Saúde da Universidade de Brasília, para o projeto “Avaliação de dois índices radiomorfométricos de mandíbula em radiografias panorâmicas de pacientes portadores de osteogênese imperfeita”, com o número: 076/2007 (anexo 1), sendo o atual trabalho uma continuação do estudo supracitado. Como material da pesquisa, foram selecionadas apenas radiografias de pacientes que assinaram o termo de consentimento livre e esclarecido (TCLE) da pesquisa anterior (apêndices 1 e 2).

\subsection{Amostra}

A amostra foi selecionada de um banco de dados pré-existente de 105 pacientes com OI atendidos no Hospital Universitário de Brasília (HUB). Para o diagnóstico da doença, todos os pacientes foram avaliados pelo setor de Endocrinologia Pediátrica do HUB. Posteriormente, os pacientes eram encaminhados para o serviço de atendimento a pacientes com doenças raras, na Clínica de Anomalias do Desenvolvimento Dentário e Facial, desse hospital, para acompanhamento e tratamento odontológico, com realização de radiografias panorâmicas. As consultas odontológicas no hospital coincidiam com os períodos em que os pacientes eram internados para a administração do pamidronato. As 
radiografias panorâmicas da face foram tiradas, portanto, em diferentes tempos ao longo do tratamento, em média uma vez por ano, no momento da admissão do paciente para o ciclo do medicamento. Por isso, na amostra final da pesquisa, todos os pacientes apresentavam radiografias panorâmicas em diferentes etapas do tratamento com o PAM, e a pesquisa foi realizada por meio da comparação dessas radiografias.

A medicação era administrada em intervalos de 4 meses, em 2 ou 3 dias consecutivos. Para crianças com mais de 3 anos, a dose era de $1.0 \mathrm{mg} / \mathrm{kg} / \mathrm{dia}$ para ciclos de 3 dias; para o esquema de 2 dias, a dose era 1,5mg/kg/dia, e a dose cumulativa anual era 9 $\mathrm{mg} / \mathrm{kg}$.

Todos os pacientes foram examinados anteriormente conforme protocolo de atendimento do HUB e as radiografias panorâmicas foram realizadas como exames complementares de diagnóstico.

\subsubsection{Critérios de Inclusão}

- Radiografias panorâmicas da face de pacientes com diagnóstico confirmado de osteogênese imperfeita

- Radiografias de pacientes entre 3 e 19 anos de idade;

- Radiografias de pacientes cujos pais ou responsáveis concordaram e assinaram o Termo de Consentimento Livre e Esclarecido (apêndice 1)

\subsubsection{Critérios de Exclusão}

- Radiografias de indivíduos portadores de outra enfermidade osteometabólica; 
- Radiografias com imagens de má qualidade, que impossibilitaram a adequada visualização das estruturas para análise.

Do banco de dados original, 38 pacientes foram excluídos do artigo 1 pelos motivos a seguir: 10 não tinham radiografias panorâmicas, 15 não preencheram o critério de qualidade das imagens radiográficas, 9 tinham mais de 19 anos, 3 tinham menos de 3 anos e 1 apresentava outra doença metabólica. Para esse artigo, a amostra final foi constituída de 206 radiografias panorâmicas de 67 crianças com OI tipos I, III e IV.

Para o artigo 2, outras 5 crianças foram excluídas por não apresentarem, até o momento do estudo, seu tipo de OI definido, consistindo, então, a amostra final de 197 radiografias panorâmicas de 62 crianças com OI tipos I, III e IV.

Ainda com relação ao artigo 2, foi utilizado como grupo controle, para a comparação do índice mentual, os resultados coletados de 92 radiografias de crianças saudáveis, entre 5 e 18 anos, colhidas de um banco de dados utilizado no projeto “Avaliação de dois índices radiomorfométricos de mandíbula em radiografias panorâmicas de pacientes portadores de osteogênese imperfeita”. Todos os pacientes deste grupo apresentavam radiografia panorâmica, densitometria óssea e TCLE.

\subsection{Procedimentos para coleta e análise dos dados}

Foram incluídas no estudo as radiografias que apresentaram qualidade técnica para a visualização clara das estruturas a serem analisadas, principalmente a cortical inferior da mandíbula, que deveria estar completamente visível. 
As radiografias panorâmicas foram executadas no mesmo aparelho, o Rotograph Plus (VILLA MEDICAL SYSTEM), localizado no HUB, tempo de exposição de 16s, miliamperagem média de $10 \mathrm{~mA}$ e 60 a $75 \mathrm{kVp}$. Todas elas foram convertidas para o formato digital por meio de um scanner com adaptador de transparência (Epson Exp, 1680Pro, Seiko Epson Corp, Nagano, Japão), com escala de cinzas de 8-bit e resolução de 300dpi. As imagens foram salvas com tamanho de 3188 x 1709 pixels (tamanho do arquivo de 5,20 M), com 256 níveis de cinza e em formato JPEG.

As imagens foram analisadas por um único examinador, que fez a avaliação de três índices radiomorfométricos e o cálculo da dimensão fractal em três sítios (ROIs Region of Interest) diferentes na mandíbula dos pacientes. A cortical inferior da mandíbula foi detectada em um dos lados, escolhido com base na melhor visualização das estruturas de interesse, distalmente aos forames mentuais.

As radiografias foram classificadas segundo a qualidade da cortical inferior da mandíbula e foram realizadas mensurações lineares de acordo com os três índices radiomorfométricos listados abaixo:

A) Índice Mandibular Cortical (IMCo): análise da qualidade da cortical inferior da mandíbula, abaixo do forame mentoniano. De acordo com a característica da cortical, os pacientes foram classificados em: C1 quando apresentavam a margem endosteal da cortical nítida em ambos os lados; C2 nos casos em que a superfície endosteal possuía defeitos semilunares (reabsorções lacunares) ou tinha resíduos de cortical; e C3 quando a camada cortical formada encontrava-se extremamente porosa, conforme especificado em Klemetti, 1994 (figura 4). 

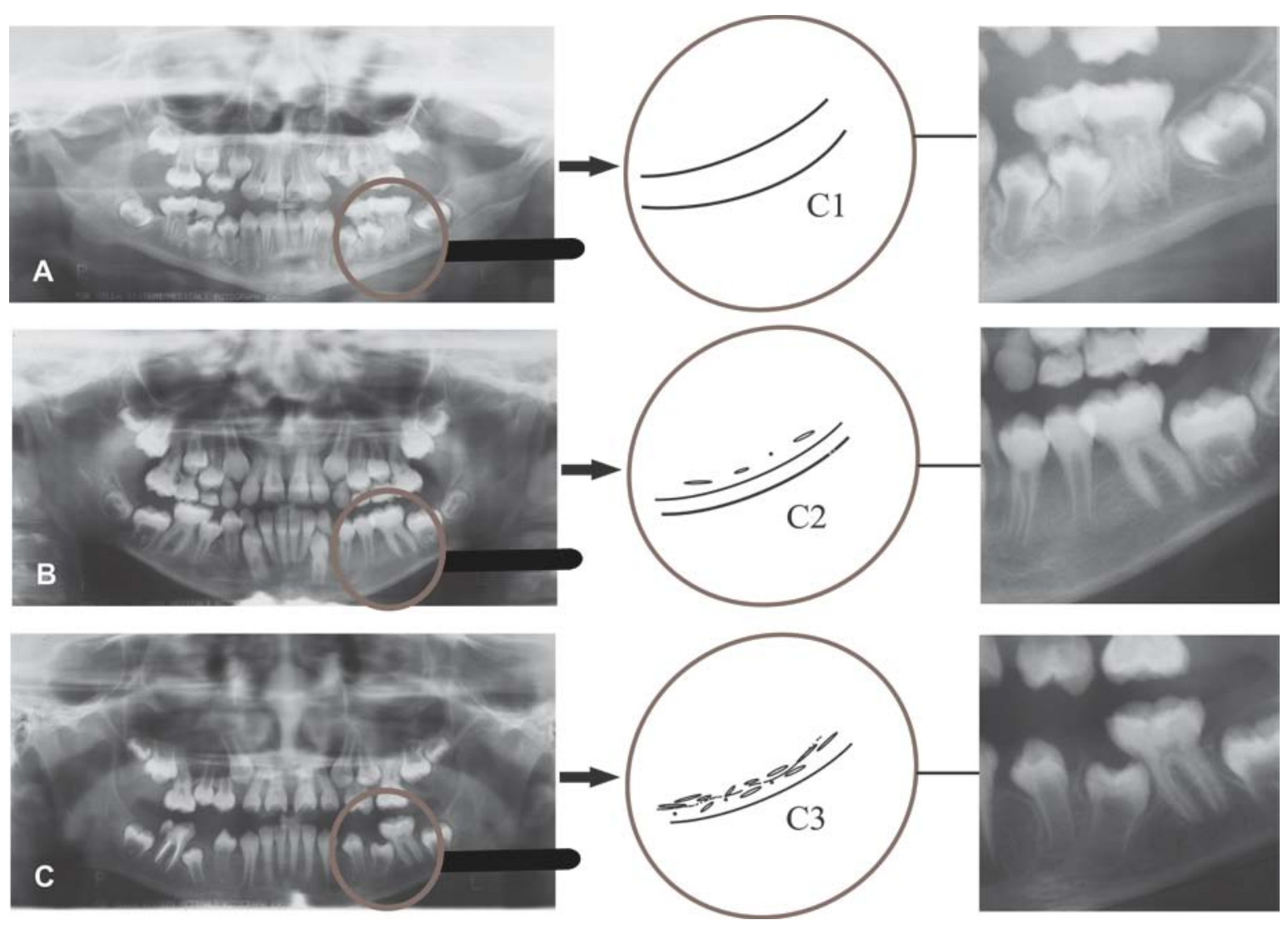

Figura 4 - Índice Mandibular Cortical (adaptado de Klemetti et al., 1994)

B) Índice Visual (IV): proposto por Lee et al, 2005, baseado na observação, classifica a cortical em fina e não fina (figura 5).

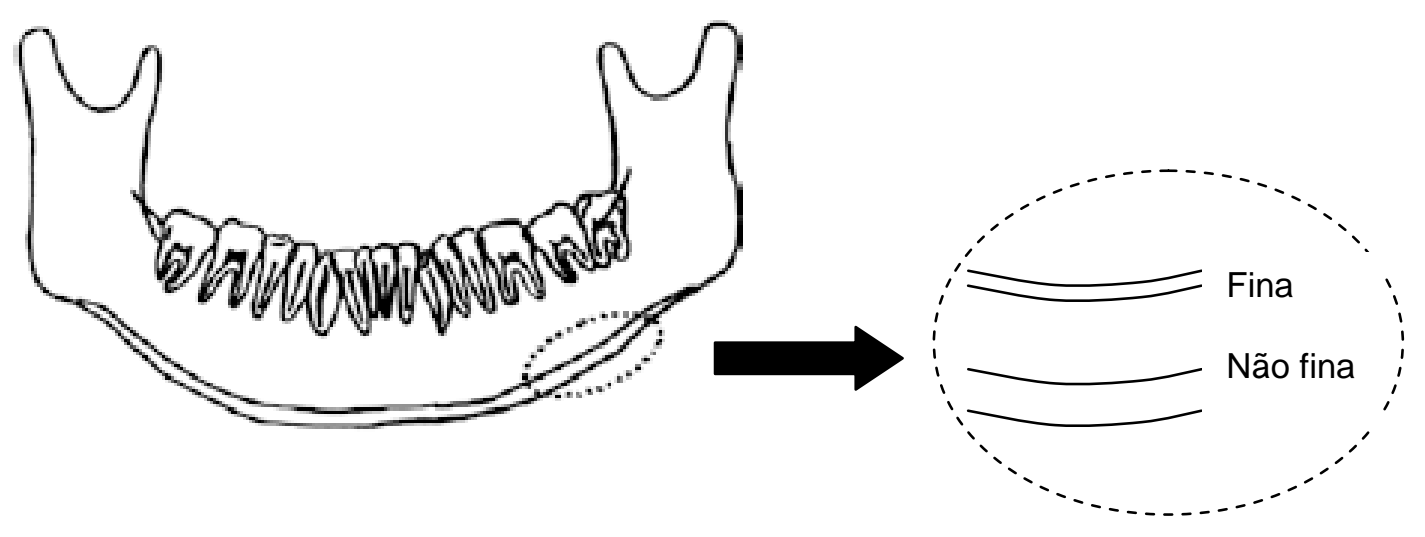

Figura 5 - Índice Visual (Lee et al, 2005) 
C) Índice Mentual (IM): corresponde à espessura da cortical inferior da mandíbula, em milímetros, em uma linha abaixo do forame mentual, perpendicular a uma reta tangente à borda inferior da mandíbula, conforme descrito por Taguchi et al, 1995 (figura 6). As medidas foram realizadas por meio do software ImageJ. Foi desprezada a magnificação do aparelho $(1,25)$.

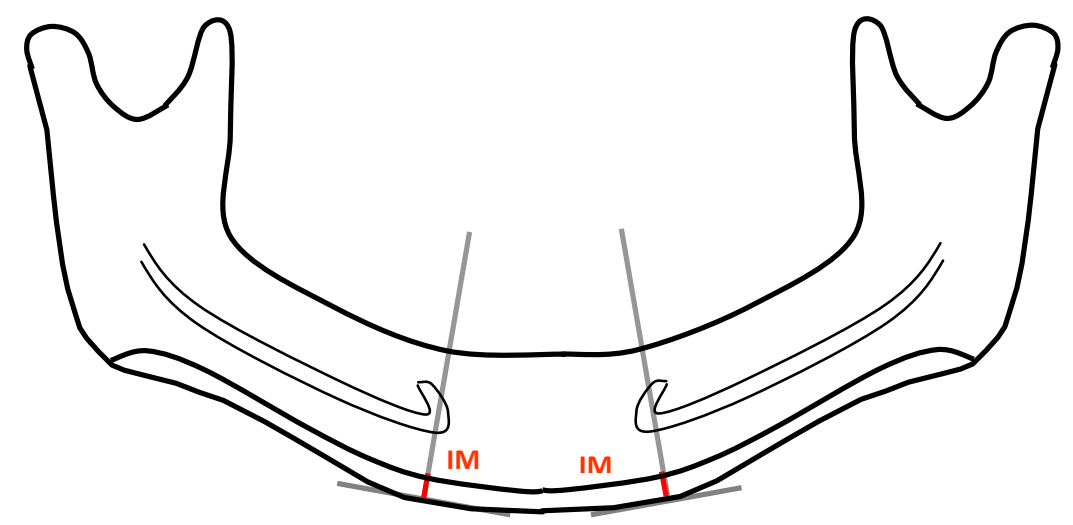

Figura 6 - Índice Mentual - IM (adaptado de Taguchi et al., 1995).

O cálculo da dimensão fractal foi realizado por meio do programa ImageJ, de domínio público, disponível no sítio http://rsb.info.nih.gov/nih-image. Foi realizado por técnica algorítmica de contagem de células (box counting), segundo método definido por White e Rudolph, 1999.

Nas imagens das radiografias escaneadas, foram escolhidas três regiões de interesse (ROIs) para a mensuração da dimensão fractal: ângulo e ramo da mandíbula, para a avaliação do osso trabecular; e cortical inferior, no lado de melhor visualização da morfologia cortical mandibular (fig.7A).

Os ROIs do ângulo e do ramo mandibular foram selecionados como dois quadrados de $25 \times 25$ pixels, no centro geométrico do ângulo e do ramo mandibular, localizados 
manualmente, de forma a não incluir outras estruturas, como a cortical do canal mandibular, que poderiam introduzir um viés na avaliação do osso trabecular. As imagens dos ROIs foram obtidas no próprio software ImageJ, por meio da ferramenta de desenho “retangular", sendo recortados da imagem da radiografia escaneada. O ROI da cortical compreendeu, na direção mésio-distal, a distância da altura do forame mentoniano até a raiz distal do primeiro molar permanente, tomando cuidado para que apenas a cortical mandibular fosse incluída no estudo. Essa imagem foi selecionada no software ImageJ, utilizando a ferramenta "polígono”.

Os ROIs recortados foram duplicados e a imagem duplicada foi borrada por um filtro Gaussiano (tamanho central = 35), para remover as variações de escala fina e média no brilho da imagem, causadas pela diferença de espessura do objeto e de exposição pela radiação. A imagem borrada foi então subtraída da original e um valor de cinza de 128 foi adicionado à cada localização de pixel, para que os objetos segmentados se aproximassem do padrão do osso trabecular. A imagem foi convertida em binária e, posteriormente, erodida e dilatada uma vez, para remover os ruídos, antes da esqueletonização. Com esse processo, as regiões que representam o osso trabecular ficam pretas e os espaços medulares ficam brancos. Finalmente a imagem foi esqueletonizada e usada para a análise fractal. Na imagem binária do esqueleto, a estrutura esquelética indica o padrão ósseo, enquanto a estrutura não-esquelética representa a medula óssea (Figura 7). 


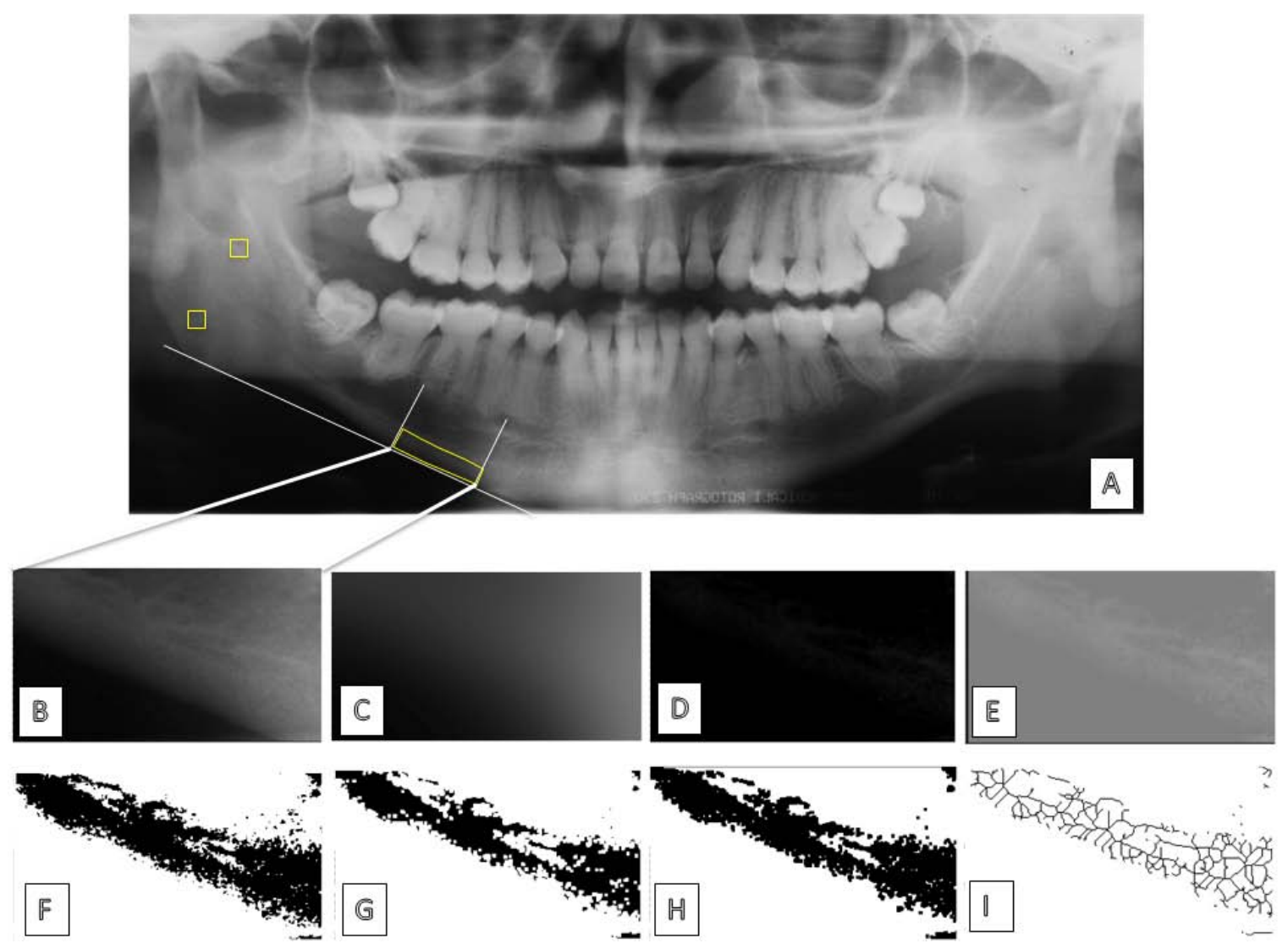

Figura 7 - Passos para o cálculo da dimensão fractal do ROIcortical

A. Radiografia panorâmica com os ROIs selecionados; B. Duplicação do ROI a ser analisado; C. Filtro Gaussiano: D. Subtração da imagem borrada: E. Adição de 128 valores de cinza; F. Conversão em binário; G. Imagem erodida; H. Imagem dilatada: I. Esqueletonização.

Todas as manipulações digitais e medidas foram realizadas nos ROIs, não nas radiografias panorâmicas como um todo. A DF da imagem esqueletonizada foi calculada com a versão 1.46r do software ImageJ, utilizando a função “box-counting” do menu “analyse”, da seguinte forma: a imagem foi coberta por uma grade quadrada, dividida por pequenos quadrados de igual tamanho. O número de quadrados que continha pelo menos 1 pixel preto (correspondente ao osso trabecular) foi contado. As larguras dos quadrados foram 2, 3, 4, 6, 8, 12, 16, 32 e 64 pixels. O número resultante dos pequenos quadrados contados foi plotado contra o número total de quadrados na escala de logaritmo dupla e a DF foi calculada a partir do declive da linha ajustada nos pontos dos dados (Fig. 8). 


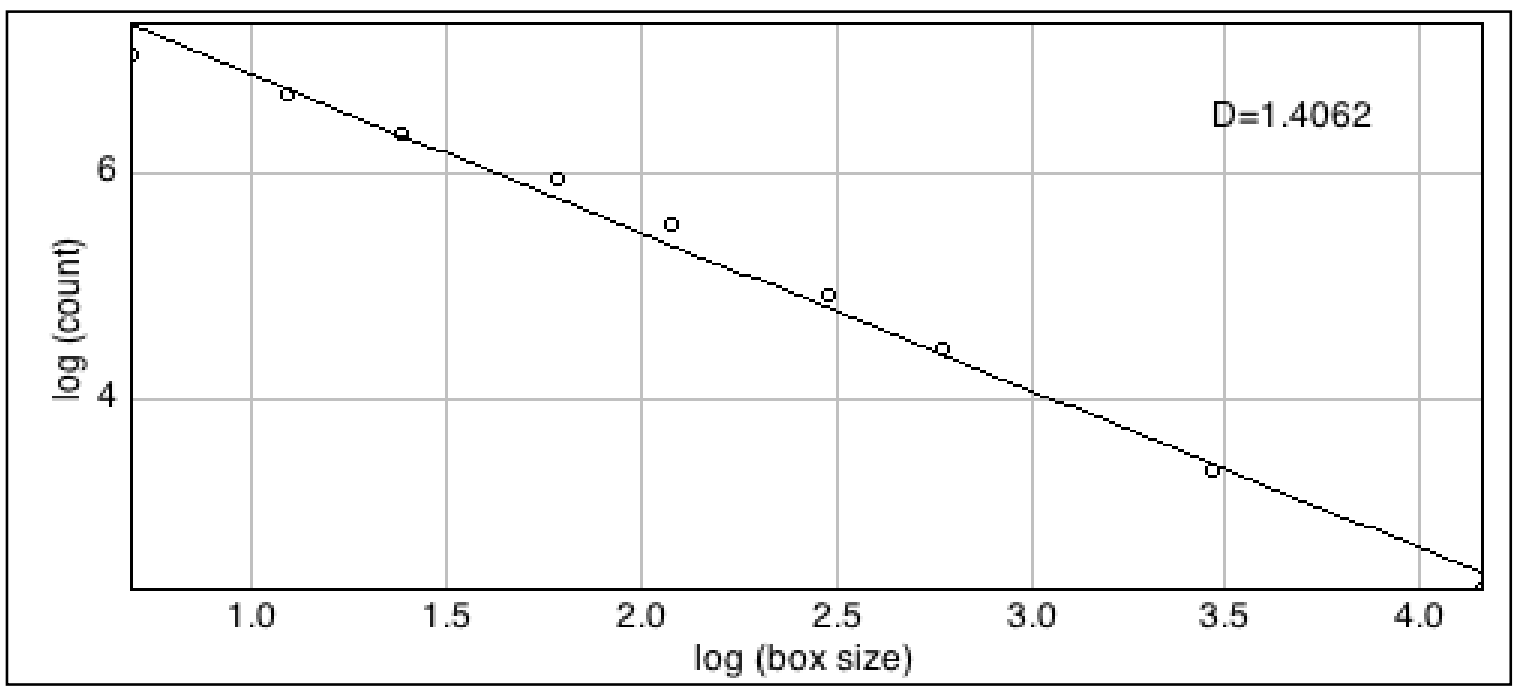

\begin{tabular}{|l|l|l|l|l|l|l|l|l|l|l|l|}
\hline \multicolumn{1}{|c|}{ ○ } & ○ \\
\hline & Label & C2 & C3 & C4 & C6 & C8 & C12 & C16 & C32 & C64 & D \\
\hline 1 & Result & 1185 & 822 & 589 & 393 & 261 & 138 & 87 & 29 & 10 & 1.406 \\
& & & & & & & & & & \\
\hline
\end{tabular}

Figura 8 - Cálculo da dimensão fractal do ROI selecionado

No grupo de crianças saudáveis, haviam sido realizadas, além das radiografias panorâmicas, radiografias da mão e punho e densitometrias ósseas.

As radiografias de mão e punho foram executadas no aparelho Rotograph Plus (Villa Medical System, Itália), tempo de exposição entre 0,20 e 0,23 segundos, miliamperagem média de 10 mA e 60 kVp.

Essas radiografias foram utilizadas para predizer as idades ósseas das crianças, de acordo com o atlas radiográfico de Greülich e Pyle, necessárias para fazer o ajuste de maturação óssea nas análises densitométricas. Todos os exames foram analisados pelo mesmo observador. 
Após a definição das idades ósseas, as crianças foram classificadas de acordo com faixas de idades ósseas, tendo 01 ano cada uma, desconsiderando os meses após a idade completa, por exemplo, uma criança que estava com 07 anos e 08 meses à época do exame foi incluída na faixa de 07 anos, assim como outra que tivesse 07 anos e 01 mês.

A densitometria óssea por dupla emissão de raios x (DXA) foi realizada com o aparelho Lunar DPX-NT, marca GE, localizado no Hospital Universitário de Brasília.

Foram consideradas as regiões de coluna lombar (L1-L4) e corpo total exceto a cabeça, sítios preferidos para medidas em crianças, de acordo com o preconizado pela Sociedade Internacional de Densitometria Clínica (ISCD, 2013). Na avaliação do diagnóstico densitométrico das crianças foi utilizado o z-score, que representa o número de desvios padrão que a densidade mineral óssea do paciente encontra-se abaixo ou acima do valor médio de referência ajustados para a idade óssea e sexo. Os resultados foram interpretados à luz do banco de dados da Lunar Pediatric, pacientes com z-scores $\leq-2,0$ foram considerados com diagnóstico de baixa massa óssea, e com z-scores $>-2,0$, diagnóstico densitométrico normal, conforme recomendado pela Sociedade Internacional de Densitometria Clínica (ISCD, 2013). Para o diagnóstico densitométrico unificado, foram consideradas com baixa massa óssea crianças que apresentaram z-score $\leq-2,0$ em pelo menos um dos sítios analisados.

\subsection{Análise estatística}

\subsubsection{Análise estatística do Artigo 1}


A análise descritiva da amostra foi realizada por meio do cálculo de médias e desvios-padrão para as variáveis quantitativas, e frequências absolutas e relativas percentuais para as variáveis qualitativas.

Os dados referentes às dimensões fractais do ângulo (ROIAng), ramo e (ROIRamo), cortical inferior da mandíbula (ROICortical), e os dados de Índice Mentual (IM) foram testados por meio do teste de Lilliefors, para avaliação do padrão de distribuição dos dados. Além disso, a homogeneidade das variâncias entre os grupos com diferentes idades de início de tratamento foi avaliada por meio do teste de Cochran.

Foram avaliadas as associações das variáveis quantitativas (ROIAng, ROIRamo, ROICortical e IM) com as categorias do Índice Visual (Cortical Fina e Não Fina) e do Índice Mandibular Cortical (C1, C2 e C3) por meio dos testes t para amostras independentes e ANOVA-fator único, respectivamente. Em casos de significância estatística para ANOVA, foi realizado o teste de acompanhamento de Fisher-LSD.

Além disso, foram calculadas as correlações entre as mesmas variáveis quantitativas para avaliação de associações entre as mesmas, por meio do coeficiente de correlação de Pearson, avaliando-se a significância pelo teste t de correlação.

Uma vez que os pressupostos de normalidade e de homocedasticidade foram assumidos, foram realizados testes de hipótese para comparação das médias entre crianças com diferentes tipos de OI e diferentes classes de administração de ciclos de pamidronato (0 a 4, 5 a 10 e mais de 10 ciclos). Para estas comparações as variáveis supracitadas foram analisadas por meio do teste de Anova - fator duplo. Em casos de significância estatística, foi aplicado o teste de acompanhamento de Fisher (Least Square Difference). 
Por fim, foi realizado o ajuste por regressão linear entre as variáveis índice mentual e DF Cortical, avaliando-se a significância do modelo por meio de Análise de Variância.

\subsubsection{Análise estatística do Artigo 2}

O padrão de distribuição do Índice Mentual foi avaliado pelo teste de Lilliefors, assim como a homocedasticidade dos grupos (tipo de OI, gêneros, idade de diagnóstico, ciclos de pamidronato) foi avaliada por meio do teste de Barttlet. Uma vez que a variável na comparação em cada um dos fatores assumiu os pressupostos de normalidade e homocedasticidade, optou-se pelo uso de testes paramétricos de análise.

Inicialmente foi realizada a comparação dos dados do índice mentual em função das classes etárias de crianças diagnosticadas com osteogênese imperfeita (OI) e crianças saudáveis, assim como a avaliação do comportamento da variável entre os gêneros destas crianças. Complementar a esta análise, os valores obtidos do índice foram comparados entre crianças com diferentes tipos de OI (I, III e IV) e saudáveis, ao longo das classes etárias de desenvolvimento. Estas primeiras análises tiveram como objetivo avaliar a evolução desta variável ao longo do desenvolvimento de crianças com OI e saudáveis.

Em seguida, com objetivo de avaliar o efeito do tratamento de crianças com OI, foram realizadas análises testando o efeito das classes de ciclos de pamidronato $(0$ a 4,5 a 10, > 10 ciclos) entre crianças que iniciaram o tratamento em idade precoce ( 0 a 5 anos) e início do tratamento tardio (> 5 anos), bem como a diferença entre os tipos de OI.

Partindo do pressuposto que a cortical mandibular em pacientes com OI possui menor espessura e que a medicação pode aumentar essa espessura, foi realizada uma 
estimativa da quantidade necessária de ciclos de pamidronato em crianças com diferentes tipos de OI para se atingir a média de espessura de cortical mandibular observada entre crianças saudáveis.

Todas estas análises foram realizadas com uso do teste ANOVA-fatorial, seguido do teste de acompanhamento de Fisher-LSD (Least Square Difference).

Os dados de densidade mineral óssea (coluna lombar e corpo total) das 98 crianças saudáveis com diagnóstico densitométrico normal e seus respectivos valores de índice mentual foram correlacionados por meio do Coeficiente de Correlação de Pearson (r) e sua significância avaliada por meio do teste t para correlação. Posteriormente, os dados foram demonstrados em diagramas de dispersão, apresentando os modelos de regressão linear, obtidos por meio da aplicação do Método dos Mínimos Quadrados.

Foi construído um modelo de variação do Índice Mentual para crianças com densidade mineral óssea normal utilizando o método de Regressão Linear Simples, realizando a avaliação dos ajustes por meio do Critério de Akaike (AIC). A significância do modelo foi testada por meio da Análise da Variância (ANOVA). A demonstração do ajuste foi realizada por meio de diagrama de dispersão com intervalo de confiança ajustado de $95 \%$.

Por fim, foi construído um modelo preditivo de índice mentual e variáveis relativas ao tratamento da osteogênese imperfeita com pamidronato intravenoso por meio do método de Regressão Múltipla, utilizando o método Stepwise para seleção do modelo, e avaliação dos ajustes do modelo por meio do Critério de Akaike (AIC). A significância do ajuste do modelo foi testada por meio da Análise da Variância (ANOVA). 
Em todas as análises dos artigos 1 e 2 foi utilizado um nível de significância de 0,05 .

As análises foram realizadas no programa Statistica 7.0 (StatSoft, Inc., 2004. STATISTICA - data analysis software system, version 7. www.statsoft.com). 
5. RESULTADOS 


\section{RESULTADOS}

5.1. Resultados do artigo 1 - Relação entre índices radiomorfométricos e dimensão fractal de mandíbula em crianças com OI em tratamento com pamidronato

A tabela 1 apresenta as características das radiografias panorâmicas dos pacientes selecionados para o estudo, relacionando as diferentes faixas etárias e o número de ciclos de pamidronato. Como não houve diferenças nos resultados entre meninos e meninas, ambos os gêneros foram avaliados conjuntamente.

Tabela 1 - Número de radiografias panorâmicas dos pacientes com OI, com relação aos diferentes grupos de idade e número de ciclos de PAM.

\begin{tabular}{clcccc}
\hline $\begin{array}{c}\text { Crianças com } \\
\text { OI }\end{array}$ & Idade & $\begin{array}{c}\text { OI tipo I } \\
(\mathbf{n}=\mathbf{5 8} \mathbf{~ r X})\end{array}$ & $\begin{array}{c}\text { OI tipo III } \\
(\mathbf{n}=\mathbf{8 3} \mathbf{~ r X )})\end{array}$ & $\begin{array}{c}\text { OI tipo IV } \\
(\mathbf{n}=\mathbf{5 6} \mathbf{~ r X})\end{array}$ & $\begin{array}{c}\text { Faltam dados } \\
(\mathbf{n}=\mathbf{9} \mathbf{~ r X )}\end{array}$ \\
\hline & $<\mathbf{5}$ anos & 2 & 10 & 3 & 1 \\
Faixas & $\mathbf{5 - 7}$ anos & 17 & 22 & 18 & 1 \\
etárias & $\mathbf{8 - 1 0}$ anos & 14 & 27 & 11 & 2 \\
& $\mathbf{1 1 - 1 4}$ anos & 17 & 15 & 19 & 5 \\
& $\mathbf{1 5 - 1 9}$ anos & 8 & 9 & 5 & 0 \\
\hline & $\mathbf{0 - 4}$ & 33 & 23 & 21 & 4 \\
Número de & $\mathbf{5 - 1 0}$ & 17 & 25 & 20 & 2 \\
ciclos de & $>\mathbf{1 0}$ & 8 & 29 & 11 & 1 \\
pamidronato & $\mathbf{1 0}$ & 0 & 6 & 4 & 2 \\
\hline
\end{tabular}




\subsubsection{Avaliação dos índices radiomorfométricos qualitativos de mandíbula em crianças com OI}

A avaliação dos índices qualitativos foi realizada apenas em um aspecto descritivo, uma vez que o n amostral impediu outras inferências estatísticas. Sendo assim, ao avaliar o índice visual, foi possível verificar que à medida que se eleva o número de ciclos de pamidronato observa-se a tendência de elevação de frequência de crianças com cortical não finas, independente do tipo de OI (figura 9).

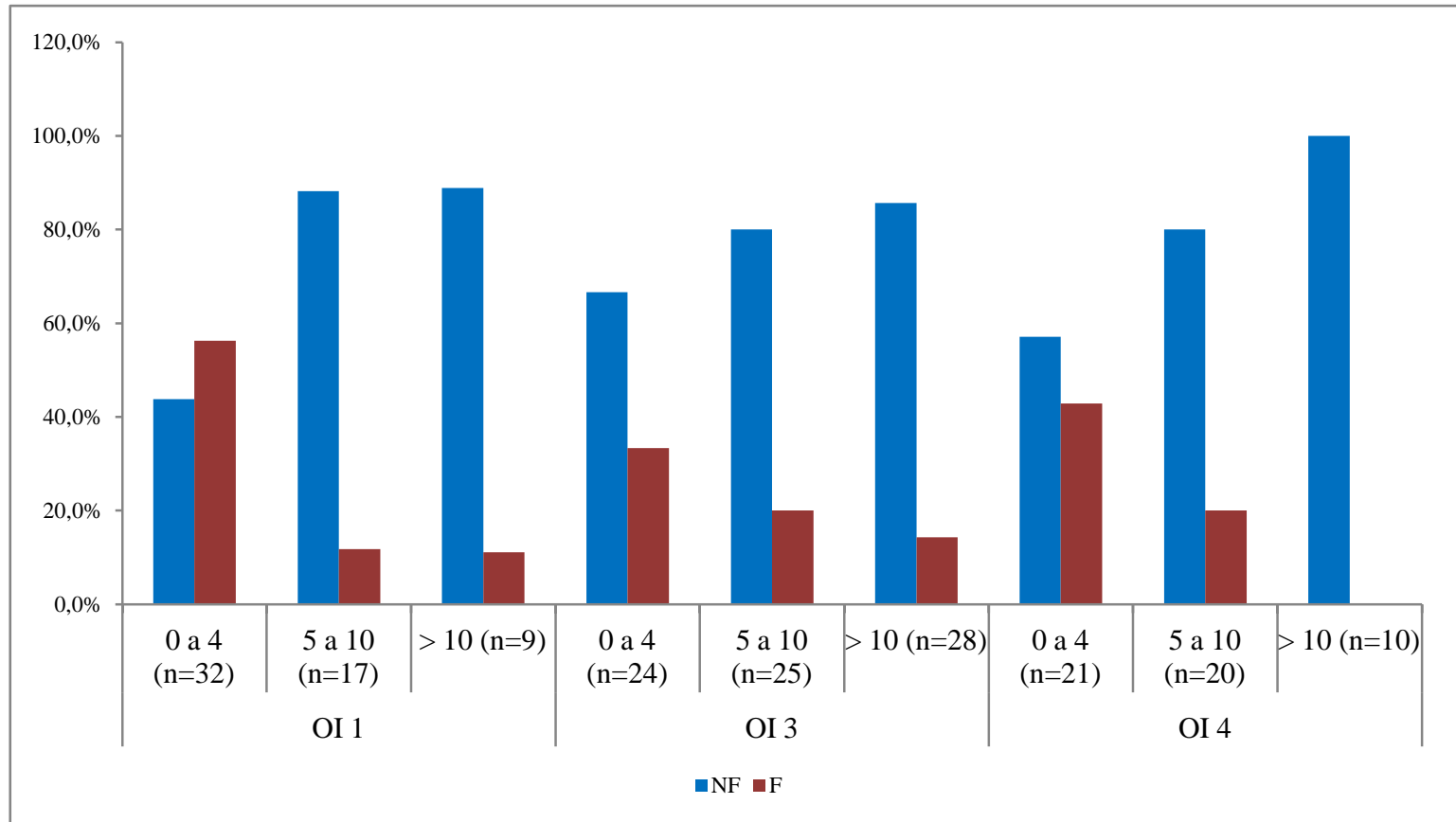

Figura 9 - Frequência relativa percentual de categorias do índice visual em função do tipo de OI e frequência de ciclos de pamidronato. OI = osteogênese imperfeita, NF = cortical classificada como não fina, $F$ = cortical classificada como fina

Quanto à classificação do índice mandibular cortical, foi possível verificar que entre as crianças OI tipo III, a frequência da classificação C1 elevava à medida que recebiam mais ciclos de pamidronato. Já entre crianças diagnosticadas com os tipos I e IV, as alterações das frequências das categorias do índice mandibular cortical não parecem ser um reflexo da quantidade de ciclos de pamidronato (figura 10). 


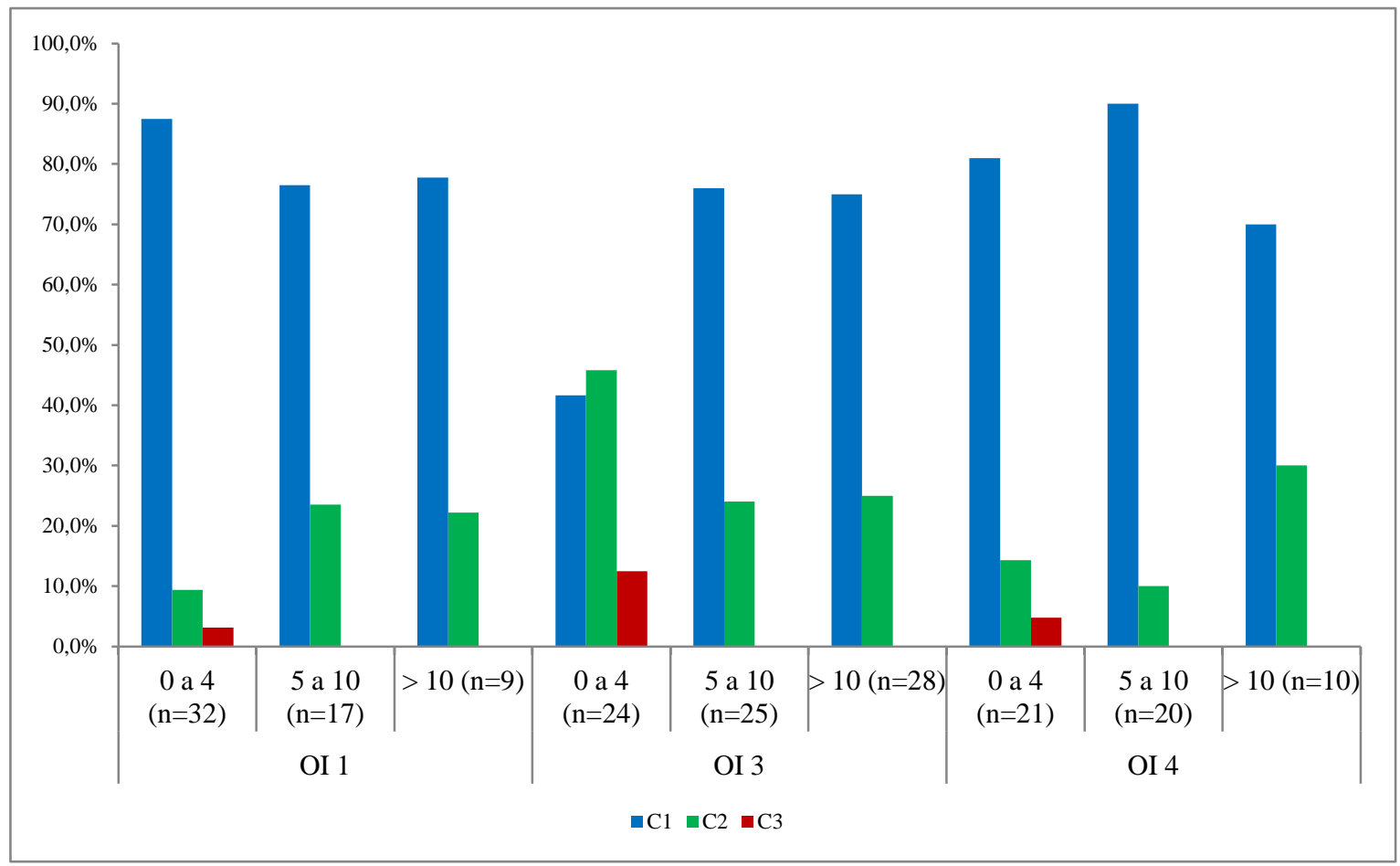

Figura 10 - Frequência relativa percentual de categorias do índice mandibular cortical em função do tipo de OI e frequência de ciclos de pamidronato.

Classificações C1, C2 e C3; OI = osteogênese imperfeita

Ao analisar o índice visual e o índice mandibular cortical, foi possível verificar a associação entre estes dois índices qualitativos, sendo possível verificar que crianças com a cortical com maior porosidade (C3) tendem a apresentá-la visualmente mais finas $\left(\chi^{2}=10,47 ; p=0,005\right)$ (figura 11). 


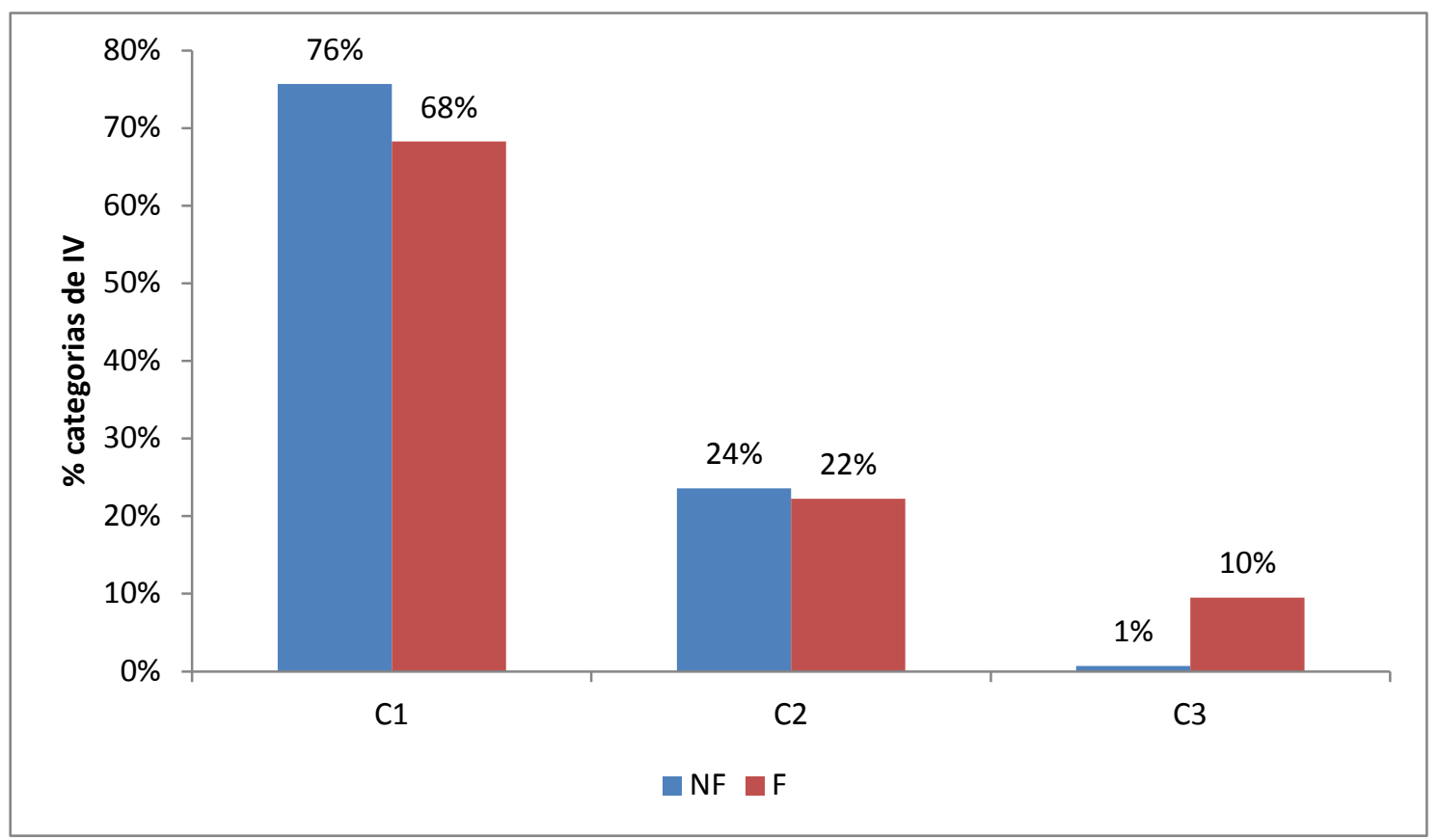

Figura 11 - Frequência relativa percentual de categorias do IV (NF - não fina e F - fina) em relação às categorias do índice mandibular cortical (C1, C2 e C3).

IV = índice visual

Ao avaliar a associação das variáveis quantitativas (índice mentual e dimensões fractais) com o índice visual, foi possível observar que apenas as variáveis índice mentual e DF cortical (ROICortical) apresentaram significância estatística $(\mathrm{p}<0,05)$, sendo que as médias foram significativamente mais baixas entre as crianças que apresentaram cortical mais fina (tabela 2). Desta forma, pôde-se estabelecer critérios numéricos para definição das categorias ‘não fina’ e ‘fina’, conforme apresentado na tabela 3. 
Tabela 2 - Relação entre as medidas de índice visual e medidas quantitativas (espessura da cortical mandibular e medidas de dimensão fractal nas regiões de interesse selecionadas)

\begin{tabular}{|c|c|c|c|c|c|c|}
\hline & $\overline{I V}$ & Média & $\overline{D P}$ & IC $-95 \%$ & IC $+95 \%$ & p-value \\
\hline \multirow{2}{*}{ índice mentual } & $\mathrm{NF}$ & 3,59 & 0,72 & 3,48 & 3,71 & \multirow{2}{*}{0,000} \\
\hline & $\mathrm{F}$ & 2,65 & 0,51 & 2,52 & 2,77 & \\
\hline \multirow{2}{*}{ ROIAng } & NF & 0,87 & 0,21 & 0,84 & 0,91 & \multirow{2}{*}{0,975} \\
\hline & $\mathrm{F}$ & 0,87 & 0,24 & 0,81 & 0,93 & \\
\hline \multirow{2}{*}{ ROIRamo } & NF & 0,86 & 0,20 & 0,82 & 0,89 & \multirow{2}{*}{0,169} \\
\hline & $\mathrm{F}$ & 0,89 & 0,15 & 0,86 & 0,93 & \\
\hline \multirow{2}{*}{ ROICortical } & $\mathrm{NF}$ & 1,11 & 0,08 & 1,10 & 1,13 & \multirow{2}{*}{0,000} \\
\hline & $\mathrm{F}$ & 1,04 & 0,07 & 1,02 & 1,06 & \\
\hline \multicolumn{7}{|c|}{$\begin{array}{l}\text { IV = índice visual, ROIAng = região de interesse para o cálculo da dimensão fractal na } \\
\text { região do ângulo da mandíbula, ROIRamo = região de interesse para cálculo da dimensão } \\
\text { fractal no ramo mandibular, ROICortical = região de interesse para cálculo da dimensão } \\
\text { fractal na cortical inferior da mandíbula, NF = cortical classificada como não fina, } \\
\text { F = cortical classificada como fina, } \mathrm{DP}=\text { desvio-padrão, IC = intervalo de confianca }\end{array}$} \\
\hline
\end{tabular}

Tabela 3 - Critérios numéricos de classificação para o índice qualitativo visual.

\begin{tabular}{lcc}
\hline & Não Fina & Fina \\
\hline Índice mentual (mm) & $3,477-3,714$ & $2,519-2,773$ \\
ROICortical & $1,098-1,125$ & $1,020-1,057$ \\
\hline
\end{tabular}

Ao avaliar a associação das mesmas variáveis com o índice mandibular cortical, foi possível verificar que apenas o índice mentual apresentou significância estatística (F2, 204=6,7933; p=0,00139), sendo que a menor média foi observada entre as 
crianças com maior porosidade (C3) (figura 12). As demais variáveis não apresentaram diferenças estatísticas significativas entre os grupos, apesar de ser evidente a tendência de decréscimo dos valores das dimensões fractais de ROIRamo e ROICortical à medida que se elevava a porosidade mandibular (tabela 4).

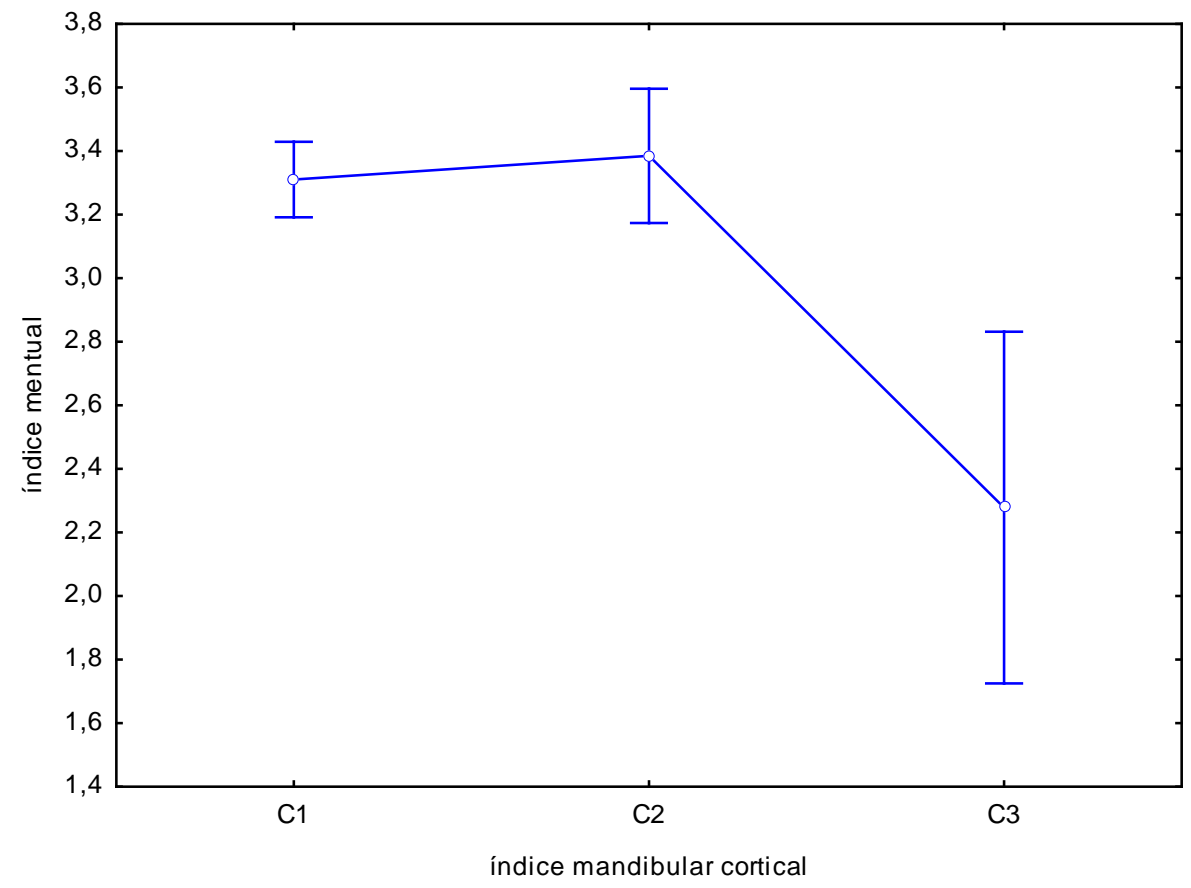

Figura 12 - Médias e intervalos de confiança do Índice Mentual em função das classes do índice mandibular cortical. 
Tabela 4 - Estatísticas descritivas dos dados de Índice Mentual, ROI Ang, ROI Ramo e ROICortical em função das classes do índice mandibular cortical (C1, C2, C3).

\begin{tabular}{|c|c|c|c|c|c|c|c|}
\hline & IMCo & $\mathbf{n}$ & Média & DP & IC -95\% & IC $+95 \%$ & p-value \\
\hline & $\mathrm{C} 1$ & 152 & 0,87 & 0,22 & 0,83 & 0,90 & \\
\hline \multirow[t]{3}{*}{ Índice Mentual } & $\mathrm{C} 2$ & 48 & 0,91 & 0,17 & 0,86 & 0,96 & 0,012 \\
\hline & C3 & 7 & 0,88 & 0,14 & 0,75 & 1,01 & \\
\hline & $\mathrm{C} 1$ & 152 & 0,86 & 0,23 & 0,83 & 0,90 & \\
\hline \multirow[t]{3}{*}{ ROI Ang } & $\mathrm{C} 2$ & 48 & 0,90 & 0,18 & 0,84 & 0,95 & 0,645 \\
\hline & C3 & 7 & 0,88 & 0,14 & 0,75 & 1,01 & \\
\hline & $\mathrm{C} 1$ & 152 & 0,88 & 0,17 & 0,85 & 0,91 & \\
\hline \multirow[t]{3}{*}{ ROIRamo } & $\mathrm{C} 2$ & 48 & 0,83 & 0,23 & 0,77 & 0,90 & 0,229 \\
\hline & C3 & 7 & 0,81 & 0,22 & 0,61 & 1,01 & \\
\hline & $\mathrm{C} 1$ & 152 & 1,09 & 0,08 & 1,07 & 1,10 & \\
\hline \multirow[t]{2}{*}{ ROI Cortical } & $\mathrm{C} 2$ & 48 & 1,10 & 0,08 & 1,07 & 1,12 & 0,466 \\
\hline & C3 & 7 & 1,06 & 0,12 & 0,95 & 1,16 & \\
\hline
\end{tabular}

IMCo = índice mandibular cortical, ROIAng = região de interesse para o cálculo da dimensão fractal na região do ângulo da mandíbula, ROIRamo = região de interesse para cálculo da dimensão fractal no ramo mandibular, ROICortical = região de interesse para cálculo da dimensão fractal na cortical inferior da mandíbula, $\mathrm{NF}=$ cortical classificada como não fina, $\mathrm{F}=$ cortical classificada como fina, $\mathrm{DP}=$ desvio-padrão, $\mathrm{IC}$ = intervalo de confiança

Uma vez que o índice mentual apresentou diferenças significativas, foi possível então, definir critérios numéricos para a diferenciação das classes do índice qualitativo mandibular cortical em crianças com OI, sendo que em C1-C2 a variação foi de 3,200 a 3,576mm e para C3, 1,896 a 2,661 . 


\subsubsection{Avaliação do índice mentual e das dimensões fractais mandibulares das crianças, em função do tipo de OI e da frequência de ciclos de pamidronato}

Ao avaliar a associação entre as variáveis de dimensão fractal e índice mentual, foi possível verificar baixos valores de correlação, com exceção da relação entre IM e ROIcortical cujo valor significativo foi $\mathrm{r}=0,616(\mathrm{p}<0,05)$ (tabela 5).

Tabela 5 - Matriz de Coeficientes de correlação de Pearson entre dimensões fractais e índice mentual. *

\begin{tabular}{lrrrr}
\hline \multicolumn{1}{c}{ Variáveis } & IM $(\mathrm{mm})$ & ROI Ang. & ROI Ramo & ROI Cortical \\
\hline IM (mm) & $\mathbf{1}$ & $-0,077$ & $-0,047$ & $\mathbf{0 , 6 1 6}$ \\
ROI Ang. & $-0,077$ & $\mathbf{1}$ & 0,004 & $-0,089$ \\
ROI Ramo & $-0,047$ & 0,004 & $\mathbf{1}$ & $-0,124$ \\
ROI Cortical & $\mathbf{0 , 6 1 6}$ & $-0,089$ & $-0,124$ & $\mathbf{1}$ \\
\hline
\end{tabular}

*Valores em negrito são diferentes de 0 e estatisticamente significantes $(p<0.05)$

$\mathrm{IM}$ = índice mentual, ROIAng = região de interesse para o cálculo da dimensão fractal na região do ângulo da mandíbula, ROIRamo = região de interesse para cálculo da dimensão fractal no ramo mandibular, ROICortical = região de interesse para cálculo da dimensão fractal na cortical inferior da mandíbula

Ao avaliar os dados referentes às dimensões fractais ROIAng e ROIRamo, verificou-se que não houve diferenças estatísticas significativas entre os tipos de OI, nem entre os ciclos de pamidronato $(\mathrm{p}>0,05)$. Sendo assim, pode-se afirmar que os tipos de osteogênese imperfeita bem como a quantidade de ciclos de pamidronato não interferiram na variação de dados das respectivas dimensões fractais (tabela 6). 
Tabela 6 - Estatísticas descritivas dos dados de ROI Ang e ROI Ramo em função dos tipos de osteogênese imperfeita e quantidade de ciclos de pamidronato.

$\begin{array}{llllllr}\text { Tipo } & \text { Ciclos de } & \text { N } & \text { Média } & \text { Desvio } & \text { IC - } & \text { IC } \\ \text { OI } & \text { Pamidronato } & & & \text { Padrão } & 95 \% & +95 \%\end{array}$

\begin{tabular}{|c|c|c|c|c|c|c|c|}
\hline \multirow[t]{9}{*}{ ROI Ang } & 1 & 0 a 4 & 33 & $0,86(a)$ & 0,20 & 0,79 & 0,93 \\
\hline & & 5 a 10 & 17 & $0,82(a)$ & 0,16 & 0,73 & 0,90 \\
\hline & & $>10$ & 8 & $0,80(a)$ & 0,16 & 0,68 & 0,92 \\
\hline & 3 & 0 a 4 & 23 & 0,93(a) & 0,27 & 0,81 & 1,04 \\
\hline & & 5 а 10 & 25 & $0,81(\mathrm{a})$ & 0,24 & 0,71 & 0,91 \\
\hline & & $>10$ & 29 & $0,86(a)$ & 0,22 & 0,77 & 0,95 \\
\hline & 4 & 0 a 4 & 21 & 0,90 (a) & 0,22 & 0,80 & 1,00 \\
\hline & & 5 a 10 & 20 & $0,89(a)$ & 0,18 & 0,81 & 0,98 \\
\hline & & $>10$ & 11 & $0,92(a)$ & 0,15 & 0,82 & 1,02 \\
\hline \multirow{9}{*}{$\begin{array}{l}\text { ROI } \\
\text { Ramo }\end{array}$} & 1 & 0 a 4 & 33 & 0,89 (a) & 0,15 & 0,84 & 0,95 \\
\hline & & 5 a 10 & 17 & 0,75 (b) & 0,34 & 0,58 & 0,93 \\
\hline & & $>10$ & 8 & $0,88(a)$ & 0,21 & 0,71 & 1,04 \\
\hline & 3 & 0 a 4 & 23 & $0,83(\mathrm{a})$ & 0,19 & 0,76 & 0,91 \\
\hline & & 5 a 10 & 25 & $0,90(\mathrm{a})$ & 0,14 & 0,85 & 0,96 \\
\hline & & $>10$ & 29 & $0,88(a)$ & 0,17 & 0,82 & 0,95 \\
\hline & 4 & 0 a 4 & 21 & $0,94(a)$ & 0,16 & 0,87 & 1,01 \\
\hline & & 5 a 10 & 20 & $0,86(a)$ & 0,16 & 0,78 & 0,93 \\
\hline & & $>10$ & 11 & $0,77(b)$ & 0,20 & 0,64 & 0,90 \\
\hline
\end{tabular}

* as letras demonstram a significância entre as categorias de comparação. Letras equivalentes demonstram a equivalência estatística das médias.

OI = osteogênese imperfeita, ROIAng = região de interesse para o cálculo da dimensão fractal na região do ângulo da mandíbula, ROIRamo = região de interesse para cálculo da dimensão fractal no ramo mandibular, IC = desvio-padrão 
Por outro lado, na avaliação da dimensão fractal da cortical mandibular, assim como no índice mentual, houve diferenças estatísticas significativas (F4,178=2,1738, $p=0,074 ; F 4,178=0,20146, p=0,937$, respectivamente). Desta forma, a interpretação resultante desta análise demonstra que as crianças com diferentes tipos de OI apresentam valores de ROICortical semelhantes quando iniciam o tratamento com pamidronato (0 a 4 ciclos). As crianças com OI tipo I elevam significativamente suas médias a partir de 5 a 10 ciclos, mantendo a elevação com mais de 10 ciclos de pamidronato. Já as crianças com OI tipo III e IV apresentam elevação de suas médias de ROI cortical apenas quando recebem mais de 10 ciclos de pamidronato $(\mathrm{p}<0,05)$.

Em relação ao IM, foi possível verificar que todos os tipos de OI apresentam valores estatisticamente equivalentes no início ( 0 a 4 ciclos de pamidronato) e na fase intermediária do tratamento (5 a 10 ciclos de pamidronato), observando-se a elevação significativa das médias em OI do tipo I e IV até esta fase. Com mais de 10 ciclos de pamidronato, observam-se médias de IM significativamente mais elevadas nas crianças OI tipo I e IV do que nas crianças OI tipo III, como pode ser observado nas figuras 13 e 14 $(\mathrm{p}<0,05)$. 

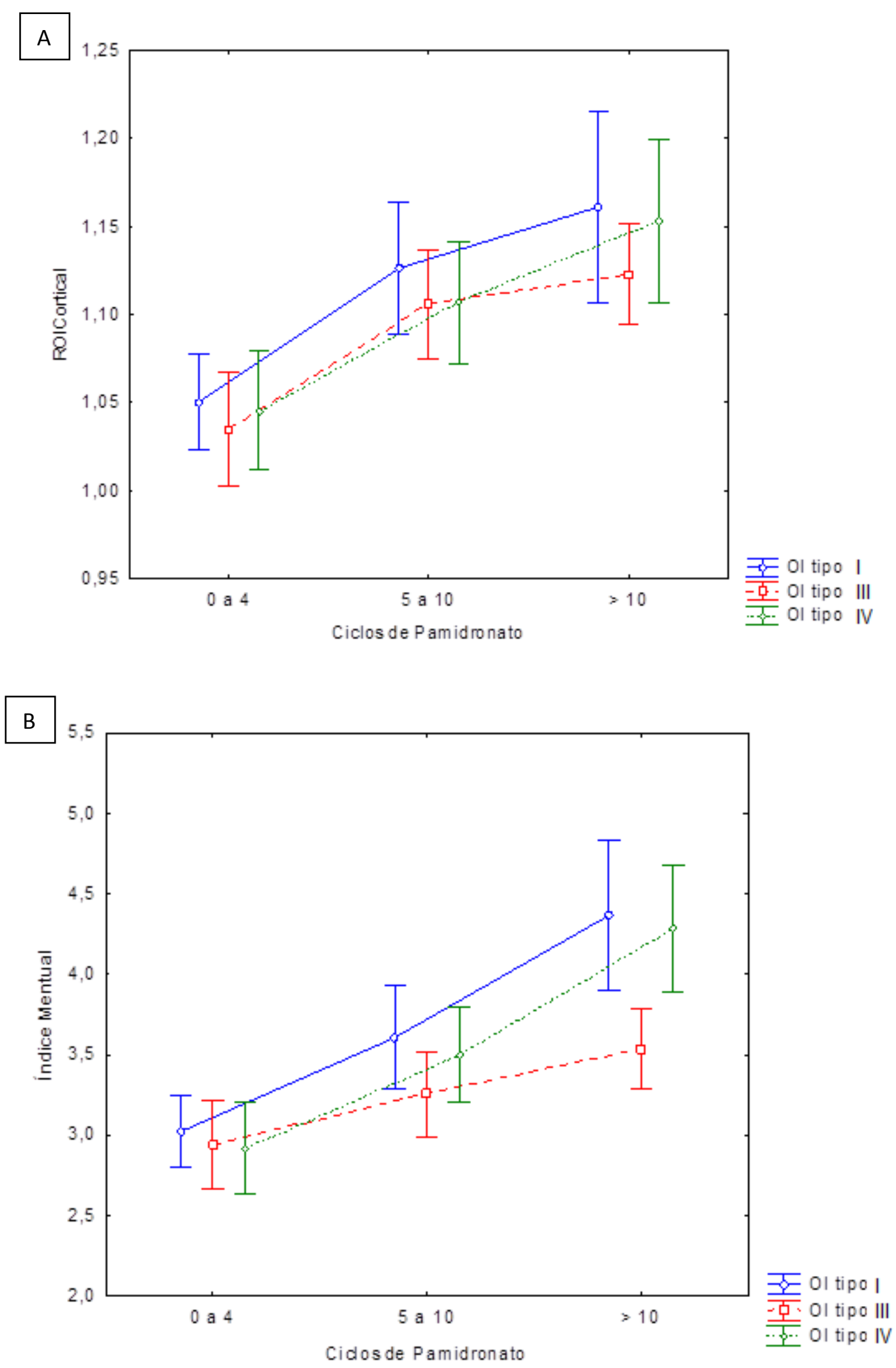

Figura 13 - Médias e intervalos de confiança das dimensões fractais ROICortical (A) e Índice Mentual (B) em função dos tipos de OI e quantidade de ciclos de pamidronato. 
Uma vez verificado que o índice mentual e a dimensão fractal da cortical mandibular (ROICortical) apresentavam associações significativas com os índices qualitativos, assim como mostravam eficácia na avaliação da evolução do tratamento com o pamidronato em crianças com OI, foi realizada a análise de associação entre as mesmas. Nesta análise, foi possível verificar que a variação dos dados de índice mentual podiam ser explicados por $40 \%$ da variabilidade de ROICortical $\left(r^{2}=0,40\right)$. Apesar do baixo valor de relação entre as variáveis, o ajuste do modelo foi significativo $\left(F_{205}=124,5734 ; p=0,00\right)$, com valor de $\beta=0.63$ para índice mentual (IC 95\% 0,52 - 0,75) (figura 14).

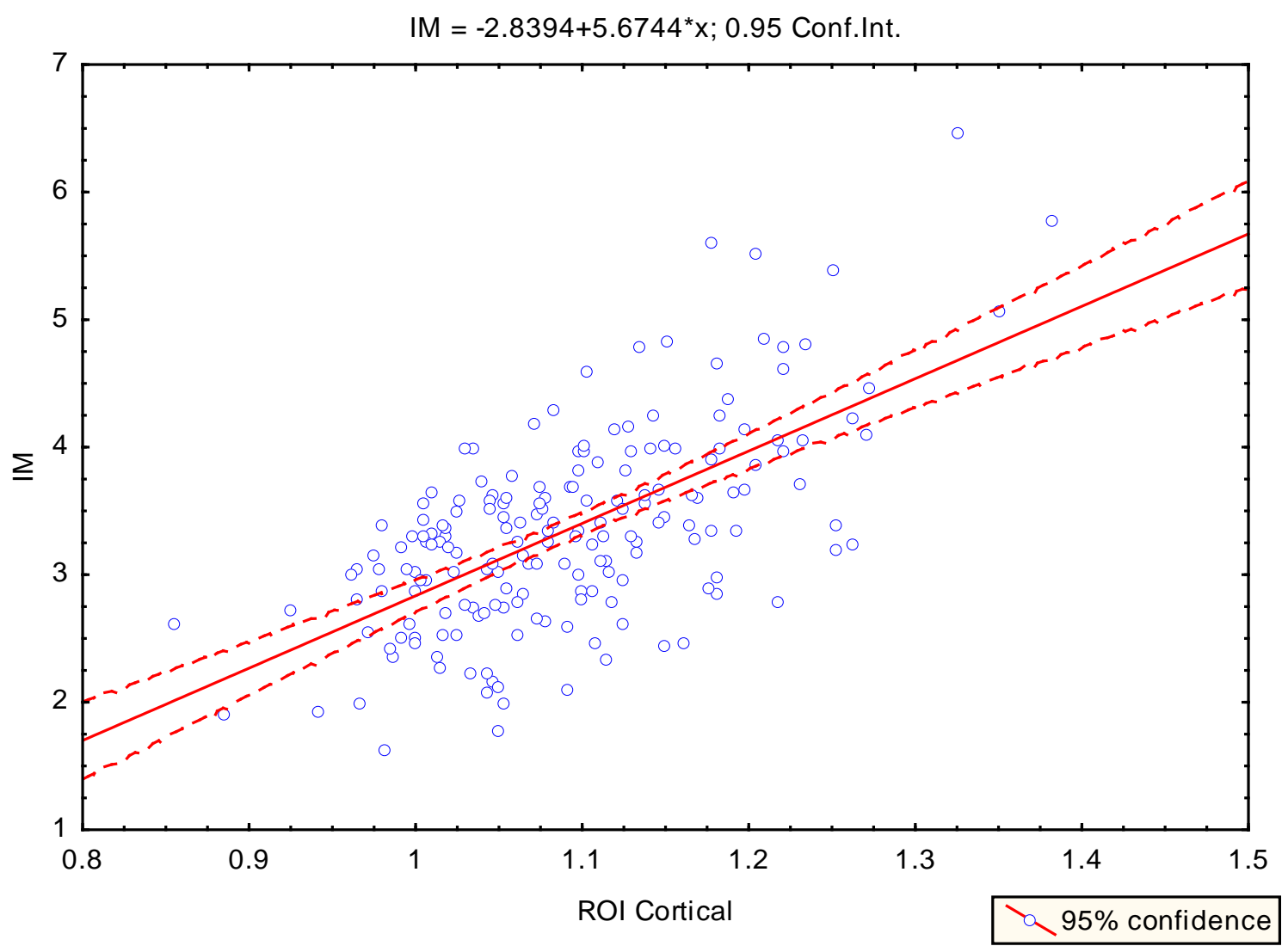

Figura 14 - Diagrama de dispersão do modelo de regressão linear de ROiCortical (X) e Î́ndice Mentual (Y). 
5.2. Resultados do artigo 2 - Efeito do pamidronato na cortical mandibular de pacientes com osteogênese imperfeita

Como não foram encontradas diferenças nos resultados das radiografias panorâmicas de meninos e meninas, ambos os gêneros foram avaliados conjuntamente $(\mathrm{F} 3,248=0,780, \mathrm{p}=0,505)$.

A tabela 7 apresenta o numero de radiografias obtidas dos pacientes com OI relacionadas às diferentes faixas etárias, número de ciclos de pamidronato e idade de início do tratamento.

Tabela 7 - Número de radiografias panorâmicas dos pacientes com OI, com relação às diferentes faixas etárias, número de ciclos de PAM e idade ao início do tratamento.

\begin{tabular}{|c|c|c|c|c|}
\hline $\begin{array}{c}\text { Crianças } \\
\text { com OI }\end{array}$ & & $\begin{array}{c}\text { OI tipo I } \\
(\mathrm{n}=58 \mathrm{rX})\end{array}$ & $\begin{array}{l}\text { OI tipo III } \\
(n=83 \text { rX) }\end{array}$ & $\begin{array}{c}\text { OI tipo IV } \\
(\mathrm{n}=56 \mathrm{rX})\end{array}$ \\
\hline \multirow{5}{*}{$\begin{array}{l}\text { Faixas } \\
\text { etárias }\end{array}$} & $<5$ anos & 2 & 10 & 3 \\
\hline & 5-7 anos & 17 & 22 & 18 \\
\hline & 8-10 anos & 14 & 27 & 11 \\
\hline & 11-14 anos & 17 & 15 & 19 \\
\hline & $15-19$ anos & 8 & 9 & 5 \\
\hline \multirow{4}{*}{$\begin{array}{l}\text { Número de } \\
\text { ciclos de } \\
\text { PAM }\end{array}$} & $0-4$ & 33 & 23 & 21 \\
\hline & $5-9$ & 17 & 21 & 19 \\
\hline & $>10$ & 8 & 33 & 12 \\
\hline & $\begin{array}{l}\text { Faltam } \\
\text { dados }\end{array}$ & - & 6 & 4 \\
\hline \multirow{3}{*}{$\begin{array}{c}\text { Idade no } \\
\text { início do } \\
\text { tratamento }\end{array}$} & 0-5 anos & 21 & 44 & 16 \\
\hline & $>5$ anos & 37 & 39 & 36 \\
\hline & $\begin{array}{l}\text { Faltam } \\
\text { dados }\end{array}$ & - & - & 4 \\
\hline
\end{tabular}


Os dados obtidos de índice mentual foram analisados com o objetivo de avaliar a sua eficácia na diferenciação de crianças saudáveis e com osteogênese imperfeita ao longo de suas classes etárias. Nesta primeira avaliação, foi possível verificar que o índice mentual foi capaz de diferenciar o desenvolvimento da espessura da cortical ao longo das classes etárias de crianças saudáveis, apresentando equivalência das médias apenas entre 8 a 10 anos e 11 a 14 anos, e as demais comparações de idades consideradas estatisticamente diferentes $(\mathrm{p}<0,05)$. Entre as crianças com OI, verificou-se que o índice mentual foi capaz de diferenciar as idades, contudo, as classes etárias de 5 a 7 e 8 a 10 anos foram consideradas estatisticamente equivalentes, assim como as idades de 11 a 14 e 15 a 19 anos $(p>0,05)$. As demais comparações foram consideradas diferentes estatisticamente $(p<0,05)$. Ao realizar a comparação entre cada uma das classes etárias das crianças saudáveis e com OI, verificou-se que o índice mentual foi capaz de diferenciá-las entre as idades, com exceção da classe etária de 11 a 14 anos em que ambos os grupos foram considerados estatisticamente equivalentes ( $\mathrm{p}>0,05)$ (tabela 8).

Tabela 8 - Estatísticas descritivas e significâncias* de índice mentual entre as classes etárias de crianças sadias e com osteogênese imperfeita (OI).

\begin{tabular}{lllcccc}
\hline Crianças & Classes etárias & $\mathbf{n}$ & Média & Desvio Padrão & IC $\mathbf{- 9 5 \%}$ & IC +95\% \\
\hline Sadias & 5 a 7 & 32 & 3,38 aA & 0,62 & 3,15 & 3,60 \\
& 8 a 10 & 26 & 3,81 bA & 0,68 & 3,54 & 4,09 \\
& 11 a 14 & 18 & 3,79 bA & 0,54 & 3,52 & 4,06 \\
& 15 a 19 & 6 & 4,45 cA & 0,43 & 4,00 & 4,90 \\
\hline OI & 5 a 7 & 57 & 3,04 aB & 0,63 & 2,87 & 3,21 \\
& 8 а 10 & 52 & 3,20 aB & 0,67 & 3,02 & 3,39 \\
& 11 a 14 & 51 & 3,83 bA & 0,80 & 3,60 & 4,05 \\
& 15 a 19 & 22 & 3,78 bB & 0,80 & 3,43 & 4,13 \\
\hline
\end{tabular}


Uma vez que foi possível diferenciar crianças saudáveis e com OI, foram analisadas possíveis diferenças da evolução do índice mentual entre as classes etárias dos gêneros feminino e masculino. Tal diferença não foi considerada estatisticamente significativa (F3,248=0,78093; p=0,50557) (tabela 9), portanto, as análises seguintes não foram realizadas com a separação de gêneros.

Tabela 9 - Estatísticas descritivas de índice mentual entre as classes etárias de crianças dos gêneros masculino e feminino, sadias e com osteogênese imperfeita (OI).

\begin{tabular}{|c|c|c|c|c|c|c|c|}
\hline Crianças & Classes etárias & Gênero & $\mathbf{n}$ & Média & Desvio Padrão & IC -95\% & IC $+95 \%$ \\
\hline \multirow[t]{8}{*}{ Sadias } & 5 a 7 & $\mathrm{M}$ & 18 & $3,48 a^{*}$ & 0,69 & 3,14 & 3,82 \\
\hline & & F & 14 & $3,24 a$ & 0,52 & 2,94 & 3,53 \\
\hline & 8 a 10 & $\mathrm{M}$ & 10 & $3,50 a$ & 0,68 & 3,01 & 3,99 \\
\hline & & $\mathrm{F}$ & 16 & 4,01a & 0,62 & 3,68 & 4,34 \\
\hline & 11 a 14 & $\mathrm{M}$ & 6 & $3,58 a$ & 0,25 & 3,32 & 3,84 \\
\hline & & $\mathrm{F}$ & 12 & 3,89a & 0,62 & 3,50 & 4,28 \\
\hline & 15 a 19 & $\mathrm{M}$ & 3 & $4,80 a$ & 0,26 & 4,14 & 5,46 \\
\hline & & $\mathrm{F}$ & 3 & $4,10 \mathrm{a}$ & 0,17 & 3,67 & 4,53 \\
\hline \multirow[t]{8}{*}{ OI } & 5 a 7 & $\mathrm{M}$ & 30 & $3,06 a$ & 0,69 & 2,80 & 3,32 \\
\hline & & $\mathrm{F}$ & 27 & $3,01 \mathrm{a}$ & 0,57 & 2,79 & 3,24 \\
\hline & 8 а 10 & $\mathrm{M}$ & 30 & $3,16 a$ & 0,71 & 2,90 & 3,42 \\
\hline & & $\mathrm{F}$ & 22 & 3,26a & 0,62 & 2,99 & 3,54 \\
\hline & 11 a 14 & $\mathrm{M}$ & 25 & $3,85 a$ & 0,92 & 3,47 & 4,23 \\
\hline & & $\mathrm{F}$ & 26 & $3,81 a$ & 0,69 & 3,53 & 4,09 \\
\hline & 15 a 19 & $\mathrm{M}$ & 15 & $3,96 a$ & 0,85 & 3,49 & 4,43 \\
\hline & & $\mathrm{F}$ & 7 & $3,40 a$ & 0,55 & 2,89 & 3,90 \\
\hline
\end{tabular}

* As letras indicam comparações entre os gêneros $\mathrm{M}=$ masculino, $\mathrm{F}=$ feminino, $\mathrm{DP}$ = desviopadrão, IC = intervalo de confiança

Considerando as crianças em uma amostra única, não separada por gênero, foi realizada a análise da evolução do índice mentual ao longo das classes etárias de crianças 
saudáveis e crianças com diferentes tipos de OI. Nesta análise foi evidente o aumento do índice em todas as crianças $\left(\mathrm{F}_{9,248}=1,388, \mathrm{p}=0,19385\right)$ (fig. 15), contudo em menor escala em crianças do tipo I e III, especialmente nas classes etárias de 5 a 7 anos, 8 a 10 anos e 15 a 19 anos $(\mathrm{p}<0,10)$.

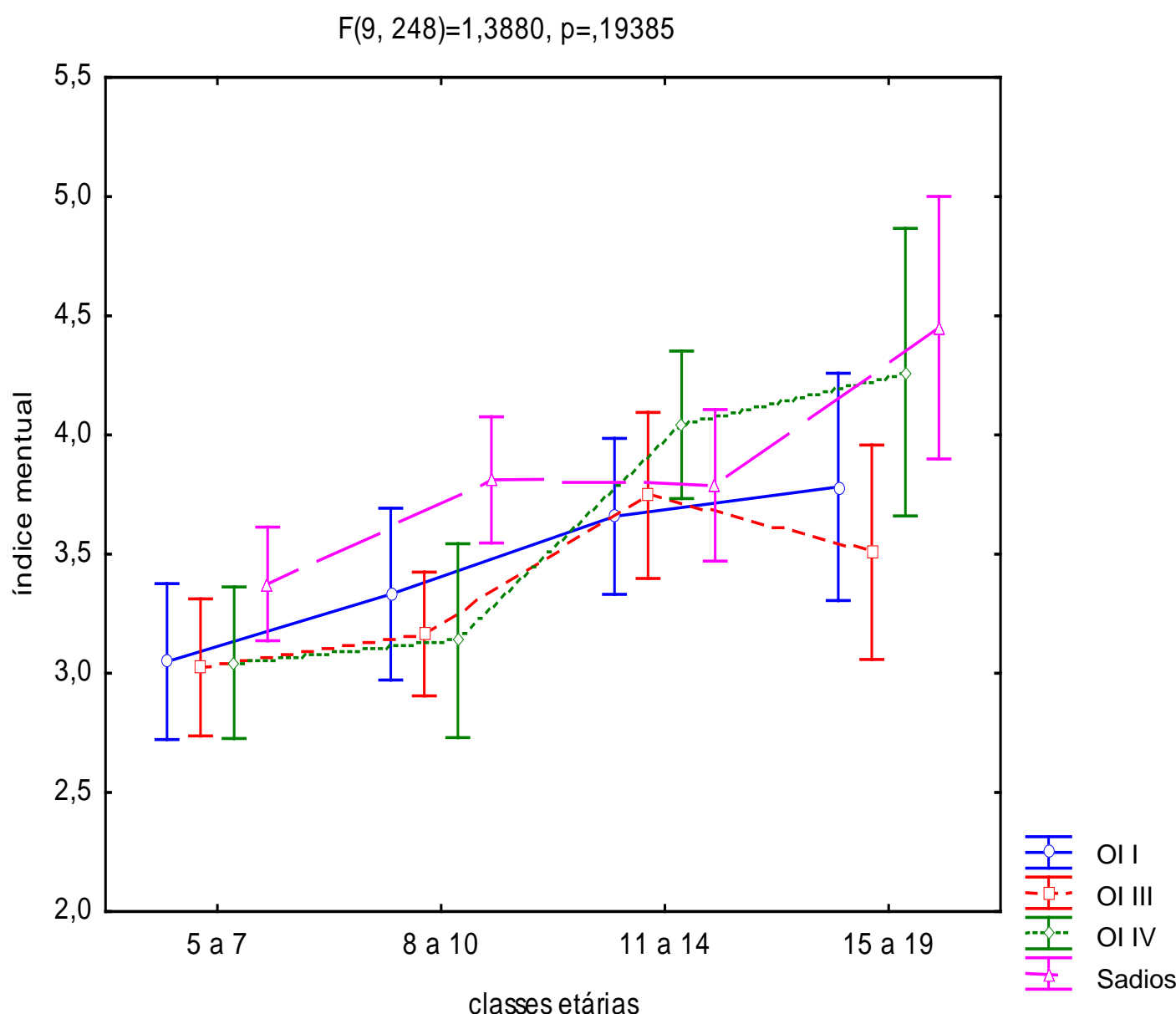

Figura 15 - Médias e intervalos de confiança de índice mentual ao longo de classes etárias de crianças sadias e com diferentes tipos de osteogênese imperfeita (OI).

Além disso, foi analisado o efeito dos ciclos de pamidronato no índice mentual, como uma tentativa de avaliar a evolução do tratamento da osteogênese imperfeita. Desta forma, foi possível demonstrar a evolução do índice mentual em crianças que iniciaram o tratamento precocemente ( 0 a 5 anos) e com mais de 5 anos, sendo que ambas apresentam 
recuperação com mesma tendência, porém aquelas que iniciaram o tratamento com idade mais avançada atigiram um IM maior $\left(\mathrm{F}_{2,181}=1,9936 ; \mathrm{p}=0,13918\right)$.

Foi possível verificar que entre as crianças que iniciaram o tratamento mais cedo, as médias de índice mentual observadas em 0 a 4 ciclos de pamidronato e em 5 a 10 ciclos foram consideradas estatisticamente equivalentes $(p>0,05)$, só existindo diferença em mais de 10 ciclos $(\mathrm{p}<0,05)$. Para as crianças que iniciaram o tratamento mais cedo, as médias de IM foram estatisticamente mais baixas entre todos os períodos de ciclos $(\mathrm{p}<0,05)$ (figura 16).

$F(2,181)=1,9936, p=, 13918$

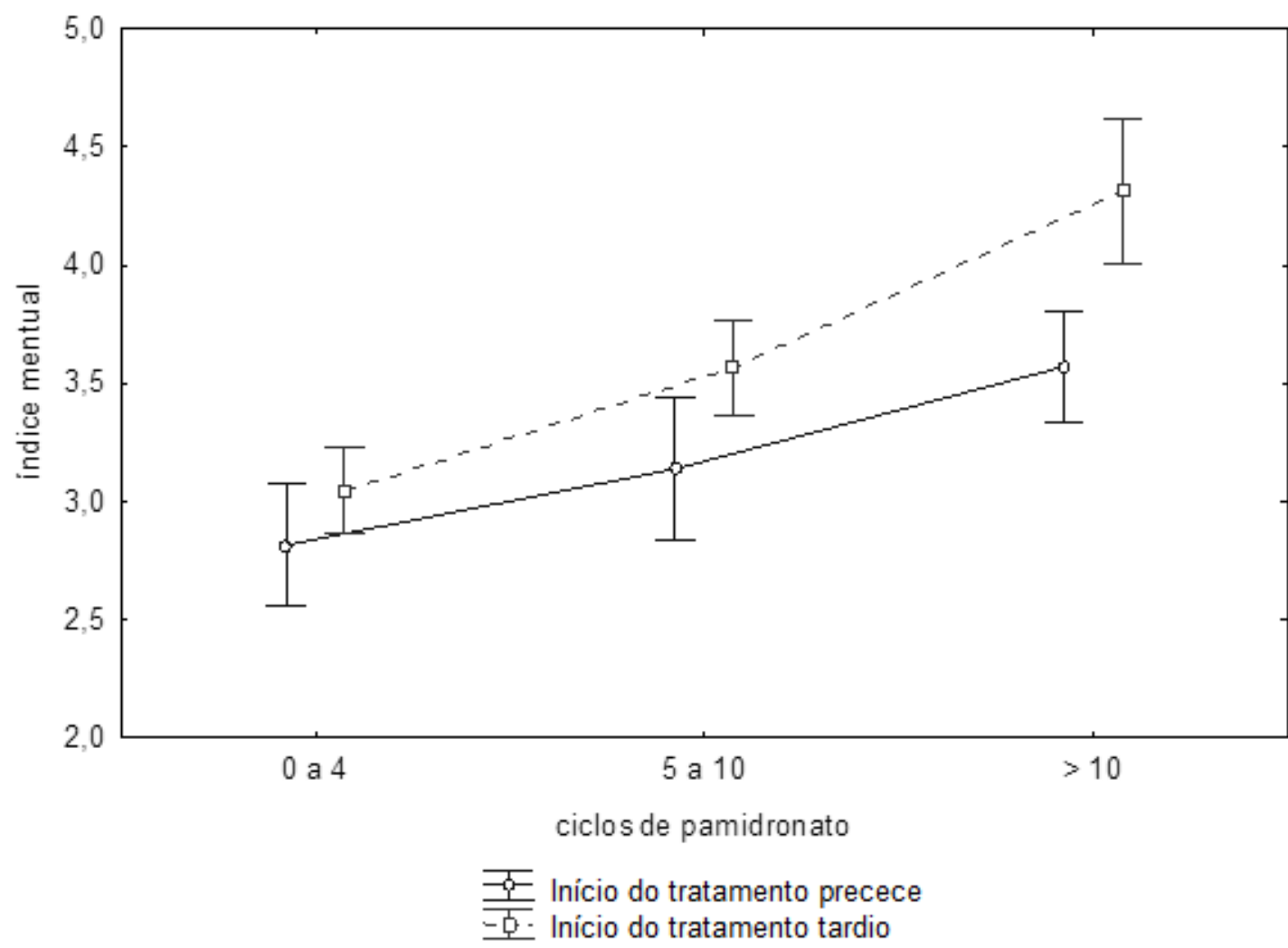

Figura 16 - Médias e intervalos de confiança de índice mentual das classes de ciclos de pamidronato em crianças osteogênese imperfeita que iniciaram o tratamento em idade precoce ( 0 a 5 anos) e tardia ( $>5$ anos). 
Foi também avaliada a diferença da evolução de índice mentual entre crianças com diferentes tipos de osteogênese imperfeita, com início de tratamento precoce e tardio. Neste caso, foi possível verificar as seguintes significâncias $(\mathrm{p}<0,05)$ (fig. 17):

- crianças OI tipo I e IV com início de tratamento precoce apresentaram aumento significativo da média de IM apenas com mais de 10 ciclos de pamidronato;

- crianças OI tipo I e IV com início de tratamento tardio apresentaram aumento significativo da média de IM já com 5 a 10 ciclos de pamidronato;

- crianças OI tipo III apresentaram aumento significativo das médias de IM apenas com mais de 10 ciclos de pamidronato, independente da idade de início do tratamento;

Ainda nesta mesma análise, realizando as comparações de médias entre as crianças com diferentes tipos de osteogênese imperfeita, verificou-se que:

- Crianças com 0 a 4 ciclos de PAM, independente do tipo de OI e da idade de início do tratamento, apresentaram médias semelhantes $(\mathrm{p}>0,05)$.

- Crianças com 5 a 10 ciclos de PAM, independente do tipo de OI e da idade de início do tratamento, apresentaram médias semelhantes $(\mathrm{p}>0,05)$.

- Em crianças com início de tratamento precoce e com mais de 10 ciclos de pamidronato, a média de IM de crianças OI tipo 3 foi significativamente mais baixa que em crianças OI tipo 1 e $4(\mathrm{p}<0,05)$;

- Crianças com início de tratamento tardio e mais de 10 ciclos de PAM, apresentaram médias semelhantes $(\mathrm{p}>0,05)$ independente do tipo de OI. 

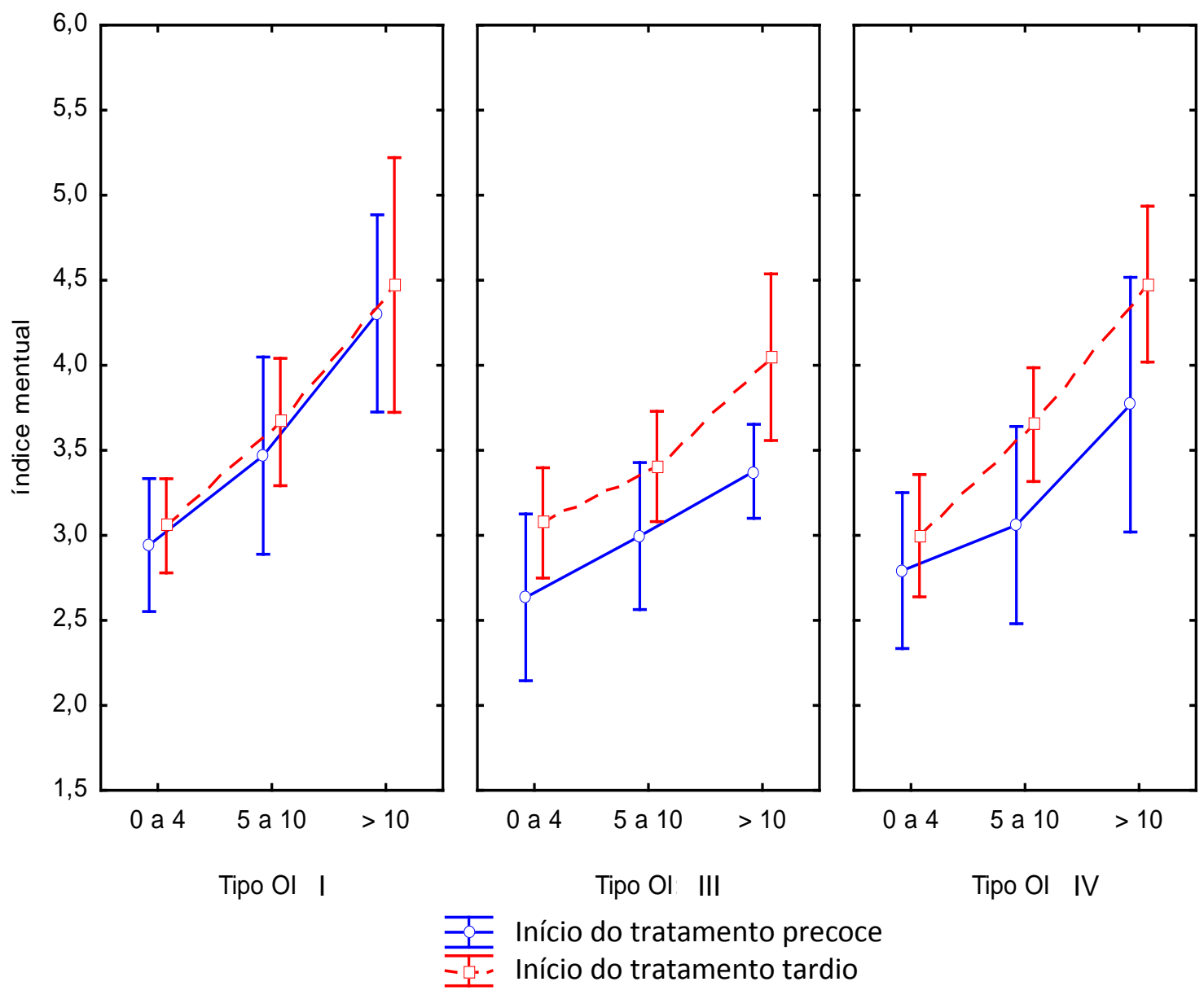

Figura 17 - Médias e intervalos de confiança de índice mentual das classes de ciclos de pamidronato em crianças com diferentes tipos de osteogênese imperfeita que tiveram diagnóstico precoce ( 0 a 5 anos) e diagnóstico tardio ( $>5$ anos).

Ao comparar com as crianças saudáveis, foi possível verificar a evolução de IM entre os tipos de OI, independentemente da idade de início de tratamento. Nesta análise obtiveram-se as seguintes significâncias $\left(F_{6,421}=7,4088 ; p=0,0000\right)$ (figura 18):

- Crianças OI, com 0 a 4 ciclos de pamidronato, apresentaram médias significativamente mais baixas do que crianças saudáveis $(\mathrm{p}<0,05)$, independente do tipo de OI;

- Crianças OI tipos I e IV, com 5 a 10 ciclos de pamidronato, apresentaram médias equivalentes às crianças saudáveis $(\mathrm{p}<0,05)$; 
- Crianças OI do tipo III somente apresentaram médias equivalentes às crianças saudáveis $(\mathrm{p}<0,05)$ com mais de 10 ciclos de pamidronato; até 10 ciclos seu IM foi significativamente mais baixo comparado com o mesmo grupo controle.

- Crianças OI do tipo I e IV, com mais de 10 ciclos de pamidronato, apresentaram médias significativamente mais elevadas do que crianças saudáveis $(\mathrm{p}<0,05)$;

$F(4,218)=2,1529, p=, 07536$

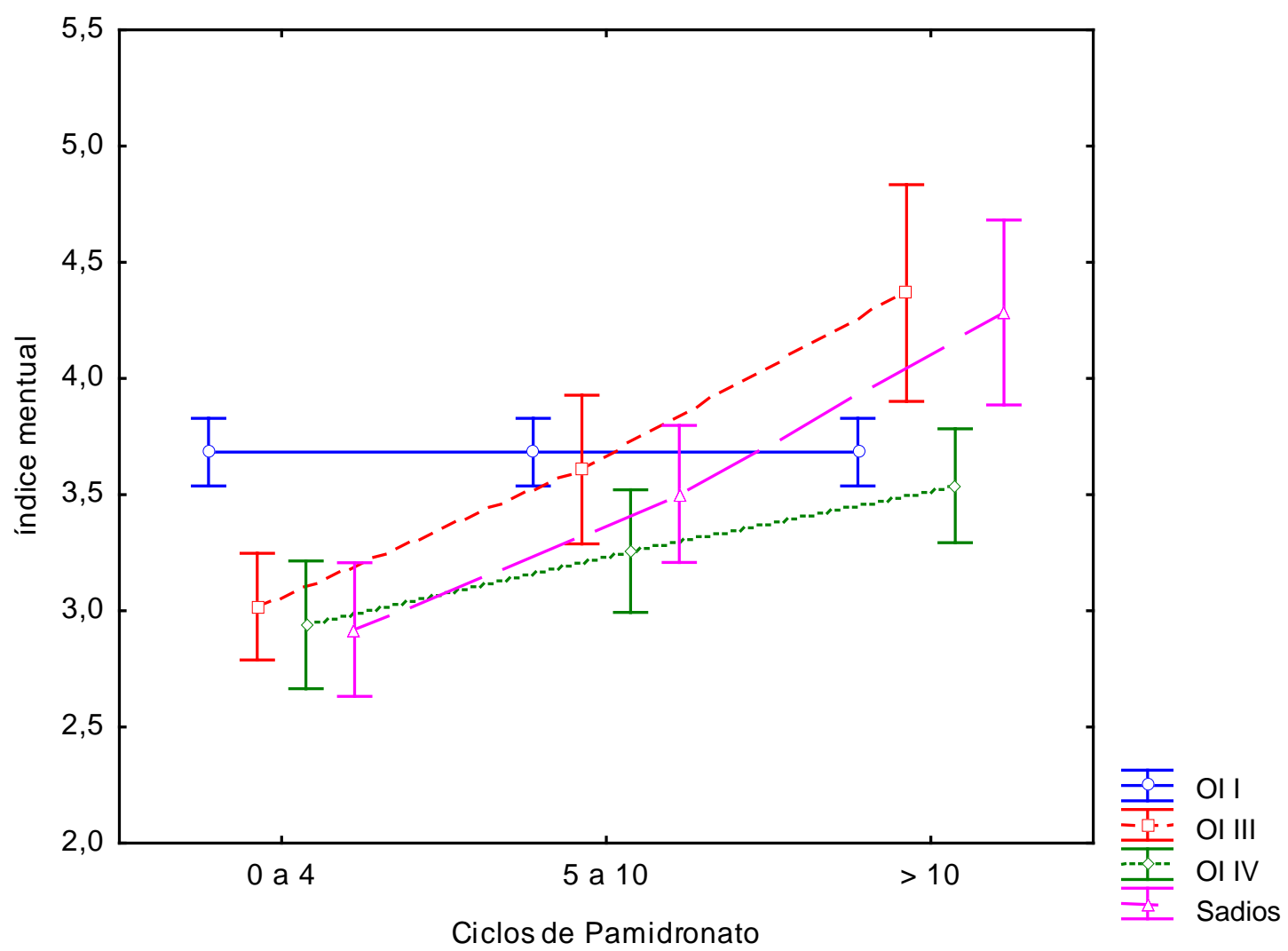

Figura 18 - Médias e intervalos de confiança de índice mentual das classes de ciclos de pamidronato em crianças sadias e com diferentes tipos de osteogênese imperfeita. 


\subsubsection{Associação entre índice mentual e densidade mineral óssea em crianças saudáveis com diagnóstico densitométrico normal}

A partir do anteriormente exposto, levantou-se a hipótese de que o índice mentual apresenta associação positiva com os valores de densidade mineral óssea, obtidos por meio de densitometria óssea por dupla emissão de raios X.

Sendo assim, com base nos dados de 92 crianças saudáveis com padrão normal de densidade óssea, foram construídos modelos de regressão linear dos valores dos índices mentuais e respectivos valores de densidade mineral óssea da coluna lombar (BMDLombar) e do corpo total (BMDTotal). Foi possível observar que em ambos os casos houve associação significativa entre as variáveis $(r=0,64, p<0,05 ; \mathrm{r}=0,63, \mathrm{p}<0,05$, respectivamente). Portanto, pode-se afirmar que à medida que ocorre o aumento do índice mentual isso se reflete na elevação dos valores de densidade mineral óssea da coluna lombar (fig. 19) e do corpo total (fig. 20) nas crianças saudáveis.

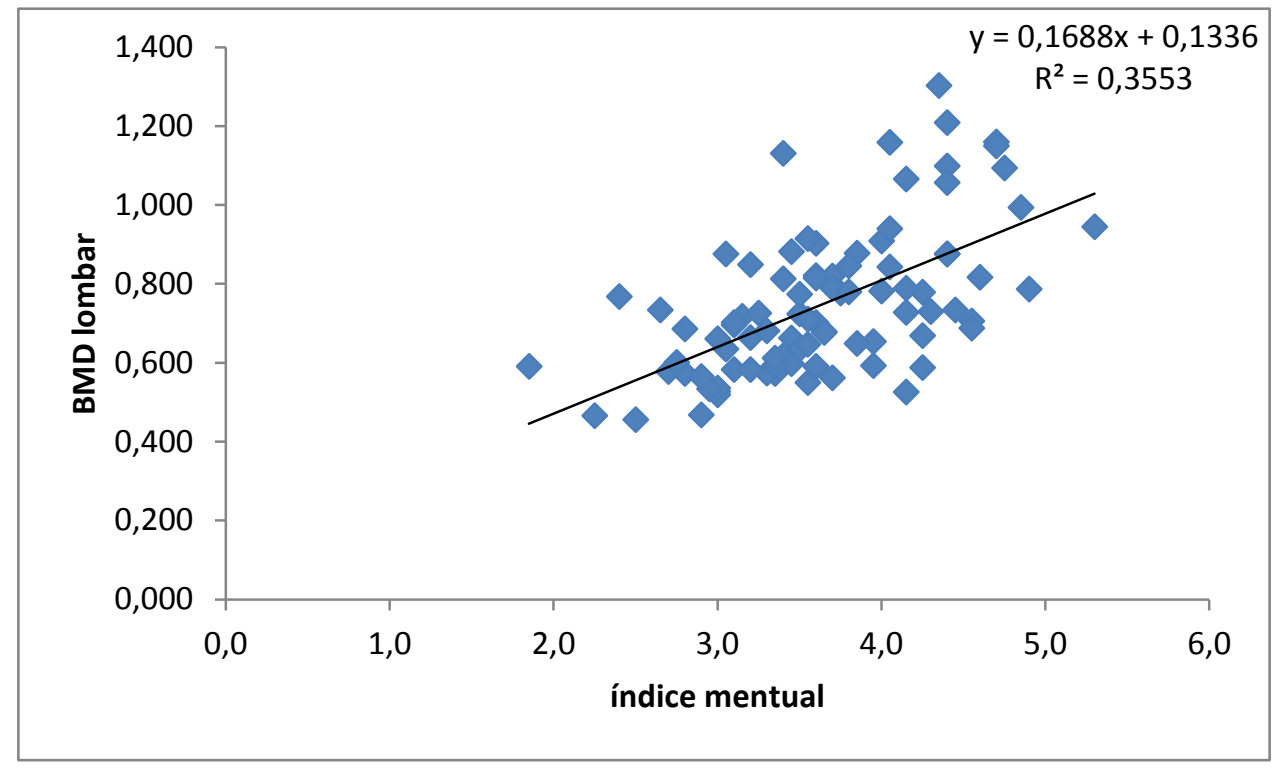

Figura 19 - Diagrama de dispersão e modelo de regressão linear entre índice mentual (X) e densidade mineral óssea da coluna lombar (BMDLombar) (Y). 


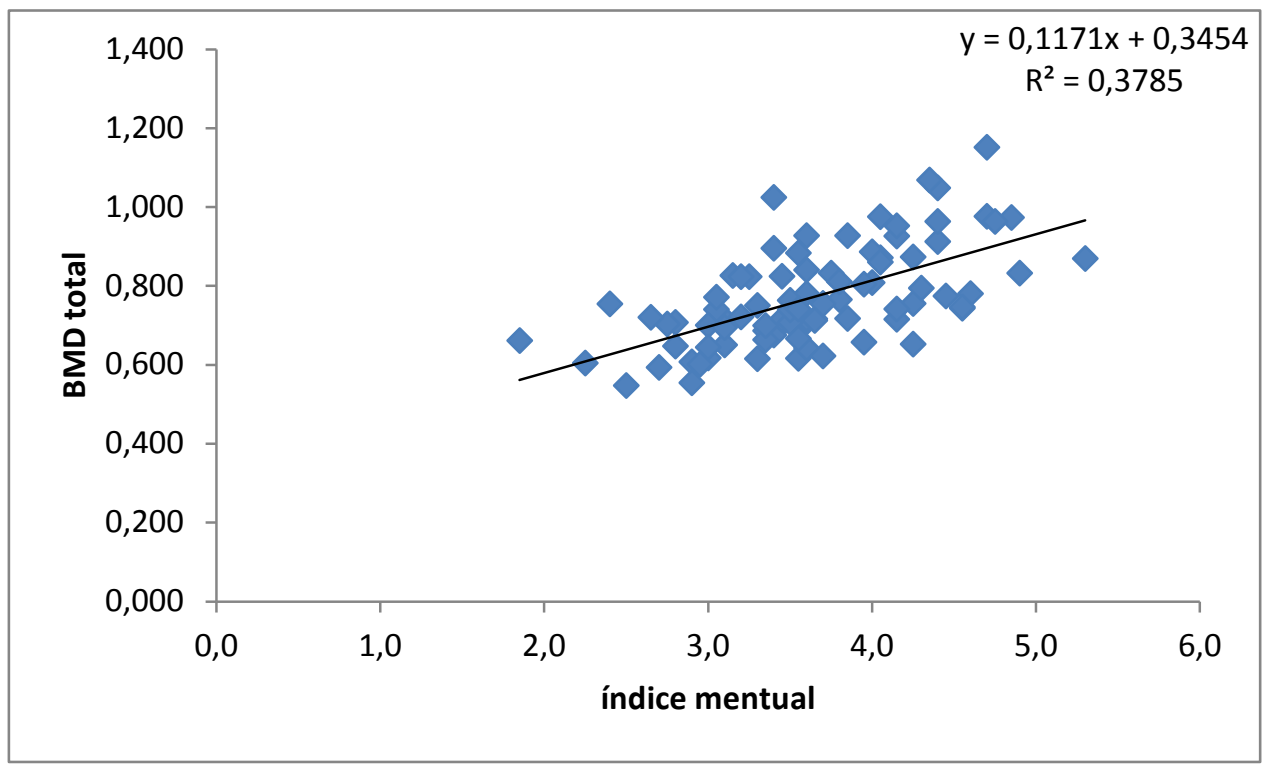

Figura 20 - Diagrama de dispersão e modelo de regressão linear entre índice mentual (X) e densidade mineral óssea do corpo total (BMDTotal) (Y).

\subsubsection{Modelo de variação do Índice Mentual para crianças saudáveis com diagnóstico densitométrico normal}

Uma vez demonstrada a possibilidade de estimar o valor do Índice Mentual ao longo do tratamento com pamidronato, levanta-se a hipótese de que há também possibilidade de classificar o padrão de densidade mineral óssea em função de uma curva de variação do índice mentual ao longo das idades de crianças normais. Foi possível verificar um ajuste dos dados de índice mentual com 76\% de explicabilidade da variação dos dados de idade das crianças $(\mathrm{F} 1,9=28,221 ; \mathrm{p}=0,000)$ (tab. 10). Vale ressaltar, que este modelo é apenas uma proposta de ajuste, uma vez que o n amostral era baixo e, além disso, fora obtido apenas das médias de índice mentual das respectivas idades (entre 6 a 17 anos). Os parâmetros do modelo ajustado estão apresentados na tabela 11 e na equação 1 , assim como a representação gráfica encontra-se na figura 21. 
Tabela 10 - Estatísticas da bondade de ajuste do modelo de regressão linear.

\begin{tabular}{lr}
\hline Estatísticas & \\
\hline $\mathrm{n}$ & 11,000 \\
$\mathrm{GL}$ & 9,000 \\
$\mathrm{R}^{2}$ & 0,758 \\
$\mathrm{R}^{2}$ ajustado & 0,731 \\
$\mathrm{AIC}$ & $-32,320$ \\
\hline
\end{tabular}

Tabela 11 - Parâmetros do modelo de regressão linear

\begin{tabular}{ccccccc}
\hline Fonte & Valor & Erro padrão & $\mathrm{t}$ & $\operatorname{Pr}>|\mathrm{t}|$ & $\begin{array}{c}\text { Limite inferior } \\
(95 \%)\end{array}$ & $\begin{array}{c}\text { Limite superior } \\
(95 \%)\end{array}$ \\
\hline Intercepto & 2,778 & 0,229 & 12,116 & $<0,0001$ & 2,259 & 3,297 \\
Estatística & 0,099 & 0,019 & 5,312 & 0,000 & 0,057 & 0,141 \\
\hline
\end{tabular}

Eq. 1) Índice Mentual=2,778+0,099*idade

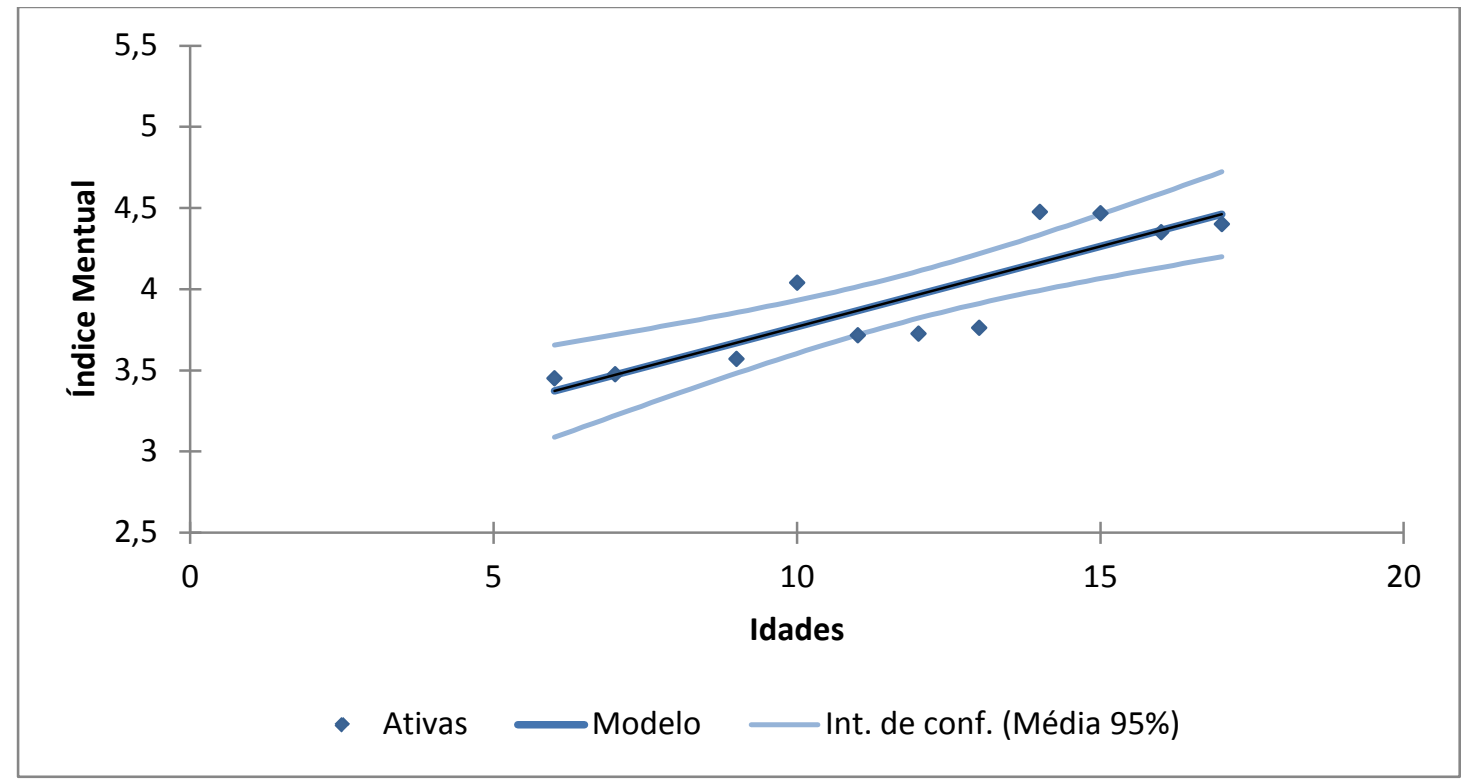

Figura 21 - Diagrama de dispersão e modelo de regressão linear entre índice mentual (Y) e idade de crianças com padrão normal de densidade óssea (X). 


\subsubsection{Modelo preditivo da quantidade necessária de ciclos de pamidronato e variáveis} relativas ao tratamento da osteogênese imperfeita

Dada a relação do IM com a DMO de crianças saudáveis, assim como a possibilidade de utilização do índice para o monitoramento do tratamento da osteogênese imperfeita, como inicialmente verificado, foi construído um modelo linear generalizado para estimar a quantidade de ciclos de pamidronato intravenoso em crianças com OI que seria necessária para se atingir valores de índice mentual equivalentes ao de crianças saudáveis para a mesma idade. Neste modelo, foram estabelecidos parâmetros de associação das idades nos momentos das radiografias, dos valores de índice mentual e do tipo de osteogênese imperfeita (I, III e IV).

Neste modelo, o número de Ciclos de Pamidronato Final (CPf) foi considerado como variável dependente (Y) e as variáveis independentes (X) foram: tipo de OI, idade inicial - primeira radiografia (Ii), idade final - última radiografia (If), número de Ciclos de Pamidronato Inicial (CPi), Índice Mentual Inicial (IMi) e índice mentual final (IMf).

No ajuste do modelo, as variáveis independentes consideradas significativas foram CPi, IMi e IMf $\left(\mathrm{F}_{3,42}=21,309 ; \mathrm{p}<0,0001\right)$. As estatísticas de ajuste e as estatísticas de significância do modelo estão apresentadas nas Tabelas 12 e 13.

Tabela 12 - Estatísticas da bondade de ajuste do modelo de regressão linear múltipla

\begin{tabular}{lr}
\hline Estatísticas & \\
\hline $\mathrm{n}$ & 46 \\
$\mathrm{GL}$ & 42 \\
$\mathrm{R}^{2}$ & 0,604 \\
$\mathrm{R}^{2}$ ajustado & 0,575 \\
$\mathrm{AIC}$ & 136,251 \\
\hline
\end{tabular}


Tabela 13 - Análise da variância do ajuste do modelo de regressão linear múltipla

\begin{tabular}{lccccc}
\hline \multicolumn{1}{c}{ Fonte } & GL & Soma dos quadrados & Quadrados médios & F & Pr $>$ F \\
\hline Modelo & 3 & 1137,740 & 379,247 & $21,309<0,0001$ \\
Erro & 42 & 747,477 & 17,797 & & \\
Total corrigido & 45 & 1885,217 & & \\
\hline
\end{tabular}

Calculado contra o modelo $Y=$ Média $(Y)$

Visto a significância do modelo, a seguinte equação foi obtida, seguindo os parâmetros do modelo e seu ajuste final.

Eq. 2) $C P f=10,31+0,91 * C P i-5,43 * I M i+3,86 * I M$

Neste ajuste ficou evidente que a quantidade necessária de ciclos de pamidronato tinha relação com a quantidade inicial de ciclos de pamidronato, bem como com os índices mentuais inicial e final (tabela 14).

Tabela 14 - Parâmetros do modelo de regressão múltipla

\begin{tabular}{lrrrrr}
\hline \multicolumn{1}{c}{ Fonte } & GL & Soma dos quadrados & Quadrados médios & F & Pr $>$ F \\
\hline OI & 0 & 0,000 & & & \\
If & 0 & 0,000 & & & \\
Cpi & 1 & 451,359 & 451,359 & 25,361 & $<0,0001$ \\
Imi & 1 & 233,184 & 233,184 & 13,102 & 0,001 \\
Imf & 1 & 453,197 & 453,197 & 25,465 & $<0,0001$ \\
\hline
\end{tabular}


6. DISCUSSÃO 


\section{DISCUSSÃO}

Até onde se sabe, esse foi o primeiro trabalho a avaliar índices radiomorfométricos e dimensão fractal de mandíbula em pacientes com osteogênese imperfeita. Além disso, embora vários estudos tenham demonstrado o efeito do pamidronato em outros ossos, esse foi o primeiro a verificar a alteração da cortical mandibular ao longo do tratamento com essa medicação.

Na literatura atual, existem vários estudos abordando a correlação entre índices radiomorfométricos em radiografias panorâmicas e a DMO, propondo seu uso como instrumento auxiliar no rastreamento de pessoas com baixa densidade mineral óssea (Drozdzowska et al, 2002; Taguchi et al, 2004 e 2006; White et al, 2005; Lee et al, 2005; Yassar e Akgünlü, 2006, Alonso et al, 2011) Esses estudos utilizaram diversos índices radiomorfométricos quantitativos e qualitativos para analisar a cortical inferior da mandibula, bem como medidas do trabeculado ósseo, como a análise da dimensão fractal. Em crianças, a utilização dessas medidas em radiografias panorâmicas se restringe a poucos trabalhos (Bras et al, 1982; Paulsson-Björnsson et al, 2014).

No presente estudo, foram avaliados alguns dos índices radiomorfométricos mais utilizados na literatura, em pacientes adultos e idosos, e o cálculo da dimensão fractal - que vem sendo testado para analisar a microarquitetura do trabeculado ósseo na mandíbula em crianças com OI que realizavam tratamento com pamidronato.

Como resultado, foi possível observar que a cortical inferior da mandíbula de crianças com OI, quando analisadas em radiografias panorâmicas da face, apresentou-se mais fina e com erosões. Nossos resultados indicam que a espessura e a dimensão fractal da cortical inferior mandibular parecem ser as medidas mais promissoras. Com relação aos 
diferentes tipos de OI e número de ciclos de PAM, as diferenças foram significativas apenas para a DF cortical e o IM. Não obstante, houve correlações entre os índices qualitativos e quantitativos, com exceção da DF do osso trabecular.

Com relação aos índices radiomorfométricos qualitativos, o índice visual mostrou aumento de corticais mandibulares classificadas como não-finas ao longo dos ciclos de PAM, o que corrobora publicações anteriores a respeito de outros ossos do corpo, as quais afirmam que a espessura da cortical quase dobra nos primeiros anos de administração do PAM (Mariani, 2003; Rauch et al, 2003a; Rauch et al, 2006). Já o índice mandibular cortical não foi tão elucidativo, salvo pelo dado de que as corticais mais porosas, associadas aos casos de osteoporose (Yassar e Akgünlü, 2006; Leite et al, 2010) e classificadas como C3, foram encontradas apenas na primeira fase do tratamento (0-4 ciclos), quando os ossos ainda estão muito frágeis, para todos os tipos de OI. Esses dois índices apresentaram uma associação positiva entre si, onde se pôde perceber que crianças com corticais mais porosas (C3) tenderam a apresentá-las visualmente mais finas, podendo ser, a associação dessas duas variáveis, um bom indicador para o diagnóstico de baixa massa óssea (BMO). Outra informação relevante é que esses dois índices apresentaram associações com a espessura da cortical mandibular - índice mentual -, podendo-se atribuir valores numéricos para a definição das categorias qualitativas - não-fina e fina; C1-C2 e C3 -, e esses números coincidiram com o ponto de corte para baixa densidade mineral óssea em adultos, de 3mm, sugerido em publicações anteriores (Devlin e Horner, 2002; Horner et al, 2002; Leite et al, 2010). Esse achado sugere que uma simples avaliação visual, sem necessidade de ferramentas sofisticadas ou softwares, pode fornecer uma ideia da evolução do tratamento com PAM em crianças com OI, por meio da comparação de 
radiografias seriadas. No entanto, mais estudos são necessários para confirmação dessa tendência.

As medidas de DF do osso trabecular não foram estatisticamente diferentes entre os tipos de OI nem entre os ciclos de PAM, além disso, não apresentaram associações com os índices qualitativos e tiveram fracas correlações com as medidas de osso cortical. Em alguns sítios, como calcâneo e fêmur, a análise da dimensão fractal demonstrou estar relacionada à microarquitetura óssea (Bianciardi et al, 2013) e, portanto, ser um bom indicador de fragilidade óssea. No entanto, os resultados para mandíbula são controversos. Os resultados negativos para osso trabecular podem estar, então, relacionados a dois fatores: o primeiro, é a possibilidade do trabeculado na mandíbula não refletir a microarquitetura óssea, como em outros sítios, isto explicaria os resultados divergentes dos poucos estudos que analisaram DF na mandíbula (Yassar e Akgünlü, 2008; Oliveira et al, 2013; Sindeaux, et al, 2014); o segundo ponto a ser considerado é o fato de que o pamidronato age primariamente em osso cortical, com pouco efeito no trabeculado ósseo (Rauch et al, 2003a). Esse resultado negativo também foi encontrado em várias outras pesquisas, na avaliação de adultos (Yasar e Akgünlü, 2006; Sindeaux et al, 2014).

Um estudo prévio (Torres et al, 2011) encontrou valores de DF maiores em regiões alveolares da mandíbula de pacientes com osteonecrose associada ao uso de bisfosfonatos quando comparados aos controles. Os autores sugeriram que a DF seria uma ferramenta promissora para a detecção de alterações ósseas em pacientes adultos em uso de bisfosfonatos. Além do estudo supracitado ter sido realizado em adultos, a DF foi realizada em exames de tomografia computadorizada por feixe cônico, o que impede uma comparação direta com os resultados do presente trabalho. Afinal, a dimensão fractal apenas pode ser comparada na utilização de radiografias com a mesma resolução espacial 
(Oliveira et al, 2012). Outro dado importante é que, até os dias atuais, não há relatos de osteonecrose mandibular associada ao uso de bisfosfonatos em pacientes pediátricos. O mecanismo de ação dos bisfosfonatos nas crianças é diferente dos adultos, sendo o osso infantil um tecido em crescimento, responde diferentemente à droga (Eghbali-Fatourechi, 2014) Com isso, tal diferença impede a generalização de nossos resultados no que diz respeito aos efeitos do PAM na cortical das crianças para adultos.

No nosso trabalho, verificamos resultados positivos para análise da dimensão fractal apenas na área de cortical inferior da mandíbula, que se mostrou diferente significativamente entre os tipos de OI e entre as classes de ciclos de PAM. Um trabalho recente que analisou a dimensão fractal da mandíbula em pacientes com e sem osteoporose encontrou resultados semelhantes para a análise da dimensão fractal da cortical inferior da mandíbula (Sindeaux et al, 2014) De acordo com nossos achados, a cortical inferior da mandíbula das crianças com OI do tipo I têm sua DF aumentada significativamente a partir de 5-10 ciclos de PAM, enquanto que as crianças tipos III e IV apresentam o mesmo resultado apenas após 10 ciclos da medicação. Apesar de terem apresentado um valor de correlação moderado entre si, a significância estatística foi bem menor para a DFCortical que para o índice mentual.

Portanto, o índice mentual, que avalia a espessura da cortical inferior da mandíbula abaixo do forame mentual, foi o que melhor respondeu às variações entre os tipos de OI e os ciclos de PAM, confirmando achados de diversos outros autores que consideram a espessura cortical mandibular a estrutura mais fidedigna para a correlação com a DMO em adultos (Dutra et al, 2005; Gulsahi et al, 2008; Sindeaux et al, 2014). A escassez de estudos que correlacionaram índices radiomorfométricos e densidade mineral óssea em crianças dificulta a comparação com os resultados do presente estudo. O único trabalho 
que incluiu indivíduos desde o nascimento até os 69 anos (Bras et al, 1982), avaliou a cortical apenas na região do ângulo mandibular, sendo que a camada de cortical nessa região somente pôde ser prontamente observada em crianças acima dos 10 anos. Além desse, o estudo de Paulsson-Björnsson et al (2014) avaliou a espessura da cortical inferior mandibular de crianças entre 8 e 10 anos para avaliar a diferença entre prematuros e nascidos a termo, com a hipótese de que crianças prematuras teriam sua cortical mais fina por apresentarem baixa massa óssea. Os autores não encontraram essa relação, porém o estudo não contou com os dados densitométricos dos sujeitos, o que inviabiliza qualquer inferência, já que as crianças podem ter tido vários estímulos externos, como suplementação nutricional e exercícios, alterando seu padrão de massa óssea. Taguchi et al, 2011, avaliou a espessura da cortical mandibular em correlação com baixa densidade mineral óssea, medida por ultrassonografia de calcâneo, em indivíduos mais jovens, mas ainda assim adultos, de 18 a 36 anos. Nesse estudo foi concluído que a espessura cortical mandibular determinada em radiografias panorâmicas pode ser usada para a identificação de baixa DMO de calcâneo em homens. Nossos achados de espessura da cortical mandibular (IM) em crianças saudáveis com diagnóstico densitométrico normal mostraram valores maiores que 3,0mm para a maioria das crianças, sendo encontrados valores menores somente em crianças na faixa etária de 5 a 8 anos (Apolinário, 2009). Esse dado sugere que os resultados desse estudo são compatíveis a estudos em adultos, que indicam um ponto de corte médio de 3,0 mm para a correlação com o diagnóstico densitométrico de baixa massa óssea (Devlin \& Horner, 2002; Horner et al, 2002; Gulsahi et al, 2008; Leite et al, 2010).

Da avaliação da variável IM, pôde-se aferir que, ao início do tratamento (0-4 ciclos), todos os tipos de OI apresentam valores equivalentes e baixos - média de 2,94mm, 
que retratam sua extrema fragilidade óssea. Na fase de 5-10 ciclos, os tipos menos graves da doença, I e IV, já apresentam um aumento de espessura de cortical significativo, média de 3,55mm, enquanto que o tipo III apenas mostra esse aumento significativo (média 3,53mm) com mais de 10 ciclos de PAM. Ainda, na fase de mais de 10 ciclos, os tipos I e IV continuam apresentando um aumento expressivo de suas médias de IM, com valores bem acima do ponto de corte para BMO em adultos (média de 4,32mm). Esse dado nos leva a crer que a resposta do osso mandibular às infusões de PAM é diferente de outros ossos. O estudo de Torres et al (2012), com exames de tomografia computadorizada por feixe cônico de pacientes adultos com osteonecrose por uso de bisfosfonatos, verificou que medidas da cortical mandibular são ferramentas potencialmente úteis na detecção de alterações ósseas dimensionais causadas por bisfosfonatos.

Tendo apresentado os resultados mais promissores, fez-se necessário o aprofundamento do estudo dessa variável e, para isso, foram feitas outras análises comparando indivíduos com OI e saudáveis com diagnóstico densitométrico normal, provenientes de um banco de dados utilizado em um estudo prévio.

Em nossos resultados, fica clara a diferença de espessura entre crianças saudáveis e com OI, de qualquer tipo, em todas as classes etárias, com exceção da classe de 11 a 14 anos. O resultado divergente para esta faixa etária pode estar relacionado ao fato de que 72,72\% dessas crianças já havia recebido mais de 5 ciclos de PAM, além disso, quase a metade desse grupo apresentava mais de 10 ciclos, enquanto que nas outras classes etárias a porcentagem de crianças com mais de 5 ciclos foi 42\%, 59\% e 68\%, para 5 a 7 anos, 8 a 10, e 15 a 19 anos, respectivamente. Além disso, como pode ser observado na figura 18, apenas crianças com OI tipo III têm corticais mais finas que a média para crianças saudáveis quando atingem mais de 10 ciclos de PAM; e na amostra de crianças entre 11 e 
14 anos, 2/3 delas eram dos tipos I e IV, o que possivelmente introduziu um viés, aumentando a espessura média do IM para essa classe etária deixando-a, assim, semelhante a das crianças saudáveis.

Visto que o índice mentual demonstrou as diferenças entre as classes etárias, entre crianças saudáveis e com osteogênese imperfeita, e ao longo dos ciclos de pamidronato, sugere-se que essa medida é capaz de servir como rastreamento de crianças com baixa densidade mineral óssea.

Uma vez que foi possível diferenciar a espessura da cortical mandibular de crianças saudáveis das crianças com OI, foram analisadas possíveis diferenças da evolução do índice mentual entre as classes etárias dos gêneros feminino e masculino. Tal diferença não foi considerada estatisticamente significativa, conforme descrito na tabela 9, portanto, as análises seguintes não foram realizadas com a separação de gêneros, seguindo a tendência de outros trabalhos que avaliaram os efeitos da terapia com pamidronato intravenoso em pacientes com OI, como Rauch et al (2003b), com 56 pacientes, Crabtree et al (2004), com 43 crianças entre 5 e 18 anos; e Miller e Hangartner (1999), que avaliaram tomografias computadorizadas de 14 indivíduos, dos 8 meses aos 45 anos, sem diferenciação por gênero.

Está claro o aumento do IM em todas as crianças, saudáveis e OI, com a evolução da idade, contudo em menor escala em crianças com osteogênese do tipo III e I. O Tipo IV apresentou uma variabilidade muito grande em seus dados, portanto, é incerto se realmente segue o padrão das crianças saudáveis ou das demais com OI. Esse fato pode ser devido ao diagnóstico de OI tipo IV não ser bem definido, já que tende a englobar os fenótipos existentes entre os casos tipo I e III (Arundel e Bishop, 2009), caracterizando a grande 
heterogênicidade deste grupo. Considerando que até os dias atuais foram identificados 9 tipos diferentes de OI, que os tipos V à IX somente podem ser assim classificados após análise genética e/ou histológica do tecido ósseo e que esses exames ainda não são viáveis nesse hospital, pode-se supor que haja indivíduos de outros tipos classificados como tipo IV.

Uma vez que já foi amplamente demonstrado que o IM é capaz de demonstrar diferenças relacionadas à densidade mineral óssea em mulheres na pós-menopausa e em homens idosos (Devlin e Horner, 2002; Drozdzowska et al, 2002; Taguchi et al, 2004 e 2006; White et al, 2005; Leite et al, 2010; Alonso et al, 2011), e que a administração intravenosa de PAM atua aumentando a DMO em crianças com OI (Letocha et al, 2005; Phillipi et al, 2008; Forlino et al, 2011), os dados foram analisados considerando o efeito dos ciclos de pamidronato na espessura da cortical mandibular como forma de tratamento em crianças com OI. Desta forma, foi possível demonstrar a evolução do IM em crianças que iniciaram o tratamento precocemente e com idade mais avançada, sendo que estas últimas apresentam recuperação com mesma tendência que as primeiras, porém mais acelerada. Foi considerada a idade de 5 anos como divisor a título de estudo, pelo fato de o primeiro surto de crescimento infantil acontecer por volta de 6 a 7 anos. Assim, o primeiro grupo foi considerado como de início precoce do tratamento, antes do primeiro surto de velocidade de crescimento ao ano; e o outro grupo como de início do tratamento tardio, após os 5 anos de idade.

Foi possível verificar que entre as crianças que iniciaram o tratamento com menos de 5 anos, as médias de IM observadas em 0 a 4 ciclos de pamidronato e em 5 a 10 ciclos foram consideradas estatisticamente equivalentes, só existindo diferença após mais de 10 ciclos. Entre essas crianças as médias de IM são estatisticamente menores que a do grupo 
de tratamento tardio em todos os períodos de ciclos. Isso pode significar que crianças com os fenótipos mais graves estão enquadradas dentro do grupo de pacientes que iniciou o tratamento mais cedo, e por isso apresentam ossos mandibulares menores e mais frágeis. Somado a esse dado, deve ser considerado o fato de que crianças mais jovens apresentam corticais mandibulares mais finas, sendo mais importante a avaliação da evolução do tratamento que das espessuras das corticais em si, já que o fator idade não foi considerado nessa análise.

Avaliando a diferença da evolução do índice mentual entre crianças com diferentes tipos de osteogênese imperfeita, com início de tratamento precoce e tardio, foi possível verificar que todas as crianças com OI tipos I e IV que iniciaram o tratamento precocemente e as crianças tipo III, que corresponde ao fenótipo mais grave, apresentaram aumento significativo da média de IM apenas com mais de 10 ciclos de pamidronato. Já crianças OI tipo I e IV com início de tratamento tardio apresentaram aumento significativo da média de IM já com 5 a 10 ciclos de pamidronato. Isso pode ser um indicador de que crianças que começaram o tratamento com PAM mais cedo podem ter apresentado um maior comprometimento físico, mesmo sendo tipo I ou IV, e buscaram auxílio médico logo no início de suas vidas. Porém esse fato necessita de maior confirmação, sendo apenas uma hipótese.

Considerando a quantidade de ciclos de PAM, pôde-se perceber que, independente do tipo de OI e da idade ao início do tratamento, crianças com 0 a 4 ciclos apresentavam médias de IM semelhantes, assim como as médias entre indivíduos que já tinham realizado 5 a 10 ciclos de PAM. As diferenças entre os tipos de OI começavam a aparecer apenas após 10 ciclos de PAM, quando crianças do tipo III, com início do tratamento precoce, apresentavam valores médios de IM mais baixos que crianças dos tipos I e IV; porém, 
todas as crianças com início de tratamento tardio apresentaram médias semelhantes, independente do tipo de OI.

Ao comparar a evolução das espessuras das corticais de crianças afetadas, de todos os tipos, ao longo dos ciclos de PAM, independente da idade de início do tratamento, com indivíduos saudáveis, verificamos que ao início do tratamento, de 0 a 4 ciclos, todas as crianças OI apresentaram IM semelhantes e menores que a média para crianças saudáveis, nas mesmas classes etárias. À medida que os ciclos de PAM foram aumentando, o IM atingiu valores equivalentes aos de indivíduos saudáveis, sendo necessários de 5 a 10 ciclos para que crianças dos tipos I e IV atingissem essa média, e mais de 10 ciclos para crianças OI tipo III. Porém, nas crianças com o tipo III, mais grave, esse valor de espessura da cortical permaneceu mais baixo que nos tipos I e IV da doença, considerando o mesmo número de ciclos de PAM.

Crianças com osteogênese tipo I e IV com mais de 10 ciclos de PAM apresentaram um aumento da média de IM maior que crianças saudáveis, mostrando um possível crescimento contínuo da cortical mandibular, diferente do que foi relatado em trabalhos anteriores, com base em avaliações de outros ossos do corpo. Esses trabalhos afirmaram que a espessura da cortical do osso ilíaco quase dobra nos primeiros anos, mas que após três anos de administração de PAM, muda pouco (Mariani, 2003; Rauch et al, 2003a; Rauch et al, 2006). O único estudo encontrado que compara a resposta celular do osso mandibular com células do ilíaco afirma que esses sítios respondem de forma diferente à medicação, sendo as células mandibulares mais susceptíveis, favorecendo uma regeneração óssea estruturalmente menos organizada e uma desregulação da homeostase do osso mandibular (Stefanik et al, 2007). 
Considerando em conjunto os tipos de OI, foi possível observar que a quantidade média de ciclos de pamidronato necessária para que esses pacientes tenham espessura da cortical inferior mandibular equivalente a crianças saudáveis é maior que 10 ciclos, independente da idade de início do tratamento.

Com a intenção de verificar a associação positiva do IM com os dados densitométricos de crianças, assim como já foi demonstrado em adultos, foram construídos modelos de regressão linear dos valores dos índices mentuais e respectivos valores de densidade mineral óssea da coluna lombar (BMDLombar) e corpo total (BMDTotal) de 98 crianças saudáveis com diagnóstico densitométrico normal. Os resultados de correlação permitem afirmar que à medida que ocorre o aumento do índice mentual isso se reflete na elevação dos valores de densidade óssea da coluna lombar e do corpo total.

Com base nos seguintes pressupostos: 1. há relação do IM com a DMO, com base em estudos prévios de adultos e no modelo de regressão apresentado para crianças saudáveis; 2. o tratamento com PAM aumenta a DMO de crianças com OI (Rauch et al, 2003a; Letocha et al; 2005; Huang et al, 2006; Philipi et al, 2008); e 3. o IM aumenta claramente ao longo dos ciclos de PAM, como visto nos resultados apresentados, foi construído um modelo de regressão logística linear para estimar a quantidade de ciclos de PAM que seria necessária para que crianças com OI atingissem valores de índice mentual compatíveis com crianças saudáveis para determinada idade. Assim, nessa análise foi possível estimar essa quantidade de ciclos (CPfinal), a partir dos valores inicial e final previsto de índice mentual (estimado para a idade). É importante salientar que se trata de um estudo preliminar e que mais esforços são necessários no sentido de aumentar a amostra e o tempo de duração do estudo para que resultados mais consistentes sejam fornecidos. 
Em síntese, a partir da aplicação de modelos com este tipo de ajuste, foi possível estimar a quantidade necessária de ciclos de pamidronato intravenoso em crianças com osteogênese imperfeita, para que se atinja uma média de espessura da cortical inferior da mandíbula compatível com crianças saudáveis em uma determinada idade, haja visto que o índice mentual apresenta relação direta com a densidade mineral óssea.

Concluindo, nossos resultados verificaram que crianças com OI apresentaram alterações do osso cortical após o início do tratamento com o pamidronato, e que tanto a espessura cortical quanto a dimensão fractal do osso cortical inferior da mandíbula aumentaram à medida que aumentavam as quantidades de ciclos da medicação. Assim, esses achados fornecem as evidências preliminares de que apenas o osso cortical deve ser considerado para análise dos pacientes com OI, assim como para acompanhamento da evolução do tratamento com pamidronato. A espessura da cortical inferior da mandíbula em pacientes com osteogênese imperfeita em tratamento com pamidronato depende do número de ciclos do medicamento e do tipo de OI.

\subsection{Limitações do estudo}

Esse foi um estudo retrospectivo e, como é intrínseco a este tipo de estudo, apresentou algumas limitações:

1. Não obtivemos os dados densitométricos das crianças com osteogênese imperfeita, o que seria importante para correlacionar a evolução do IM com o aumento da DMO. Assim, a afirmação de que as crianças tiveram suas densidades minerais ósseas aumentadas deriva-se de estudos prévios que relatam os dados densitométricos de pacientes com OI ao longo do tratamento com bisfosfonatos. 
2. As radiografias foram realizadas em diferentes tempos e idades ao longo do tratamento. Por ser a osteogênese imperfeita uma doença rara e o Hospital Universitário de Brasília um centro de referência para seu tratamento, esse estudo dependeu dos dados encontrados nos prontuários, não sendo possível o pareamento das radiografias e tempos de tratamento.

3. Esse foi o primeiro estudo a avaliar índices radiomorfométricos e dimensões fractais de mandíbula em OI, por tanto, a ausência de estudos semelhantes impede alguma comparação.

\subsection{Considerações finais}

Nosso trabalho oferece os indícios preliminares de que o IM pode ser usado como forma de monitoramento da evolução da deposição óssea em crianças com osteogênese imperfeita, sendo um método barato e viável para o sistema de saúde pública. Além disso, embora esse estudo tenha avaliado a espessura da cortical em um grupo de pacientes jovens com OI, nossos resultados indicam que o pamidronato altera a cortical mandibular e, sendo os bisfosfonatos usados em outras doenças, como osteoporose e metástases ósseas, é possível que essa mesma evolução possa ser acompanhada por radiografias panorâmicas. Estudos prospectivos são necessários para avaliar essa premissa.

Mais estudos são necessários para avaliar a correlação entre os índices radiomorfométricos de mandíbula e a DMO em crianças com OI em tratamento com pamidronato, utilizando uma amostra maior, com número igual de indivíduos de cada tipo de OI e com radiografias em tempos iguais de tratamento e idade. 
Mais pesquisas, com amostras maiores, também são necessárias para avaliar a correlação entre as medidas da cortical inferior da mandíbula e DMO na população pediátrica, para determinar se esses índices podem servir como auxiliares na triagem do diagnóstico densitométrico de baixa massa óssea em crianças. Assim, avaliar se as radiografias panorâmicas podem ser consideradas ferramentas auxiliares para outras condições relacionadas à baixa densidade mineral óssea, e também para visualizar os resultados de tratamentos nessas populações. 
7. CONCLUSÕES 


\section{CONCLUSÕES}

\subsection{Conclusões do artigo 1}

- Crianças com diferentes tipos de OI apresentaram dimensões fractais de osso cortical e IM semelhantes ao início do tratamento com o PAM e até 5 a 10 ciclos, porém, com mais de 10 ciclos, crianças do tipo III apresentaram valores de espessura da cortical inferior bem menores que os outros tipos, mas, os índices qualitativos (IV e IMCo) e as dimensões fractais de osso trabecular não foram capazes de distinguir os diferentes tipos de OI

- Com relação à evolução do tratamento com o PAM, somente houve corticais classificadas como C3 na primeira fase ( 0 a 4 ciclos) para todos os tipos de OI e, à medida que aumentavam os ciclos havia mais corticais classificadas como Não-Finas. A DF e espessura do osso cortical aumentaram ao longo do tratamento com o PAM, mas as DF de osso trabecular não apresentaram modificações significativas com a evolução do tratamento;

\subsection{Conclusões do artigo 2}

- A espessura da cortical inferior da mandíbula foi semelhante entre os tipos de OI em todas as classes etárias, com excessão da classe de 15 a 19 anos, na qual a espessura da cortical das crianças do tipo III era bem mais baixa que a dos outros tipos;

- A idade de início do tratamento pareceu não influenciar a evolução do tratamento;

- A espessura da cortical inferior da mandíbula foi menor em indivíduos com OI, de todos os tipos, que em crianças saudáveis com diagnóstico densitométrico normal em todas as faixas etárias, com exceção do período entre 11 e 14 anos; 
- A espessura da cortical inferior da mandíbula aumentou ao longo dos ciclos de PAM, sendo que crianças dos tipos I e IV atingiram médias de IM compatíveis com as saudáveis após 5 a 10 ciclos e as do tipo III somente atingiram essa média após mais de 10 ciclos.

- Parece ser possível, por meio de um modelo matemático, estimar a quantidade de ciclos de PAM que crianças com OI precisam receber para que atinjam a média de IM compatível com crianças saudáveis com a mesma idade. 


\section{REFERÊNCIAS}




\section{Referências*}

Alman AC, Johnson LR, Calverley DC, Grunwald GK, Lezotte DC, Hokanson JE. Diagnostic capabilities of fractal dimension and mandibular cortical width to identify men and women with decreased bone mineral density. Osteoporos Int 2011 Jun 2.

Alonso MB, Cortes AR, Camargo AJ, Arita ES, Haiter-Neto F, Watanabe PC. Assessment of panoramic radiomorphometric indices of the mandible in a Brazilian population. ISRN Rheumatol; 2011 Sept.

Alvarez R1, García R, Luis J, López J, Gutiérrez A, González M et al. Bone mineral density in children with osteogenesis imperfecta. Rev Esp Med Nucl 2003 Jul-Ago; 22(4): 224-8.

Apolinário, ACE. Índices radiomorfométricos de mandíbula e densidade mineral óssea em crianças saudáveis e com diagnóstico de Osteogênese Imperfeita. Brasília. Dissertação [Mestrado em Ciências da Saúde] - Universidade de Brasília; 2009.

Ardakani, FE.; Niafar, N. Evaluation of changes in the mandibular angular cortex using panoramic images. J Contemp Dent Pract 2004 Aug; 5(3): 1-15.

Arundel, P; Bishop, N. Diagnosing osteogenesis imperfecta. Paediatrics and child health 2009; 20 (5): 225-31.

Bachrach, LK. Consensus and controversy regarding osteoporosis in the pediatric population. Endocr Prat 2007 Sep; 13(5): 513-520.

Bianciardi G, Bisogno S, Bertoldi I, Laurini L, Coviello G, Frediani B. Fractal dimension of bone texture in radiographs correlates to ultrasound broadband attenuation T-score. Clin Exp Rheumatol 2013 May-Jun; 31(3): 389-93.

Bishop, N. Characterizing and treating osteogeneisis imperfect. Early Human Development 2010; 86: 743-46.

Bocanegra-Pérez MS, Vicente-Barrero M, Sosa-Henríquez M, Rodríguez-Bocanegra E, Limiñana-Cañal JM, López-Márquez A, et al. Bone metabolism and clinical study of 44 patients with bisphosphonate-related osteonecrosis of the jaws. Med Oral Patol Oral Cir Bucal 2012 Nov 1; 17(6): e948-55.

Borges JLC; Brandão CMA. Low bone mass in children and adolescents. Arq Bras Endocrinol Metab 2006; 50(4): 775-782.

Bosshardt D D, Bergomi M, Vaglio G, Wiskott A. Regional structural characteristics of bovine periodontal ligament samples and their suitability for biomechanical tests. J. Anat 2008; 212: 319-29.

*De acordo com International Committee of Medical Journal Editors. Uniform Requirements for Manuscripts Submitted to Biomedical Journals. New Engl J Med 1997; 336 (4): 309-15. Abreviatura de periódicos segundo Base de Dados MEDLINE. 
Bras J, van Ooij CP, Abraham-Inpijn L, Kusen GJ, Wilmink JM. Radiographic interpretation of the mandibular angular cortex: A diagnostic tool in metabolic bone loss. Part I. Normal State. Oral Surg Oral Med Oral Pathol Oral Radiol Endod 1982 May; 53: 541-545.

Byers PH, Pyott SM. Recessively inherited forms of osteogenesis imperfecta. Annu Rev Genet 2012; 46: 475-97.

Chen S, Oviir T, Lin C, Leu L, Cho B, Hollender L. Digital imaging analysis with mathematical morphology and fractal dimension for evaluation of periapical lesions following endodontic treatment. Oral Surgery Oral Medicine Oral Pathology Oral Radiology and Endodontology 2005; 100: 467-72.

Cheung MS, Glorieux FH. Osteogenesis Imperfecta: update on presentation and management. Rev Endocr Metab Disord 2008; 9: 153-60.

Crabtree NJ, Kibirige MS, Fordham JN, Banks LM, Muntoni F, Chinn D, et al. The relationship between lean body mass and bone mineral content in paediatric health and disease. Bone 2004; 35: 965-972.

Devlin, H; Horner, K. Mandibular radiomorphometric indices in the diagnosis of reduced skeletal bone mineral density. Osteoporos Int 2002; 13: 373-8.

Demirbaş AK, Ergün S, Güneri P, Aktener BO, Boyacioğlu H. Mandibular bone changes in sickle cell anemia: fractal analysis. Oral Surg Oral Med Oral Pathol Oral Radiol Endod 2008 Jul; 106(1): e41-8.

Drake MT. Bisphosphonates: Mecanism of action and role in clinical practice. Mayo Clin Proc 2008 Sep; 83(9): 1032-45.

Drozdzowska, B.; Pluskiewicz, W.; Tarnawska, B. Panoramic-based mandibular indices in relation to mandibular bone mineral density and esqueletal status assessed by dual energy X-ray absorptiometry and quantitative ultrasound. Dentomaxillofacial radiology 2002; 31: 361-367.

Dutra V, Yang J, Devlin H, Susin C. Radiomorphometric indices and their relation to gender, age, and dental status. Oral Surg Oral Med Oral Pathol Oral Radiol Endod 2005 Apr; 99(4):.479-84.

Dwan, K, Philipi CA, Steiner RD, Basel D. Bisphosphonate therapy for osteogenesis imperfect. Cochrane Database Syst Rev 2014 Jul 23; 7. CD005088.

Eckstein F, Matsuura M, Kuhn V, Priemel M, Müller R, Link TM, Lochmüller EM. Sex differences of human trabecular bone microstructure in aging are site-dependent. J Bone Miner Res 2007 Jun; 22(6): 817-24.

Eghbali-Fatourechi, G. Bisphosphonate therapy in pediatric patients. J Diabetes Metab Disord 2014 Dec; 13(1):109. 
Ergün S, Saraçoglu A, Güneri P, Ozpinar B. Application of fractal analysis in hyperparathyroidism. Dentomaxillofac Radiol. 2009 Jul; 38(5): 281-8.

Forlino, A; Cabral1, WA; Barnes, AM; Marini, JC. New Perspectives on Osteogenesis Imperfecta. Nat Rev Endocrinol., 2011; 7(9): 540-557.

Gatti D, Colapietro F, Fracassi E, Sartori E, Antoniazzi F, Braga V et al. The volumetric bone density and cortical thickness in adult patients affected by osteogenesis imperfecta. $\mathrm{J}$ Clin Densitom 2003 Summer; 6(2): 173-7.

Glorieux FH. A disease of the osteoblast. The Lancet Supplement. 2001 Dec; 358.

Glorieux FH. Treatment of Osteogenesis Imperfecta: Who, Why, What? Horm Res 2007; 68(suppl 5): 8-11.

Glorieux FH. Osteogenesis Imperfecta. Best Pract Res Clin Rheumatol. 2008 Mar; 22(1): 85-100.

Gulsahi A, Yüzügüllü B, Imirzalioglu P, Genç Y. Assessment of panoramic radiomorphometric indices in Turkish patients of different age groups, gender and dental status. Dentomaxillofac Radiol 2008; 37(5): 288-92

Heo M, Park K, Lee S, Choi S, Koak J, Heo S, et al. Fractal analysis of mandibular bony healing after orthognathic surgery. Oral Surgery Oral Medicine Oral Pathology Oral Radiology and Endodontology 2002; 94: 763-7.

Hoff AO, Toth BB, Altundag K, Johnson MM, Warneke CL, Hu M, et al. Frequency and risk factors associated with osteonecrosis of the jaw in cancer patients treated with intravenous bisphosphonates. J Bone Miner Res 2008 Jun; 23(6): 826-36.

Horner K, Devlin H, Harvey L. Detecting patients with low skeletal bone mass. J Dent. 2002; 30: 171-175

Hough JP1, Boyd RN, Keating JL. Systematic review of interventions for low bone mineral density in children with cerebral palsy. Pediatrics 2010 Mar; 125(3): e670-8.

Huang, RP; Ambrose, C.; Sulliva, E.; Haynes, RJ. Functional significance of bone density measurements in children with osteogenesis imperfecta. J Bone Joint Surg Am 2006 Jun; 88(6): 1324-30.

ISCD - International Society for Clinical Densitometry. The International Society for Clinical Densitometry, Official Positions Adult and Pediatric, 2013. Available at: http://www.iscd.org/documents/2014/02/2013-iscd-official-position-brochure.pd

Kindelan J, Tobin M, Roberts-Harry D, Loukota RA. Orthodontic and orthognatic management of a patient with osteogenesis imperfecta: a case report. J. Orthod 2003; 30: 291-6.

Klemetti E, Kolmakow S, Kröger H. Pantography in assessment of the osteoporosis risk group. Scand J Dent Res 1994; 102: 68-72. 
Kusumi K, Ayoob R, Bowden SA, Ingraham S, Mahan JD. (2014). Beneficial effects of intravenous pamidronate treatment in children with osteogenesis imperfecta under 24 months of age. J Bone Miner Metab 2014 Oct 16. [Epub ahead of print]

Law AN, Bollen AM, Chen SK. Detecting osteoporosis using dental radiographs: a comparison of four methods. Journal of the American Dental Association 1996; 127: 1734-42.

Lee K, Taguchi A, Ishii K, Suei Y, Fujita M, Nakamoto T et al. Visual assessment of the mandibular cortex on panoramic radiographs to identify postmenopausal women with low bone mineral densities. Oral Surg Oral Med Oral Pathol Oral Radiol Endod 2005 Aug; 100(2): 226-31.

Leite AF, Figueiredo PT, Guia CM, Melo NS, de Paula AP. Correlations between seven panoramic radiomorphometric indices and bone mineral density in postmenopausal women. Oral Surg Oral Med Oral Pathol Oral Radiol Endod 2010 Mar; 109(3): 449-56.

Letocha AD, Cintas HL, Troendle JF, Reynolds JC, Cann CE, Chernoff EJ, Hill SC, Gerber LH, Marini JC. Controlled trial of pamidronate in children with types III and IV osteogenesis imperfect confirms vertebral gains but not short-term functional improvement. J Bone Miner Res 2005 Jun; 20(6): 977-86.

Leonard MB, Zemel BS. Assessment of bone mineralization in children and adolescents. Clin Rev Bone Min Metab 2004, Spring; 2(1): 3-18.

Maines E1, Monti E, Doro F, Morandi G, Cavarzere P, Antoniazzi F. Children and adolescents treated with neridronate for osteogenesis imperfecta show no evidence of any osteonecrosis of the jaw. J Bone Miner Metab 2012 Jul; 30(4): 434-8.

Malmgren B, Aström E, Söderhäll S. No osteonecrosis in jaws of young patients with osteogenesis imperfecta treated with bisphosphonates. J Oral Pathol Med 2008 Apr; 37(4): 196-200.

Mariani JC. Do Bisphosphonates make children's bones better or brittle? N Eng J Med 2003; 349: 423-426.

Miller ME, Hangartner TN. Bone density measurements by computed tomography in osteogenesis imperfecta type I. Osteoporos Int 1999; 9: 427-32.

National Institutes of Health. Osteoporosis prevention, diagnosis and therapy. NIH Consens Statement 2000 March 27-29; 17(1): 1-36.

Oliveira ML, Pedrosa EF, Cruz AD, Haiter-Neto F, Paula FJ, Watanabe PC. Relationship between bone mineral density and trabecular bone pattern in postmenopausal osteoporotic Brazilian women. Clin Oral Investig 2012; Dec 14.

OSTEOGENESIS IMPERFECTA FOUNDATION. http://www.osteo.org em 05 de junho de 2013. 
Paulsson-Björnsson L, Adams J, Bondemark L, Devlin H, Horner K, et al. The impact of premature birth on the mandibular cortical bone of children. Osteoporos Int 2015 Feb; 26(2): 637-44

Phillipi CA, Remmington T, Steiner RD. Bisphosphonate therapy for osteogenesis imperfect. Cochrane Database Syst Rev 2008 Oct; 8(4)

Pothuaud L, Lespessailles E, Harba R, Jennane R, Royant V, Eynard E, Benhamou CL. Fractal analysis of trabecular bone texture on radiographs: discriminant value inpostmenopausal osteoporosis. Osteoporos Int 1998; 8(6): 618-25.

Rauch F, Plotkin H, Zeitlin L, Glorieux F. Bone mass, size, and density in children and adolescents with osteogenesis imperfect: effect of intravenous pamidronate therapy. J Bone Miner Res 2003a; 18(4): 610-4.

Rauch F, Plotkin H, Travers R, Zeitlin L, Glorieux F. Osteogenesis Imperfecta types I, II and IV: Effect of pamidronate treatment on bone and mineral metabolism. J Clin Endocrinol Metab 2003b; 88(3): 986-92.

Rauch F; Glorieux FH. Osteogenesis imperfecta. Lancet 2004 Apr; 363: 1377-85.

Rauch F, Land C, Cornibert S, Schoenau E, Glorieux FH. High and low density in the same bone: A study on children and adolescents with mild osteogenesis imperfecta. Bone 2005; 37: 634-41.

Rauch F, Munns C, Land C, Glorieux FH. Pamidronate in children and adolescents with Osteogenesis Imperfecta: effect of treatment discontinuation. J Clin Endocrinol Metab 2006 Apr; 91(4): 1268-74.

Rothe LE, Bollen A, Little RM, Herring SW, Chaison JB, Chen CS, et al. Trabecular and cortical bone as risk factors for orthodontic relapse. American Journal of Orthodontics and Dentofacial Orthopedics 2006; 130: 476-84

Santili C, Akkari M, Waisberg G, Júnior JOCB, Ferreira WM. Avaliação clínica, radiográfica e laboratorial de pacientes com osteogênese imperfeita. Rev Assoc Med Bras 2005; 51(4): 214-20

Schwartz S, Joseph C, Iera D, Vu DD. Bisphosphonates, osteonecrosis, osteogenesis imperfecta and dental extractions: a case series. J Can Dent Assoc 2008 Jul-Aug; 74(6): 537-42.

Sillence DO, Senn A, Danks DM. Genetic heterogeneity in osteogenesis imperfecta. J Med Genet 1979; 16: 101-16.

Sindeaux R, Figueiredo PT, de Melo NS, Guimarães AT, Lazarte L, Pereira FB et al. Fractal dimension and mandibular cortical width in normal and osteoporotic men and women. Maturitas 2014 Feb; 77(2): 142-8. 
Stefanik D, Sarin J, Lam T, Levin L, Leboy PS, Akintoye SO. Disparate osteogenic response of mandible and iliac crest bone marrow stromal cells to pamidronate. Oral Dis 2008 Jul; 14(5): 465-71.

Taguchi A, Tanimoto K, Suei Y, Wada T (1995). Tooth loss and mandibular osteopenia. Oral Surg Oral Med Oral Pathol Oral Radiol Endod 79: 127-132

Taguchi A1, Suei Y, Sanada M, Ohtsuka M, Nakamoto T, Sumida H et al. Validation of dental panoramic radiography measures for identifying postmenopausal women with spinal osteoporosis. AJR 2004 Dec; 183: 1755-1760.

Taguchi A1, Tsuda M, Ohtsuka M, Kodama I, Sanada M, Nakamoto T,. et al. Use of dental panoramic radiographs in identifying younger postmenopausal women with ostoporosis. Osteoporos Int 2006; 17: 387-394.

Taguchi A, Sugino N, Miki M, Kozai Y, Mochizuki N, Osanai H, Yamada S, Kuroiwa H, Fujiki T, Uchida K, Yoshinari N, Kashima I. Detecting young Japanese adults with undetected low skeletal bone density using panoramic radiographs. Dentomaxillofac Radiol 2011 Mar; 40(3): 154-9.

Torres SR, Chen CS, Leroux BG, Lee PP, Hollender LG, Schubert MM. Fractal dimension evaluation of cone beam computed tomography in patients with bisphosphonate-associated osteonecrosis. Dentomaxillofac Radiol 2011 Dec; 40(8): 501-5.

Torres SR, Chen CSK, Leroux BG, Lee PP, Hollender LG, Santos ECA et al. Mandibular cortical bone evaluation on cone beam computed tomography images of patients with bisphosphonate-related osteonecrosis of the jaw. Oral Surg Oral Med Oral Pathol Oral Radiol Endod 2012; 113: 695-703.

Tosoni GM, Lurie AG, Cowan AE, Burleson JA. Pixel intensity and fractal analyses: detecting osteoporosis in perimenopausal and postmenopausal women by using digital panoramic images. Oral Surgery Oral Medicine Oral Pathology Oral Radiology \& Endodontics 2006; 102: 235-41.

Traini T, Novaes AB, Piattelli A, Papalexiou V, Muglia V. The relationship between interimplant distances and vascularization of the interimplant bone. Clinical Oral Implants Research 2010; 21: 822-9.

Vallo A, Rodriguez-Leyva F, Soriano JR. Osteogenesis imperfecta: Anthropometric, skeletal and mineral metabolic effects of long-term intravenous pamidronate therapy. Acta Paediatr 2006; 95: 332-9.

Van Dijk, F.S. and Sillence, D.O. Osteogenesis imperfecta: clinical diagnosis, nomenclature and severity assessment. Am J Med Genet A. 2014 Jun; 164A(6): 1470-81.

White SC, Rudolph DJ. Alterations of the trabecular pattern of the jaws in patients with osteoporosis. Oral Surgery Oral Medicine Oral Pathology Oral Radiology \& Endodontics 1999; 88: 628-35. 
White SC, Taguchi A, Kao D, Wu S, Service SK, Yoon D, et al. Clinical and panoramic predictors of femur bone mineral density. Osteoporos Int 2005; 16(3): 339-346.

Yasar F, Akgünlü F. The differences in panoramic mandibular indices and fractal dimension between patients with and without spinal osteoporosis. Dentomaxillofac Radiol 2006 Jan; 35(1): 1-9.

Yasar F, Akgunlu F. Evaluating Mandibular Cortical Index Quantitatively. European Journal of Dentistry 2008 Oct; 2: 283-90.

Yu Y, Chen H, Lin C, Chen C, Oviir T, Chen S, et al. Fractal dimension analysis of periapical reactive bone in response to root canal treatment. Oral Surgery Oral Medicine Oral Pathology Oral Radiology and Endodontology 2009; 107: 283-8.

Zeitlin L,Rauch F, Plotkin H, Glorieux FH. Height and weight development during longterm therapy with cyclical intravenous pamidronate in children and adolescents with osteogenesis imperfecta types I, III and IV. Pediatrics 2003; 111: 1030-1036. 
ANEXO 


\title{
Anexo 1
}

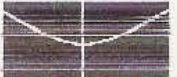 \\ Universidade de Brasilia \\ Faculdade de Ciências da Saúde \\ Comitê de Ética em Pesquisa -CEP/FS
}

\section{PROCESSO DE ANÁLISE DE PROJETO DE PESOUISA}

Registro do Projeto: 076/2007

Título do Projeto: "Avaliação de dois indices radiomorfométricos de mandíbula em radiografias panorâmicas de pacientes com osteogênese imperfeita".

Pesquisadora Responsável: Ana Carolina Esmeraldo Apolinário

Data de Entrada: 13/07/2007.

Com base nas Resoluções 196/96, do CNS/MS, que regulamenta a ética da pesquisa em seres humanos, o Comitê de Ética em Pesquisa com Seres Humanos da Faculdade de Ciências da Saúde da Universidade de Brasília, após análise dos aspectos éticos e do contexto técnico-científico, resolveu APROVAR o projeto 076/2007 com o título: "Avaliação de dois índices radiomorfométricos de mandibula em radiografias panorâmicas de pacientes com osteogênese imperfeita". Analisado na $7^{\text {a }}$ Reunião ordinária, realizada no dia 14 de agosto de 2007 .

O pesquisador responsável fica, desde já, notificado da obrigatoriedade da apresentação de um relatório semestral e relatório final sucinto e objetivo sobre o desenvolvimento do Projeto, no prazo de 1 (um) ano a contar da presente data (item VII.13 da Resolução 196/96).

Brasilia, 24 de setembro de 2007.

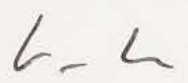

Prof. Volnei Garrafa Coordenador do CEP/FS-UnB

Campus Universitário Darcy Ribeiro

Faculdade de Ciências da Saúde Cep: $70.910-900$ 


\section{APÊNDICES}




\section{Apêndice 1}

\section{Termo de Consentimento Livre e Esclarecido}

As informações abaixo descreverão o estudo para o qual a criança sob sua responsabilidade está sendo convidada a participar. A pesquisadora poderá esclarecer todas as dúvidas que tiver a respeito do estudo e desta carta. Por favor, leia cuidadosamente e não deixe de perguntar qualquer coisa que considerar necessária sobre as informações fornecidas a seguir.

Iremos realizar um estudo dos exames que já foram realizados e estão no prontuário da criança: radiografia panorâmica, para avaliar os ossos maxila e mandíbula e os dentes; radiografia da mão e do punho, para avaliar o crescimento; e a densitometria óssea, que serve para verificar a força do osso, também conhecida como densidade óssea. A intenção da pesquisa é estudar a Osteogênese Imperfeita, doença que torna os ossos fracos e verificar se esta doença pode ser vista na radiografia panorâmica.

Não haverá nenhum custo, e o(a) senhor(a) será informado(a) do resultado dos exames e de qualquer descoberta que surja no período do estudo e que seja importante.

Lembre-se que a participação neste trabalho é voluntária, portanto, poderá recusarse a participar ou descontinuar a sua participação a qualquer momento, sem penalidades ou perda de benefícios a que tenha direito. Quando terminarmos a análise dos dados, será informado(a) sobre a conclusão que este estudo encontrou.

Este termo de consentimento foi redigido em duas vias, sendo que uma delas ficará com o(a) senhor(a) e a outra será arquivada pela pesquisadora.

DATA:

Assinatura do responsável pelo paciente

Assinatura da pesquisadora

Pesquisador responsavel:

Ana Carolina E. Apolinário -telefone: 8428-7232

Hospital Universitário de Brasília - SGAN 605 - Divisão de Odontologia - Anomalias do Desenvolvimento Dentário

Telefone: 3448-5263

Telefone do CEP (Comitê de Ética em Pesquisa): 3307-3799 


\section{Apêndice 2}

\section{Termo de Consentimento Livre e Esclarecido}

As informações abaixo descreverão o estudo para o qual a criança sob sua responsabilidade está sendo convidada a participar. A pesquisadora poderá esclarecer todas as dúvidas que tiver a respeito do estudo e desta carta. Por favor, leia cuidadosamente e não deixe de perguntar qualquer coisa que considerar necessária sobre as informações fornecidas a seguir.

Iremos realizar um estudo da radiografia panorâmica, para avaliar os ossos maxila e mandíbula e os dentes; exame que já foi realizado e está no prontuário odontológico da criança. Também será necessária a realização de outros exames: radiografia da mão e do punho, para avaliar o crescimento; e a densitometria óssea, que serve para verificar a força do osso, também conhecida como densidade óssea. Esses exames não causam risco à saúde, a dose de raios $\mathrm{X}$ é muito baixa, menor que a de um microondas.

A intenção da pesquisa é estudar a Osteogênese Imperfeita, doença que torna os ossos fracos e verificar se esta doença pode ser vista na radiografia panorâmica. Para isso serão estudados e comparados dois grupos, um de crianças com essa doença e outro de crianças normais. Sua criança está sendo convidada para participar do grupo de pessoas normais.

Não haverá nenhum custo, e o(a) senhor(a) será informado(a) do resultado dos exames e de qualquer descoberta que surja no período do estudo e que seja importante.

Lembre-se que a participação neste trabalho é voluntária, portanto, poderá recusarse a participar ou descontinuar a sua participação a qualquer momento, sem penalidades ou perda de benefícios a que tenha direito. Quando terminarmos a análise dos dados, será informado(a) sobre a conclusão que este estudo encontrou.

Este termo de consentimento foi redigido em duas vias, sendo que uma delas ficará com o(a) senhor(a) e a outra será arquivada pela pesquisadora.

DATA:

Assinatura do responsável pelo paciente

Assinatura da pesquisadora

Pesquisador responsável:

Ana Carolina E. Apolinário - telefone: 8428-7232

Hospital Universitário de Brasília - SGAN 605 - Divisão de Odontologia - Anomalias do Desenvolvimento Dentário

Telefone: 3448-5263

Telefone do CEP (Comitê de Ética em Pesquisa): 3307-3799 